Janaína Monique Ferreira de Souza

\title{
AVALIAÇÃO DOS CUSTOS DIRETOS HOSPITALARES DE UM HOSPITAL PÚBLICO MUNICIPAL DA CIDADE DE SÃO PAULO
}

Dissertação apresentada à Sociedade Beneficente Israelita Brasileira Albert Einstein para obtenção do Título de Mestre em Ciências da Saúde. 
Janaína Monique Ferreira de Souza

\section{AVALIAÇÃO DOS CUSTOS DIRETOS HOSPITALARES DE UM HOSPITAL PÚBLICO MUNICIPAL DA CIDADE DE SÃO PAULO}

Dissertação apresentada à Sociedade Beneficente Israelita Brasileira Albert Einstein, para obtenção do Título de Mestre em Ciências da Saúde.

Orientador: Prof. Dr. Eliézer Silva Coorientador: Prof. Dr. Adriano José Pereira 
$\mathrm{S} 729 \mathrm{a}$

Souza, Janaína Monique Ferreira de

Avaliação dos custos diretos hospitalares de um hospital público municipal da cidade de São Paulo / Janaína Monique Ferreira de Souza. -- São Paulo, 2018.

xii, $66 \mathrm{f}$.

Dissertação (Mestrado) - Sociedade Beneficente Israelita Brasileira Albert Einstein. Instituto Israelita de Ensino e Pesquisa Albert Einstein. Programa de Pós-Graduação em Ciências da Saúde.

Título em inglês: Evaluation of the direct hospital costs of a municipal public hospital in São Paulo, Brazil.

1. Alocação de custos. 2. Custos e análise de custo. 3. Controle de custos. 4. Custos hospitalares.

NLM - W 74

Elaborada pelo Sistema Einstein Integrado de Bibliotecas 
SOCIEDADE BENEFICENTE ISRAELITA BRASILEIRA ALBERT EINSTEIN

Coordenador do Curso de Pós-Graduação: Prof. Dr. Luiz Vicente Rizzo 
Janaína Monique Ferreira de Souza

\section{AVALIAÇÃO DOS CUSTOS DIRETOS HOSPITALARES DE UM HOSPITAL PÚBLICO MUNICIPAL DA CIDADE DE SÃO PAULO}

Presidente da banca: Prof. Dr. Eliézer Silva

BANCA EXAMINADORA

Membros titulares:

Prof. Dr. Marcelo Katz

Profa. Dra. Luci Corrêa

Prof. Dr. Guilherme de Paula Pinto Schettino

Membros suplentes:

Profa. Dra. Márcia Mello Costa de Liberal

Prof. Dr. Maycon Anderson Pires de Novais

Aprovada em: 25/05/2018. 


\section{Dedicatória}

A Deus, por sua graça e misericórdia, por me proporcionar muito mais do que necessito.

A minha mãe (in memoriam), Maria de Fátima, por todo sacrifício para criar a mim e a minhas irmãs, pelo contínuo amor, admiração incondicional e por ser meu fôlego de vida diário.

Ao meu marido, Mateus, pelos incontáveis momentos de ajuda e consolo, além de contribuir significativamente na minha vida profissional, pessoal e espiritual.

Às minhas irmãs, Jaqueline e Joice, pelas constantes palavras de incentivo e oração, por me amarem e apoiarem meus sonhos.

Aos meus sogros, Natalino e Nadir, pelas orações, carinho e incentivo.

A minha cunhada, Giane, por ser minha intercessora constante.

Às minhas sobrinhas, Ana Laura, Raphaela e Ana Alice, por serem minha inspiração. 


\section{Agradecimentos}

Minha eterna gratidão a Deus, por permitir viver este momento até o fim, depois de trilhar um longo caminho.

Ao diretor do Hospital Municipal Vila Santa Catarina, Guilherme de Paula Pinto Schettino, por me autorizar o livre acesso ao hospital para os treinamentos e auditorias de prontuários.

A gerente do Hospital Municipal Vila Santa Catarina, Gabriela Sato, por me ajudar em todas as informações necessárias para realização deste trabalho.

Ao Dr. Eliézer Silva sou muitíssimo grata e sinto grande privilégio em ter sido aceita como sua orientanda. Muito obrigada pelo aceite, pelas oportunidades em conhecer a prática da pesquisa, pela constante prontidão em orientar e incentivar, pela preocupação e interesse no meu desenvolvimento profissional. Espero ter a oportunidade de retribuir.

Ao Dr. Adriano José Pereira, meu coorientador, jamais esquecerei a paciência em me ensinar o caminho que estava trilhando, por proporcionar o meu desenvolvimento, por me responder prontamente em todos os questionamentos.

Ao gerente da auditoria de contas, Gilberto Cunha Galletta, pela oportunidade em trabalhar na área. Sua confiança em meu profissionalismo permitiu grande liberdade em poder conciliar as disciplinas e minha rotina de trabalho.

A coordenadora da auditoria de contas, Glauce Roseane de Almeida Brito, que me proporcionou inesquecíveis e significativos momentos de aprendizagem pessoal e profissional.

Aos meus professores e colegas do MBA em Gestão e Economia da Saúde da Escola Paulista de Medicina que me auxiliaram e transmitiram todo conhecimento na área de análise econômica em saúde.

Aos meus professores, Dr. Carlos Oliva, Dr. Marcelo Katz e Dra. Márcia de Liberal, pela participação na minha banca de qualificação.

Aos meus colegas de trabalho da auditoria de contas e demais setores do Hospital Israelita Albert Einstein e Hospital Municipal Vila Santa Catarina por toda disponibilidade e auxílio nessa longa jornada. Às estatísticas do Instituto Israelita de Ensino e Pesquisa, Ana Carolina Cintra Nunes Mafra e Elivane da Silva Victor, por 
compartilhar o conhecimento, pela compreensão, e empenho para ajudar com os testes estatísticos.

A gerente de custo, Helena Lumi Fukumoto, por me ajudar com o entendimento da metodologia de apuração de custos da instituição.

A diretora financeira do Hospital Israelita Albert Einstein, Patrícia Leisnock Santos, pela disponibilidade de fornecer os dados de custo para realização do meu trabalho, por me permitir participar das reuniões gerenciais para entendimento das tomadas de decisões.

Ao analista de custo, Marco Antônio de Salvo Júnior, por me auxiliar com o entendimento de todo processo que estava sendo realizado na determinação dos critérios de rateio da instituição.

A todos os demais docentes e assistentes do Programa de PósGraduação Stricto Sensu do Instituto de Ensino e Pesquisa do Hospital Israelita Albert Einstein, que contribuíram com seus inestimáveis ensinamentos para minha formação e constantes incentivos.

À Laudiceia Maurício de Almeida e Jaciele Conceição da Silva por todo esforço, dedicação, solidariedade e paciência, ajudando na solicitação de informações e agilizando os processos para a concretização deste trabalho.

A todos os amigos do Programa de Pós-Graduação Stricto Sensu do Instituto de Ensino e Pesquisa do Hospital Israelita Albert Einstein, velhos e novos, sempre serei grata pela oportunidade em aprender com vocês e a colaboração de todos nas atividades em grupo. 


\section{Sumário}

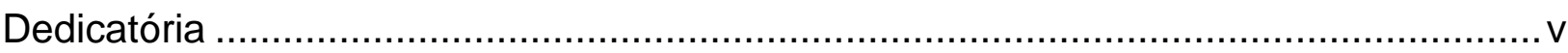

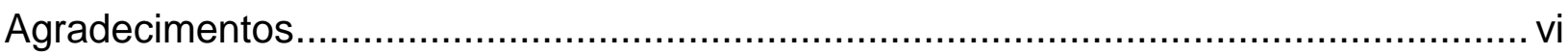

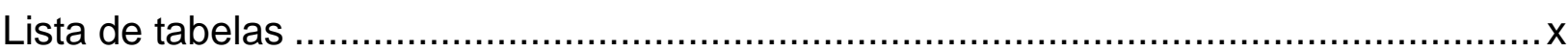

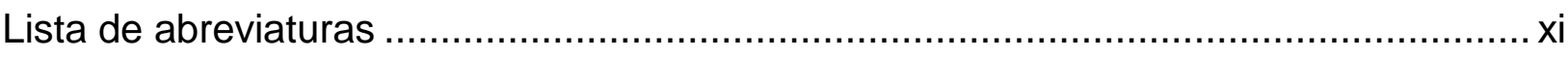

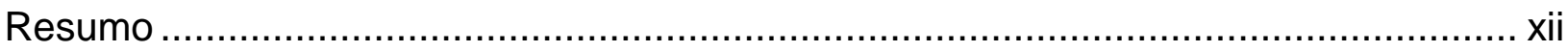

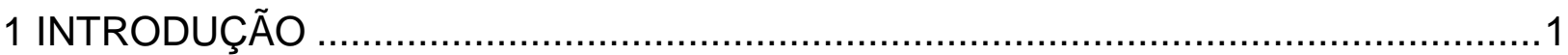

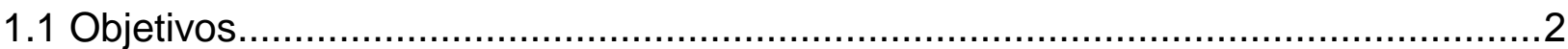

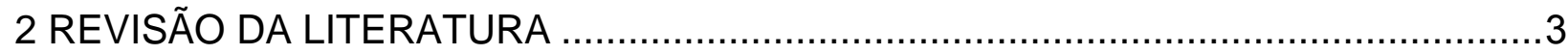

2.1 Aspectos sociodemográficos do Brasil .........................................................

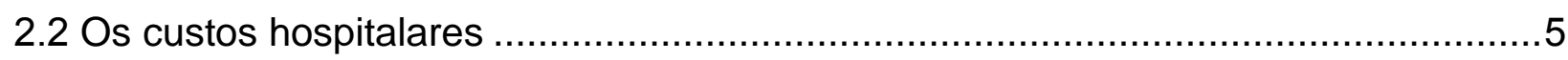

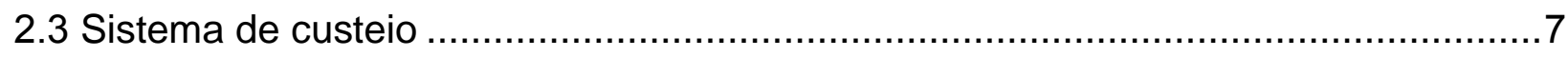

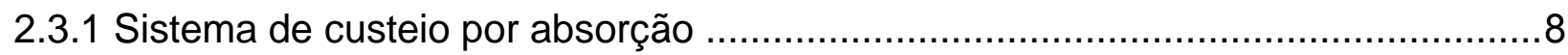

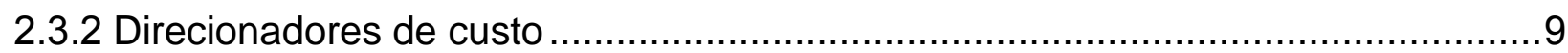

2.4 Sistema de financiamento brasileiro ..........................................................

2.4.1 Hospital Israelita Albert Einstein ........................................................ 10

2.4.2 Programa de Apoio ao Desenvolvimento Institucional ao Sistema Único de Saúde

2.4.3 Hospital Municipal Vila Santa Catarina.................................................. 11

2.4.3.1 Modelo de apuração do Programa de Apoio ao Desenvolvimento Institucional ao Sistema Único de Saúde .............................................................................. 14

$2.5 \mathrm{O}$ Sistema de diagnosis related groups...................................................... 14

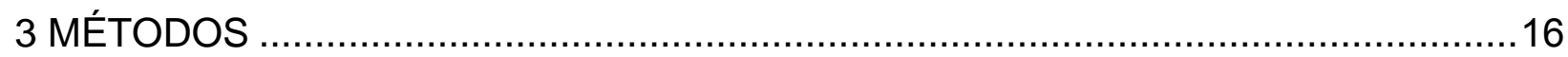

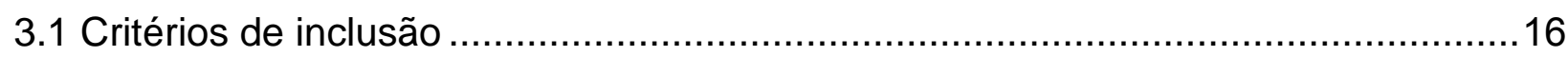

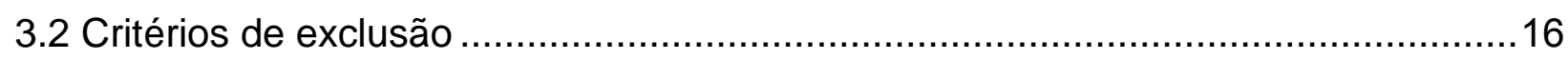

3.3 Modelo de apuração de custo e desfecho ..................................................... 16

3.3.1 Dados clínicos e demográficos ....................................................................... 16

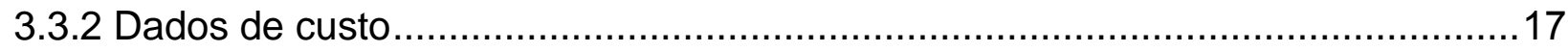

3.3.3 Dados de desfecho - Diagnosis Related Groups ....................................... 17

3.3.4 Integração dos bancos de dados...................................................... 18

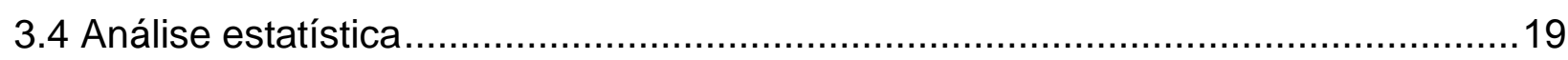

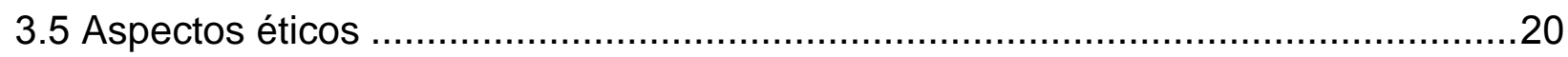


4 RESULTADOS

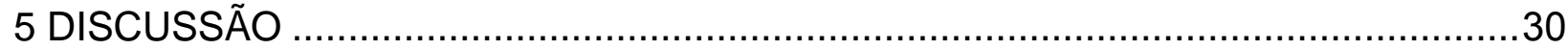

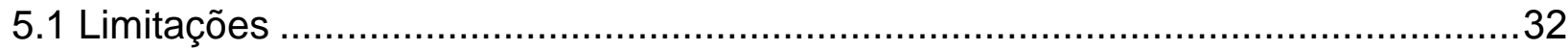

5.2 Lições aprendidas e contribuições ................................................................ 33

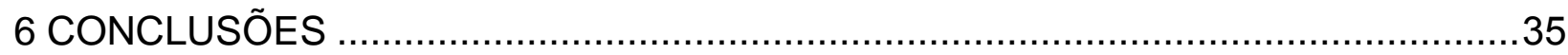

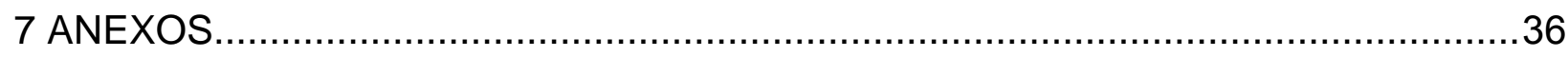

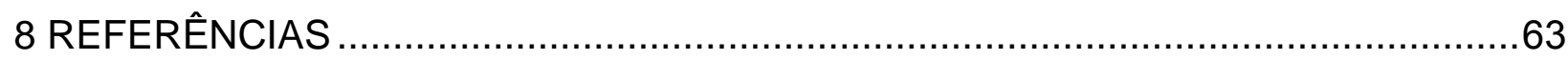

Abstract

Apêndices 


\section{Lista de tabelas}

Tabela 1. Características demográficas dos pacientes do Hospital Municipal Vila Santa

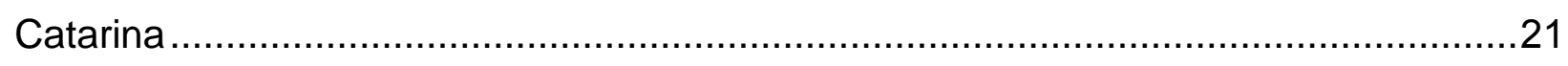

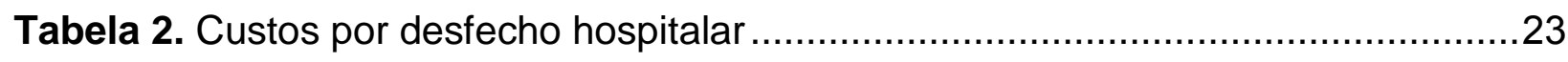

Tabela 3. Diagnóstico de alta e custos das Internações durante o ano ......................24

Tabela 4. Características dos pacientes segundo o custo total das internações ..........26

Tabela 5. Associação entre alto custo da internação, tempo de permanência e direcionadores de custo por internação................................................................27 


\section{Lista de abreviaturas}

$\mathrm{BI}$

Inteligência empresarial (Business Inteligence)

BW Armazém de negócios (Business Warehouse)

CID Classificação Internacional de Doenças

CFC Conselho Federal de Contabilidade

CROSS Central de Regulação de Ofertas de Serviços de Saúde

DRG Grupo de doenças relacionadas (Diagnosis Related Groups)

DW Armazém de dados (Data Warehouse)

HIAE Hospital Israelita Albert Einstein

HMVSC Hospital Municipal Vila Santa Catarina

IBGE Instituto Brasileiro de Geografia e Estatística

MDC Categoria de diagnósticos maiores (Major Diagnosis Categories)

OMS Organização Mundial de Saúde

PROADI Programa de Apoio ao Desenvolvimento Institucional

SAP Sistemas, Aplicativos e Produtos para Processamento de Dados

SGH Sistema de Gestão Hospitalar

SUS Sistema Único de Saúde

UPA Unidade de Pronto Atendimento

UTI Unidade de Terapia Intensiva 


\section{Resumo}

Objetivos: Mensurar o custo operacional, de um hospital público municipal da cidade de São Paulo e identificar fatores que influenciaram no aumento do custo durante o ano de 2016. Métodos: Estudo de coorte prospectivo realizado de janeiro a dezembro de 2016, em pacientes internados no Hospital Municipal Vila Santa Catarina, hospital público municipal terciário de São Paulo, Brasil. Resultados: Um total de 8.702 pacientes foram identificados com um custo médio por paciente/dia de $R \$ 3.093,33$ com mediana de $R \$ 5.950,82$, com um custo operacional total de $R \$ 158.861 .058,90$. $\mathrm{O}$ transplante obteve a maior mediana de custo, enquanto que a maternidade obteve a menor. A taxa de pacientes com custo até $R \$ 10.000,00$ foi de $69,9 \%$. Dentre os fatores que influenciaram o aumento do custo por internação, a idade está associada com um aumento de $6,6 \%$ no custo para cada acréscimo de um ano na idade. As internações de pacientes do sexo feminino apresentaram chance 1,1 vezes a chance de aumento do custo associado a pacientes internados do sexo masculino. Observouse também que todos os diagnósticos de alta por categoria Major Diagnostic Category apresentaram chances de alto custo comparadas aos pacientes da categoria diagnóstica recém-nascidos e outros neonatos que não demonstrou significância estatística associado aos fatores influenciadores de aumento no custo. Pacientes que foram a óbito tiveram 8 vezes mais chance de aumento no custo comparados aos pacientes que obtiveram alta hospitalar. Os pacientes do departamento materno-infantil tiveram menor proporção de alto custo, enquanto que oncologia, transplante e clínicamédica apresentam respectivamente chances estimadas em 18,8 vezes $(p<0,001)$, 15,8 vezes $(p<0,001)$ e 13,7 vezes $(p<0,001)$ a chance de alto custo do departamento de maternidade. Conclusões: Os dados puderam subsidiar o conhecimento da alocação dos recursos, reforçando a necessidade de implantação de uma metodologia de apuração de custo nas instituições públicas brasileiras. Dentre os fatores que influenciaram o aumento do custo hospitalar destacou-se o aumento na idade, a raça branca, óbito hospitalar, tempo de permanência hospitalar, bem como as internações no departamento de oncologia. Dentre os Major Diagnostic Category, a categoria doenças e distúrbios do sistema reprodutor masculino destacou-se como maior influenciador de aumento do custo. 


\section{INTRODUÇÃo}

Custo direto médico em saúde dentro da área da economia da saúde expressa a avaliação do valor monetário gasto nos insumos utilizados para prover as intervenções sob análise, levando em consideração o ambiente médicohospitalar, como recursos humanos, instalações físicas, medicamentos, internações e diagnósticos. ${ }^{(1)}$ Para Alonso, "o conhecimento dos custos dos serviços hospitalares é fundamental para se atingir uma alocação eficiente de recursos". O desconhecimento dos custos é o maior indicador de ineficiência no provimento dos serviços. ${ }^{(2)}$

Segundo a Organização Mundial da Saúde (OMS) o Brasil já consome cerca de $9 \%$ do seu produto interno bruto em saúde abaixo do que países como Estados Unidos (17,1\%), Canadá $(10,4 \%)$ gastam na promoção de saúde, e semelhante ao Reino Unido (9,1\%), com a diferença no valor per capita, onde são investidos USD(\$)3,377 e no Brasil USD(\$)1,318 per capita e não alcançou-se os padrões de eficiência necessário. ${ }^{(3)}$

Por meio da primeira e grande conquista do Movimento da Reforma Sanitária, em 1988, houve a definição na Constituição Federal relativa ao setor de saúde no país. ${ }^{(4)}$ Diante disso as instituições hospitalares estão com um novo desafio, demonstrar os custos reais, permitindo iniciar um novo movimento de reforma na saúde brasileira, neste momento a maior necessidade das instituições hospitalares é deixar de conhecer seus preços e passarem a conhecer seus custos, estabelecerem um parâmetro de comparação entre o quanto custa e quanto se recebe pelo serviço, Dussault descreve que "o aumento dos recursos não vai, de per si, elevar a eficácia nem a eficiência dos serviços". Escolhas das prioridades pelo conhecimento da alocação de recursos ajudarão a escolher melhores estratégias para as organizações, capazes de atingir os objetivos de saúde para a comunidade. ${ }^{(5)}$

Dentre os maiores desafios enfrentados para a construção do sistema de saúde, o financiamento tem se destacado como preocupação permanente de todos os envolvidos diretamente no processo. Garantir a universalidade e a integralidade de atendimento, em cenário marcado por tantas restrições orçamentárias e financeiras, e alocar recursos de forma equânime, num país de tantas desigualdades sociais e regionais, tem representado um grande desafio para os gestores. ${ }^{(6)}$ 
As instituições privadas iniciaram uma busca na melhoria dos modelos de financiamento na saúde suplementar do Brasil, em 2014 o Hospital Israelita Albert Einstein (HIAE), adotou a governança Triple Aim, ${ }^{(7)}$ que estabelece mudanças na abordagem, estruturação e monitoramento dos serviços de saúde, com foco na experiência do cuidado, redução do custo per capita dos serviços de saúde e abordagem populacional. O Value Management Office (VMO), um escritório integrado dentro do HIAE desde 2017 tem com o objetivo de divulgar a cultura e alinhar os conceitos de value-based health care (VBHC) em todo o sistema hospitalar, integrando dados de diferentes fontes e fornecendo informações para definir a viabilidade de novos modelos de pagamentos baseados em valores para diferentes condições médicas, com base na prática e na variação de custos. ${ }^{\left({ }^{(8)}\right.}$

O VBHC descrito em 2010 por Porter ${ }^{(9)}$ refere que o modelo de apuração de custo deve estar direcionado em um ciclo completo de tratamento do paciente, sendo a proposta apresentada ao Ministério da Saúde no Programa de Apoio ao Desenvolvimento Institucional (PROADI) do Sistema Único de Saúde (SUS) para o triênio 2015-2017 como norteador do projeto de custo e desfecho para o Hospital Munipal Vila Santa Catarina. ${ }^{(10)}$

Portanto, assim como a saúde suplementar brasileira tem se preocupado com a sustentabilidade do setor privado de saúde, há uma necessidade de iniciar a mesma discussão no setor público, permitindo conhecer os custos dos pacientes do SUS em um ciclo completo de tratamento, disponibilizando dados à gestão, ao Ministério da Saúde e a sociedade sobre como e onde os recursos provenientes de pagamento de impostos estão sendo utilizados pelos administradores. Mas isto só será possível se houver a mensuração dos custos no setor de saúde pública, iniciando pelos custos diretos hospitalares, que permitirá uma avaliação da eficiência entre o orçamento e o custo real de operação destas unidades.

\subsection{Objetivos}

1. Mensurar o custo operacional de um hospital público municipal da cidade de São Paulo no ano de 2016;

2. Identificar os determinantes relacionados aos altos custos nas internações. 


\section{REVISÃO DA LITERATURA}

\subsection{Aspectos sociodemográficos do Brasil}

O Instituto Brasileiro de Geografia e Estatística (IBGE) estima que até 2050 a taxa de natalidade para o Brasil seja de 8,1\% por 1.000 habitantes. Em 2010 a população se constituía por 51\% de mulheres e 49\% de homens, sendo que em 2011 o número de habitantes residentes no país era de 195.243 milhões, com estimativa projetada de 208.200.473 em novembro de 2017 com um novo nascimento a cada 21 segundos. ${ }^{(11,12)}$ A pirâmide etária brasileira foi invertida nos últimos 70 anos, esse fato iniciou de forma lenta até 1940 e com uma acelerada mudança a partir de 1960 com a queda da taxa de fecundidade, crescimento populacional de pessoas em idade ativa e idosa. ${ }^{(13)}$ Com a diminuição da taxa de natalidade e um declínio na taxa de mortalidade, onde recuamos de 21 para 10 óbitos por mil habitantes, pode-se dizer que essa mudança no perfil foi impulsionada pelo sistema de saúde público, a previdência social, a infraestrutura urbana e a regulamentação do trabalho na principais regiões do país, também aliado a esses fatores temos o crescimento da indústria farmoquímica que foi fundamental para o controle das doenças infectocontagiosas e pulmonares que era responsável por grande parte do alto índice de mortalidade. ${ }^{(14)}$

Em consequência dessa mudança, ainda segundo dados do IBGE, percebe-se o estreitamento da base da pirâmide com redução significativa no número de crianças e adolescentes, com perspectivas do aumento da média da idade para 2020 que poderão chegar a média de 35,0 anos e em 2050, a 48,3 anos, o número de pessoas com mais de 60 anos duplicará passando de 14,2 milhões alcançando 66,5 milhões de pessoas em 2050. A maior preocupação desta tendência é o fato de uma redução da carga econômica potencial, em 2020 haverá em torno de 53,2 inativos para cada 100 pessoas com idade ativa, chegando em 2050 a 76,8 inativos para cada 100 pessoas em idade ativa tornando o perfil populacional brasileiro de pessoas idosas. ${ }^{(14)}$ O impacto das mudanças demográficas leva a novas demandas com relação aos serviços que os governos e a sociedade devem prestar aos distintos grupos etários por meio de implementação de programas e políticas públicas, o fato mais preocupante está relacionado a área da saúde como os indicadores de média de tempo de internações, gasto médio dessas internações, e médias de dias de permanência 
hospitalar. Levando a uma reflexão sobre a complexidade crescente das doenças, dos procedimentos médicos e os aspectos da aceleração das despesas resultantes do processo de envelhecimento. ${ }^{(14)}$ Os gestores responsáveis por esta cadeia de atendimento precisam levar em consideração que o número de 19,6 milhões saltará para 66,5 milhões, entre 2010 a 2050 representando um aumento de $239 \%$ e será necessário pensar em como prover saúde a está população com recursos finitos. ${ }^{(14,15)}$

É necessário pensar em como resolver os problemas de financiamento e sustentabilidade do sistema, Kaplan et al. afirmaram que o conhecimentos dos custos, vai muito além do que a contabilidade para fins fiscais que os hospitais realizam com a finalidade de pagamento de impostos, custo por departamento ou financiamento de receitas pelo estado, as noções de custo visam disponibilizar informações sobre o perfil dos pacientes, das internações possibilitando definir as prioridades, discutir sobre a eficiência das suas operações, e propor sugestões pautadas em indicadores socioeconômicos, direcionando o caminho para uma adequada mensuração dos recursos necessários para operação da organização, a fim de utilizá-los de forma mais racional, direcionando esforços para aquilo que agrega valor e aumenta a qualidade da assistência ao paciente. ${ }^{(16)}$ Os aspectos sociais e demográficos da população, associado com a informação dos custos dos avanços e o incremento científico, tecnológico, desperdícios, uso irrestrito de insumos permite um melhor gerenciamento dos recursos financeiros tornando o sistema sustentável e financiável.

A tecnologia deve estar estruturada a serviço do homem e não o contrário, seu uso abusivo é um mito que deve ser revertido por meio de uma interação mais próxima entre médicos, pacientes e provedores de financiamentos, que precisam questionar inclusive os modelos de remuneração, modelos de financiamento realizados no Brasil tanto no sistema privado e principalmente pelo SUS que utiliza-se de uma tabela pré-fixada com valores há muitos anos defasadas. ${ }^{(17)}$ Para que o governo e a sociedade saibam quanto custa para prover efetivamente os serviços públicos Porter descreveu que é necessário que as instituições apurem seus custos como medida de eficiência na administração dos recursos, dado que a eficiência é a relação entre os resultados e o custo para obtê-los, portanto se não sabemos os nossos custos, não podemos discutir como e onde é necessário realizar mudanças operacionais e práticas clínicas. ${ }^{(9)}$ As ações sobre os determinantes de saúde não se limitam às ações tradicionais do Ministério da Saúde, cada provedor precisa ser responsável por ações 
que vinculam a alocação de recursos ao desenvolvimento de serviços com objetivo de saúde expresso em termos de indicadores observáveis, de uma maneira eficaz. ${ }^{(5)}$

\subsection{Os custos hospitalares}

As instituições hospitalares são instituições pluralistas, responsáveis pelo gasto de $60 \%$ do financiamento público dentro do sistema de saúde, e com o aumento dos gastos públicos e privados com estas instituições é necessária a urgente necessidade de discussão sobre a aplicação dos recursos existentes, pois para que se alcance mudanças de financiamento ou de resolutividade de alocação de recursos é preciso que entendam se há insuficiência de recursos ou falta de gerenciamento. ${ }^{(18)}$

Lee descreveu a preocupação com os custos das epidemias na Filadélfia. Ele utilizou de uma pergunta que até hoje é debatida, "qual o valor monetário de uma vida humana?" (19) No contexto de sistema de saúde onde a medicina é responsável pela busca, aperfeiçoamento técnico e científico no que tange aos tratamentos, afinamento das tecnologias, percebe-se nas últimas décadas um ganho incremental nos custos, demandando uma preocupação quanto ao financiamento desses tratamentos, entendemos que há dificuldade em valorar a vida, mas há como mapear os custos de tal forma que possa tornar os recursos que são finitos capazes de gerir os pagamento e sustentabilidade do sistema. ${ }^{(20)}$

Percebe-se que os hospitais possuem uma baixa margem operacional indicando a necessidade de conhecimento e controle da apuração de seus custos, para que otimizem negociações com os setores de compras, evitem desperdícios, perdas financeiras com produtos vencidos, mas principalmente controle o uso excessivo, identificando a solicitação de pedidos de exames desnecessários, desperdícios de materiais e medicamentos e ainda a percepção para cada ação, como no caso de adequação do cuidado individual como a devida indicação de cirurgia no momento certo e não tardiamente, não reconhecer distanásia, entre outros. As buscas do conhecimento dos custos institucionais precisam estar interligadas aos seus desfechos clínicos, permitindo um conhecimento destes custos por paciente e/ou internações e não apenas o custo por departamento ou procedimento, pois a mudança na prática clínica só é gerada com a aproximação entre gestores e equipe multidisciplinar, responsáveis por solicitar o cuidado adequado, gerindo a quantidade 
demandada de serviços, sem essa aproximação, não há como agregar valor ao paciente segundo Brownlee et al. ${ }^{(21)}$

Arashiro ${ }^{(22)}$ relata como as organizações vêm sofrendo pressão para, cada vez mais, reduzirem seus custos e alocarem de maneira eficaz os seus recursos. Especialmente na área da saúde, esse desafio torna-se foco, na busca de formas sustentáveis de prestação de serviços eficazes e gerenciamento efetivo dos recursos. ${ }^{(23)}$

Mas o grande desafio em termos de gerenciamento de custos ainda segundo Kaplan et al. ${ }^{(16)}$ é obter uma visão estratégica e gerencial, de forma integrada, e não somente como uma ação de controle ou corte de custo.

Sabe-se que há falta de recursos financeiros, mas também falta gestão, e há falta de conhecimento sobre a importância do gerenciamento das instituições públicas. ${ }^{(24,25)} \mathrm{A}$ demanda por tratamentos aumenta a cada ano, sendo crescente a necessidade de profissionais capacitados para gerir e melhorar a assistência à saúde das instituições visando um melhor desempenho e redução de custos diretos hospitalares. ${ }^{(26-29)}$

O conhecimento dos custos de tratamento dos pacientes internados nas instituições hospitalares permite um avanço na tomada de decisão, trazem a eficiência operacional, redução de ociosidade, e até mesmo estruturação de especialização do setor, uma vez que o custo é tudo que foi gasto para produzir um bem ou na apresentação de um serviço, de uma forma mais simples, o custo somente ocorre quando, efetivamente, o gasto é utilizado para produção de um bem ou prestação do serviço. ${ }^{(16)}$

Com a baixa adesão de hospitais públicos que utilizam algum sistema de apuração de custo no país percebe-se a necessidade urgente do setor em entender onde os recursos estão sendo consumidos, em pensar em um sistema de informação que seja capaz de gerenciar os custos, atingindo informações locais que forneçam dados concretos sobre qual a necessidade do setor, obtenção de mais recursos para o financiamento ou aperfeiçoamento da alocação e gestão destes recursos. ${ }^{(30)}$ Estudo publicado por Gomes et al. sobre investigação de métodos de custeio hospitalares apontou que a baixa apuração de custos nas instituições públicas não são realizadas por falta de orientação técnica, viabilidade de um software de sistema de apuração de custo e pelo fato de que os custos são considerados irrelevantes para a gestão. ${ }^{(30)}$ 
Um estudo realizado por Barros et al. em hospitais universitários federais no Brasil concluíram que apenas $20 \%$ dos hospitais federais, ou seja, apenas 9 dos 45 existentes no país, possuíam algum sistema de apuração de custo implantado, e dos que possuíam a implantação do sistema estava sendo realizada de forma lenta por falta de pessoal, equipamento de informática e um sistema de apuração de custo. ${ }^{(31)}$

A avaliação dos hospitais é uma tarefa difícil, e existe pouca orientação a respeito de metodologias apropriadas, os estudos na grande maioria vêm dos Estados Unidos, Europa e Canadá, que discutem o problema de ineficiência de gestão financeira desde os anos 1970 e 1980, onde o uso de um processo estruturado mudou e reduziu os custos operacionais. ${ }^{(32,33)}$

No Brasil, em 2013, o Ministério da Saúde por meio do Plano Nacional de Gestão de Custo realizou a descrição das diretrizes metodológicas para que as instituições hospitalares brasileiras pudessem utilizar os métodos contábeis como norteador da implantação de um sistema de apuração de custos. Nestas diretrizes são apontadas duas metodologias para fim de gerenciamento de suas decisões, são os sistemas de custeio por macrocusteio (top down) ou microcusteio (bottom-up). ${ }^{(24)}$

\subsection{Sistema de custeio}

Belke et al. definiram sistemas de custeio como conjuntos de procedimentos adotados para calcular algo, avaliar os bens e serviços nela processados. O sistema de custeio estabelece a metodologia aplicada ao desenvolvimento da estimativa de custos. ${ }^{(34)}$

Estas ferramentas segundo Abbas et al. são necessárias para gerar informações que possibilitam o uso desses dados para tomar decisões, eles precisam ser compatíveis com o objetivo e as características das organizações. ${ }^{(35)}$ Os métodos de custeio dividem-se em tradicionais e avançados, são considerados, métodos como tradicionais o custeio por absorção ou (top down) que atendem a legislação e o segundo método, o bottom-up o mais apropriado a tomada de decisão. ${ }^{(35)}$

Kaplan et al. descreveram a metodologia Time Driven Activity Based Costing, ${ }^{(16)}$ um modelo que apura os custos por microcrocusteio (bottom-up), 
metodologia que utiliza o tempo para determinar os direcionadores de custo, e permitir um melhor gerenciamento dos custos para tomada de decisão sobre a maneira de alocação dos recursos, devido ao alto custo de implantação e grande dificuldade de gerenciamentos deste método em instituições que possuem um grande volume de informações, os métodos tradicionais top down tem sido o mais utilizado nas instituições brasileiras que adotam um sistema de custeio. ${ }^{(35)}$ Este método da contabilidade de custo permite apurar custos para fins fiscais, pagamentos de imposto e para fins gerenciais, onde possibilita utilizar relatórios fornecidos pela área da contabilidade após apuração dos custos diretos hospitalares incorridos mensalmente para análise, assim como o método bottom-up, ambos têm a finalidade de possibilitar o gerenciamento e tomadas de decisões. ${ }^{(35)}$ Com isso, cada um dos métodos possuem características gerenciais voltadas para o planejamento, avaliação, controle, tomada de decisão e visam atender também dispositivos legais exigidos aos serviços de saúde que utilizam algum sistema de custos, na demonstração de resultado e comprovação da eficácia e eficiência econômica. Porém, não há um método universal de sistemas de informação de custos, cada instituição precisa buscar qual deles podem atendar às necessidades locais com maior ou menor grau de especialização. ${ }^{(1)}$

\subsubsection{Sistema de custeio por absorção}

O sistema de custo por absorção segue a Resolução do Conselho Federal de Contabilidade (CFC) № 1.366, de 25 de novembro de 2011. Este método apropria todos os custos da produção dos bens e todos os gastos de produção são distribuídos nos produtos ou serviços realizados. ${ }^{(36)}$

O método de custeio por absorção (top down) mais comum nas instituições que utilizam o método empregam a divisão dos centros de custos por departamentalização, ele agrega cada um dos produtos ou serviços pelas suas semelhanças, são setores ou áreas da organização que realizam atividades homogêneas no processo produtivo e sua divisão se dá pela natureza de sua atividade. ${ }^{(32)}$

Segundo o Wilson et al. e Fishman et al. a maior vantagem do sistema top down é que essa metodologia suporta estimativa do custo marginal de um 
diagnóstico específico no contexto de múltiplas comorbidades, especificamente, as doenças interagem com comorbidades no aumento do uso de recursos e custos. ${ }^{(37,38)}$

Após o término de apuração dos custos de cada um dos centros de custos estipulados estes custos são alocados nos direcionadores de custos.

\subsubsection{Direcionadores de custo}

Os direcionadores de custos são fatores que determinam a ocorrência de uma atividade, identificam como que as atividades exigem recursos para serem realizadas, o direcionador de custos é a verdadeira causa dos custos. ${ }^{(2)}$

Stock et al. utilizam a expressão de direcionadores de custos como indicativo de atividade que são responsáveis pelas características de precisão, custo e indução ao comportamento, o gerador de custo e o definidor de "qualquer fator que causa uma alteração nos custos de uma atividade."(29)

Os direcionadores de custo são utilizados como ferramentas de rastreabilidade e alocação dos custos, permitindo a identificação do custo por paciente e por internação.

\subsection{Sistema de financiamento brasileiro}

O Brasil se organiza em um sistema político federativo constituído por três esferas de governo, união, estados e municípios, todas consideradas pela Constituição da República de 1988 como entes com autonomia administrativa e sem vinculação hierárquica, possuem um sistema descentralizado, onde cada unidade utiliza sua própria ferramenta de gestão na tomada de decisão e gerenciamento dos recursos, isso torna mais complexa a implementação de políticas sociais de abrangência nacional, particularmente nos casos em que a situação de diversidade diz respeito à existência de marcantes desigualdades e exclusão social. ${ }^{(39)}$

De acordo com a Constituição Federal no Art. 196 a "saúde é direito de todos e dever do Estado, garantido mediante políticas sociais e econômicas que visem à redução do risco de doença e de outros agravos e ao acesso universal e igualitário às ações e serviços para sua promoção, proteção e recuperação". 
Quanto ao financiamento dos hospitais públicos, estes são realizados com recursos públicos dentro do sistema de saúde brasileiro condicionado a três modelos: pagamento per capita: onde há uma fixação dos gastos; pagamento por prestações de serviços; pagamento por orçamentos diretos. ${ }^{(40)}$ Através do SUS, as instituições recebem os recursos pelo orçamento da seguridade social, da união, dos estados, do distrito federal e dos municípios, além de outras fontes, sendo que as instituições privadas participam de forma complementar do SUS no gerenciamento das instituições públicas, segundo diretrizes deste, mediante contrato de direito público ou convênio, tendo preferência as entidades filantrópicas e as sem fins lucrativos. ${ }^{(41)}$ As instituições privadas participam no financiamento complementar ao SUS por meio do Certificado de Entidade Beneficente de Assistência Social em Saúde (CEBAS-SAÚDE) que até 2008 deveriam destinar $20 \%$ da receita ou $60 \%$ de atendimento SUS, conforme inciso VI do artigo $3^{\circ}$ do decreto $n^{\circ}=2.536$.

A partir de 2009 o Ministério da Saúde alterou as exigências, as instituições filantrópicas devem agora destinar 100\% das isenções usufruídas nos benefícios fiscais recebidos, são eles: [cota patronal + contribuição para 0 financiamento da seguridade social (COFINS) + programa de integração social (PIS)] conforme decreto $n^{\circ} 5.895$ e portarias $n^{\text {os }} 3.276$ e 2.734 , ratificados pela lei $n^{\circ} 12.101$ de 27 novembro de 2009.

Os hospitais filantrópicos participantes da parceria público-privada com o Ministério da Saúde precisam realizar prestações de contas conforme determinação da Portaria 936 - vigente desde 2011. Sendo que a Portaria 2.814 que revogou a Portaria 1.826 determina o modelo de prestação de constas dos projetos realizados por meio desta parceria, e que tiveram início em agosto de 2012. Estas diretrizes foram estabelecidas para acompanhamento, monitoramento, e prestação de contas, além dos layouts os relatórios de prestação de contas semestral e anual. ${ }^{(10)}$

\subsubsection{Hospital Israelita Albert Einstein}

O HIAE é um hospital terciário de natureza filantrópica, localizado na zona sul da cidade de São Paulo. Foi fundado pela comunidade judaica em 4 de junho de 1955. É uma das unidades de saúde mais conhecidas do Brasil pela qualidade de atendimento e pelos equipamentos e especialidades médicas de que dispõe para tratar 
os principais tipos de patologias, sendo o hospital privado mais moderno da América Latina. Em 1999 tornou-se a primeira instituição de saúde fora dos Estados Unidos a ser reconhecida pela Joint Commission International (a certificadora de serviços de saúde mais importante do mundo). ${ }^{(42)}$

É considerado uma das melhores instituições médicas latinoamericanas e configura-se como um complexo de saúde cujo foco de atuação está nas áreas da medicina de alta complexidade. ${ }^{(43)}$

O HIAE em parceria com a prefeitura, Ministério da Saúde através do CEBAS-SAÚDE, gerencia o Hospital Municipal Vila Santa Catarina (HMVSC), instituição pertencente ao PROADI-SUS.

\subsubsection{Programa de Apoio ao Desenvolvimento Institucional ao Sistema Único de Saúde}

O PROADI-SUS nasceu do reconhecimento dos hospitais de excelência. Essa parceria público-privada tem como papel, transferir experiências e processos de melhoria para o SUS. Este programa é realizado por meio de projetos, que são apresentados pelas entidades de saúde ao Ministério da Saúde que os avalia por meio de suas secretarias competentes ou entidades vinculadas. Uma vez aprovados, são pactuados mediante um termo de ajuste. Os resultados são comprovados com base no custo de execução dos projetos. ${ }^{(10)}$

O PROADI-SUS segue diretrizes estabelecidas pelo Ministério da Saúde sobre as isenções concedidas versus comprovação como gastos com mão de obra, PIS, COFINS (receita), verificando isenções versus comprovações.

A vigência de cada projeto é de três anos. Os projetos são executados pelas entidades de saúde com os recursos da isenção fiscal usufruída (contribuições sociais) a que têm direito, em função do CEBAS-SAÚDE.

\subsubsection{Hospital Municipal Vila Santa Catarina}

O HMVSC Doutor Gilson de Cássia Marques de Carvalho foi inaugurado em junho de 2015, esta unidade hospitalar encontrava-se desativada desde 
2011 por falência do grupo particular que a administrava. Foram utilizados para o custeio cerca de $R \$ 160,00$ milhões por ano de recursos do HIAE para sua viabilização e funcionamento. A estrutura hospitalar foi instalada em um terreno de oito $\mathrm{mil}^{2} \mathrm{e}$ área construída de 25 mil metros quadrados.

O HMVSC possui um total de 170 leitos, assim distribuídos: a) 118 leitos de internação, 20 leitos de unidade de terapia intensiva (UTI) adulto, 09 leitos de UTI pediátrica, 11 leitos de UTI neonatal, 12 leitos de semi-intensiva neonatal, 05 salas cirúrgicas (geral e transplante), 03 salas de centro obstétrico, 03 salas de parto natural, 05 posições de diálise e 21 salas de ambulatório.

Com 1.052 funcionários, dentre estes 124 médicos, 152 enfermeiros, 204 técnicos e auxiliares de enfermagem, 46 profissionais de equipe multidisciplinar (biomédicos, fisioterapeutas, fonoaudiólogos, farmacêuticos) e 526 profissionais não assistenciais.

O HMVSC é uma unidade hospitalar composta por atendimentos de diversos projetos do programa PROADI-SUS. O departamento de transplante está subdivido no atendimento de pacientes em fases de pré-transplante, transplante e póstransplante:

a) Pré-transplante: fase que compreende a avaliação dos pacientes, quanto aos critérios definidos para inscrição em lista de espera, período em que o paciente permanece aguardando a oferta do órgão até a data do transplante;

b) Transplante: fase em que ocorre, de fato, o implante do órgão. Esta fase compreende a data de internação para a cirurgia até a sua alta;

c) Pós-transplante: fase de tratamento que compreende todos os atendimentos/procedimentos/exames pós-alta do período de internação após o transplante. Esta fase de acompanhamento se encerra em caso de óbito, transferência do paciente para outros centros e/ou perda de seguimento.

O departamento de clínica médico-cirúrgica, destina-se a pacientes recebidos por meio da solicitação de vaga pela Central de Regulação de Ofertas de Serviços de Saúde (CROSS), serviço que busca otimizar os recursos assistenciais disponíveis, garantindo a melhor alternativa assistencial face à necessidade do paciente.

O departamento de oncologia destina-se a pacientes oncológicos, com indicação de cirurgia geral, urológica ou vascular, vindos da Rede Municipal de 
Saúde, por meio do agendamento pelo Sistema Integrado de Gestão de atendimento (SIGA).

O departamento materno-infantil caracteriza-se pelo recebimento de gestantes de alto risco, por meio de encaminhamentos das Unidades de Referência ou Pronto Atendimento Obstétrico e neonatos de baixo e alto risco, nascidos das gestantes recebidas para o parto.

A unidade de pronto atendimento (UPA) Santa Catarina, parte do HMVSC, pertence à gestão da Prefeitura Municipal de São Paulo e atende usuários com quadro clínico agudo nas especialidades: clínica médica, pediatria, cirurgia geral e ortopedia.

Os atendimentos no HMVSC são serviços oferecidos por meio da rede pública e são regulados pela Secretaria de Saúde. O sistema de gerenciamento é feito por meio de duas centrais - a Central de Regulação de Internação Hospitalar e a Central de Marcação de Consultas e Exames. O sistema ordena as solicitações de 24 tipos de exames, consultas em sete especialidades (com diversas subespecialidades), leitos de UTI, além de cirurgias vasculares e plásticas, obedecendo a uma classificação de risco com o objetivo de facilitar o acesso do paciente aos serviços de saúde.

O HMVSC foi planejado para utilizar toda a estrutura de informação do HIAE para que houvesse rastreabilidade das informações, portanto os pacientes na admissão são cadastrados no Sistema de Gestão Hospitalar (SGH) (InterSystems TrakCare ${ }^{\circledR} 1996-2017$, Cambridge, MA), um sistema eletrônico que armazena os dados clínicos, demográficos, e utilização de recursos.

Cada paciente tem um número de prontuário e esse número de identificação do paciente permanece sempre o mesmo em todas as internações. A cada nova admissão gera-se um número de registro hospitalar para a internação atual.

No momento da admissão hospitalar, são coletados os seguintes dados: data da hospitalização, idade, sexo, etnia, número de registro hospitalar, motivo (ou diagnóstico) de admissão, diagnósticos secundários, comorbidades.

$\mathrm{Na}$ alta, óbito ou transferência do paciente, o médico realiza o preenchimento do diagnóstico de alta no sistema de grupo de doenças relacionadas (DRG - Diagnosis Related Groups). 


\subsubsection{Modelo de apuração do Programa de Apoio ao Desenvolvimento Institucional ao Sistema Único de Saúde}

A partir da parceria entre HIAE e Ministério da Saúde para financiamento do HMVSC houve a necessidade de iniciar a descrição do modelo de apuração de custo do PROADI-SUS.

O HIAE realiza a apuração de custo por meio de um sistema totalmente automatizado, utilizando o SGH para identificar o paciente, os centros de custos e o volume de lançamentos, e um Sistemas, Aplicativos e Produtos para Processamento de Dados (SAP) para realizar a apuração de custo de insumos (materiais e medicamentos), onde um algoritmo integrado aos sistemas Business Warehouse (BW) realiza o agrupamento das informações de custo por departamento, por internação e por paciente, processo descrito no anexo 1.

Ao final da apuração é emitido pela área de custo um relatório de custo por paciente, por internação dos pacientes do HMVSC. Assim fornecendo uma carga de dados com as informações de todas as unidades produtivas. O modelo de apuração de PROADI-SUS, encontra-se descrito no anexo 2.

\subsection{O Sistema de diagnosis related groups}

Como visão geral, a classificação empregada pelo DRG, determina pacientes em grupos com as mesmas características clínicas e tratamentos, com consumo de recursos similares desde sua admissão até a alta, proporcionando às instituições de saúde uma melhor análise de suas atividades, custos e qualidade dos serviços. $^{(44-46)}$

O DRG foi desenvolvido pela Yale University (EUA). Inicialmente, foi concebido para identificar produtos (conjunto de intervenções) aplicados a determinados pacientes, para fins de pagamentos pelo sistema de saúde, o sistema abrange e quantifica três diferentes dimensões de uma determinada doença, todos com grande importância em pesquisa e/ou no gerenciamento de custos: gravidade da doença, risco de mortalidade e intensidade no uso de recursos. O processo de formação dos DRG foi iniciado dividindo todos os possíveis diagnósticos principais em 23 áreas de diagnósticos principais mutuamente exclusivas, mencionadas como 
categoria de diagnósticos maiores (MDC - Major Diagnostic Categories). Dois novos MDCs foram criados na oitava versão dos DRGs.

Os MDCs foram formados por painéis médicos, como o primeiro passo para garantir que os DRGs sejam clinicamente coerentes. Os diagnósticos em cada MDC correspondem a um único sistema de órgãos ou etiologia e, em geral, estão associados a uma determinada especialidade médica. Assim, a fim de manter o requisito de coerência clínica, nenhum DRG final pode conter pacientes em diferentes MDCs. O MDC foi construído para corresponder a um sistema de órgãos principal (sistema respiratório, sistema circulatório, sistema digestivo) em vez de etiologia (malignidades, doenças infecciosas). Esta abordagem foi utilizada, uma vez que o atendimento clínico é geralmente organizado de acordo com o sistema de órgãos afetados, e não a etiologia. Assim, doenças envolvendo tanto um sistema de órgãos particular quanto uma etiologia particular (por exemplo, neoplasia maligna de rim) foram atribuídos ao MDC correspondente ao sistema de órgãos envolvido. No entanto, nem todas as doenças ou distúrbios podem ser atribuídos a um MDC baseado em sistema orgânico e um número assim foram criados MDCs residuais (por exemplo, doenças infecciosas sistêmicas, doenças mieloproliferativas e neoplasias pouco diferenciadas). Por exemplo, as doenças infecciosas por envenenamento alimentar são atribuídas ao MDC do sistema digestivo enquanto a tuberculose pulmonar é atribuída ao MDC do sistema respiratório. Por outro lado, doenças infecciosas como a malária, tuberculose e septicemia, que normalmente envolvem todo o corpo, são atribuídas à categoria "sistêmica doença infecciosa" no MDC. ${ }^{(47)}$

No Brasil quando os grupos de trabalho que discutem o uso do DRG enfatizam que a ferramenta permitirá um sistema de remuneração mais justo, aos provedores de saúde que conseguirem uma entrega de saúde mais efetiva. ${ }^{(48)}$

No HIAE a ferramenta ainda não está validada para ser utilizada no modelo de remuneração de pagamento dos serviços, o sistema DRG vem sendo utilizado no apoio ao conhecimento do perfil nosológico do hospital e para avaliar a qualidade da assistência. ${ }^{(48)}$ 


\section{MÉTODOS}

Foi realizado um estudo de coorte prospectivo, com foco na descrição dos custos diretos hospitalares do HMVSC, disponibilizando a gestão, ao Ministério da Saúde e à sociedade o conhecimento sobre como e onde os recursos foram alocados por meio da mensuração do custo operacional e identificação dos fatores que influenciaram o aumento do custo hospitalar.

\subsection{Critérios de inclusão}

Todos os pacientes internados que receberam alta administrativa ou foram a óbito hospitalar no HMVSC, com uma ou mais internações, pertencentes aos projetos PROADI-SUS, nos departamentos de clínica médico-cirúrgica, maternoinfantil, oncologia e transplante no período de 1 de janeiro a 31 de dezembro de 2016.

\subsection{Critérios de exclusão}

Pacientes da UPA que não internaram, pacientes pertencentes a outros projetos PROADI-SUS não descritos nos critérios de inclusão, pacientes ambulatoriais e diagnósticos. Internações com custos sendo lançados duplicados em dois projetos, esses casos foram checados pela pesquisadora e excluídas as duplicidades.

\subsection{Modelo de apuração de custo e desfecho}

\subsubsection{Dados clínicos e demográficos}

Os dados das variáveis como idade, sexo, raça, desfecho de alta, número de internações, perfil das internações foram extraídas do SGH. 


\subsubsection{Dados de custo}

Os dados de custos foram obtidos pela área da contabilidade após apuração dos custos no final de cada mês, pelo método de absorção (top down).

As variáveis coletas foram custo médio de cada direcionador, diárias (unidades de internação), taxas (centro cirúrgico e centro obstétrico), honorários (anestesistas), atendimentos (equipe multiprofissional), exames (laboratório e imagem), enfermagem (centro de diálise); procedimentos (banco de sangue e hemodinâmica), materiais e medicamentos por paciente e por internação para os projetos incluídos neste estudo e utilizando como norteador o departamento cadastrado na primeira internação. Pacientes que foram atendidos em outras unidades do HIAE, em caso de procedimentos não realizados no HMVSC, tiveram seus custos de atendimentos alocados no projeto PROADI-SUS.

\subsubsection{Dados de desfecho - Diagnosis Related Groups}

Para mensuração do custo por paciente, utilizamos o DRG da última internação para pacientes que tiveram uma nova internação com período menor de 8 horas, considerando para cálculo de custo como mesma internação, estes casos ocorreram em pacientes que realizaram transferências de unidades para realização diagnóstica ou internações entre HIAE e HMVSC.

Para mensuração do custo por departamento, direcionadores de custo e diagnóstico de alta DRG, utilizamos os dados de custo por internações dos pacientes e posteriormente agrupados por MDC e identificados os principais DRG de cada departamento, também foi utilizado na identificação dos fatores que influenciaram o aumento do custo o diagnóstico de alta hospitalar caracterizado por DRG de cada internação.

As informações utilizadas foram extraídas do banco de dados do sistema All Patient DRGS (AP-DRG), após verificação pelo departamento de Serviço de Arquivos Médicos (SAME), que realizou averiguação de todos os diagnósticos quanto ao correto preenchimento pelo médico, e posterior correção ou complementação dos dados permitindo que não houvesse falta de preenchimento ou documentos 
incompletos, nenhum diagnóstico foi excluído do banco por falta de informação ou preenchimento.

\subsubsection{Integração dos bancos de dados}

Ao término da coleta de todas as variáveis das internações do período, as cargas de dados foram armazenados por um Data Warehouse (DW) ${ }^{(49)}$ onde utilizamos um algoritmo Business Intelligence $(\mathrm{BI})$ e por meio da ferramenta de visualização (Qlikview ${ }^{\circledR}$, Radnor, PA, EUA), conforme demonstrado na figura 1, integramos as bases de dados de custo, dados demográficos, desfecho e DRG viabilizando a criação do banco de dados dos custos, por paciente, internação e DRG.

Após emissão de relatórios dos dados de custos e desfecho foram extraídos para o Microsoft Excel ${ }^{\circledR}$ (Microsoft, EUA, versão 2013) e, então, analisados com auxílio do pacote estatístico.

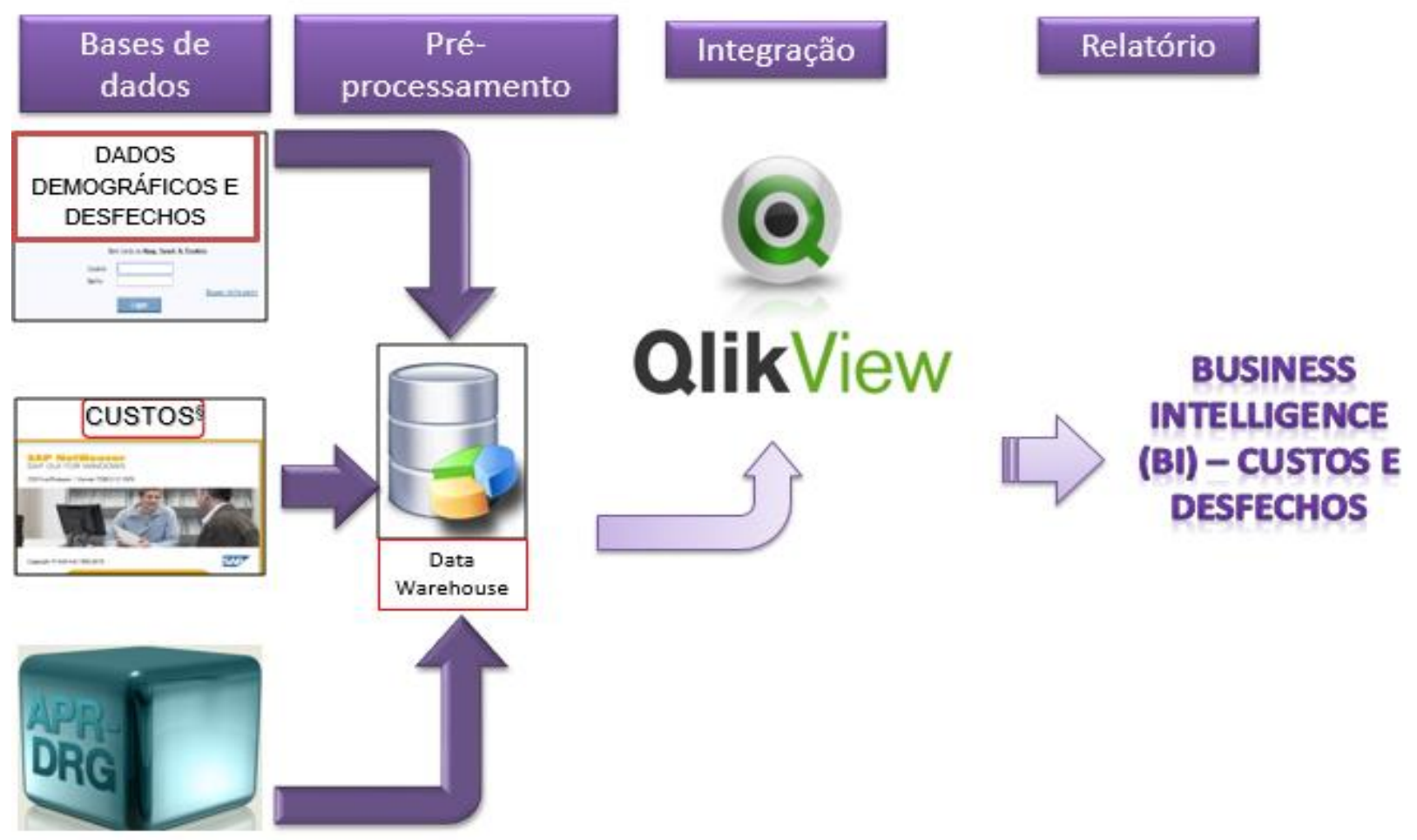

Figura 1. Integração de bases de dados 


\subsection{Análise estatística}

Para a mensuração dos custos operacionais por pacientes e por internação os custos totais de cada paciente foram calculados somando-se todos os custos médios dos direcionadores de custo de cada paciente. A proporção de custo de cada fator está apresentada em porcentagem e gráficos de setores.

Os custos médios estão descritos por histogramas e boxplots e também por medidas resumo como média, desvio-padrão (DP), valores mínimos e máximos, mediana (MED) e quartis.

Para cálculo dos custos médio por DRG utilizou-se a soma dos custos de todos os pacientes com o mesmo DRG dividido pelo número encontrado de pacientes com o mesmo DRG.

As análises foram feitas com auxílio do pacote computacional $R(R$ Core Team, 2016), versão 3.4.1.

Para análise dos fatores que influenciaram o aumento do custo hospitalar, as internações foram divididas segundo o custo total em alto e não alto custo, utilizando a mediana do custo total de todas as internações, devido à grande variação do custo médio na mensuração do custo operacional, dessa forma custos inferiores à mediana foram considerados não altos e os valores maiores ou iguais a esse valor considerados de alto custo.

As variáveis categóricas foram descritas por frequências absolutas e porcentagens e as variáveis quantitativas por mediana e quartis.

Foram ajustados modelos de equações de estimação generalizada, ${ }^{(50)}$ para investigar associações entre internação de alto custo e as variáveis dos pacientes e das internações em abordagem simples de forma a contemplar a dependência entre as diferentes internações de um mesmo paciente no período de estudo. Os resultados foram apresentados por razões de chances $(\mathrm{RC})$ e intervalos de confiança (IC) de 95\%.

Os pacientes divididos nos grupos de pacientes de alto custo e não alto custo foram comparados quanto ao tempo de permanência hospitalar e quanto aos custos por tempo de permanência por testes não paramétricos de Mann-Whitney.

As análises foram realizadas com auxílio do programa SPSS (IBM SPSS Statistics for Windows, Version 24.0), considerando nível de significância 5\%. 


\subsection{Aspectos éticos}

O estudo teve aprovação do Comitê de Ética em Pesquisa do HIAE e do Comitê de Ética da Secretaria Municipal de Saúde da cidade de São Paulo, registrado sob o número CAAE 55094716.2.0000.0071. Também foram seguidas as orientações da Declaração de Helsinque.

Este é um estudo observacional, anonimizado, sem qualquer tipo de intervenção sobre os pacientes, por isso foi solicitado e concedido isenção do termo de consentimento livre e esclarecido para esta pesquisa, que em si, oferece baixo risco adicional a quaisquer dos indivíduos participantes. Os investigadores do presente estudo se comprometem a manter a confidencialidade dos dados durante e após sua análise. 


\section{RESULTADOS}

As análises foram conduzidas com 9.818 passagens de 8.702 pacientes com admissão e alta em 2016, que após verificação de data e hora de alta e readmissões, o número de internações reduziu para 9.602.

Os pacientes internados que foram considerados no estudo, têm entre zero e 98 anos de idade com mediana de 23 anos. A maioria é do sexo feminino $(67,2 \%)$. Quanto à raça, 32,7\% são brancos e $27,8 \%$ são pardos. A maioria obteve alta $(97,3 \%)$ e $2,7 \%$ foram a óbito.

Verificou-se ainda que durante o período do estudo os pacientes foram internados de uma a oito vezes, sendo que $92,9 \%$ internaram apenas uma vez nesse período.

As internações ocorreram de um a 231 dias de permanência no hospital com mediana de três dias e terceiro quartil de quatro dias, mostrando uma alta concentração de internações mais curtas (Tabela 1).

Tabela 1. Características demográficas dos pacientes do Hospital Municipal Vila Santa Catarina

\begin{tabular}{|c|c|}
\hline Características dos pacientes & Total \\
\hline Idade (anos) & $\mathrm{N}(8702)$ \\
\hline Mediana [1ㅇ; $3^{\circ}$ quartis] & $23,00[1,00 ; 36,00]$ \\
\hline Mínimo; Máximo & 0,$00 ; 98,00$ \\
\hline \multicolumn{2}{|l|}{ Custo total por paciente $(\mathrm{R} \$$ ) } \\
\hline Mediana [1ㅇ; $3^{\circ}$ quartis] & $5.950,82[2.373,33 ; 11.340,63]$ \\
\hline Mínimo; Máximo & 7,$68 ; 2.487 .697,39$ \\
\hline \multicolumn{2}{|l|}{ Sexo, $n(\%)$} \\
\hline Feminino & $5849(67,2)$ \\
\hline Masculino & $2853(32,8)$ \\
\hline \multicolumn{2}{|l|}{ Raça, $n(\%)$} \\
\hline Branca & $2844(32,7)$ \\
\hline Parda & $2422(27,8)$ \\
\hline Negra & $855(9,8)$ \\
\hline Amarela & $52(0,6)$ \\
\hline Indígena & $2(0,0)$ \\
\hline Não informado & $2527(29,0)$ \\
\hline \multicolumn{2}{|l|}{ Desfecho hospitalar, $\mathrm{n}(\%)$} \\
\hline Óbito & $236(2,7)$ \\
\hline Alta & $8466(97,3)$ \\
\hline Não informado & $47(0,5)$ \\
\hline Número de internações no período, n(\%) & \\
\hline
\end{tabular}




\begin{tabular}{lc}
...continuação & \\
\hline Uma & $8086(92,9)$ \\
Duas & $445(5,1)$ \\
Três & $97(1,1)$ \\
Quatro & $48(0,5)$ \\
Perfil das internações & Total \\
Tempo de permanência (dias) & 5,7 \\
Mediana [1ㅜㅜํ quartis] & $2,95[2,35 ; 4,22]$ \\
Mínimo; Máximo & 1,$00 ; 230,70$ \\
Taxa de ocupação (\%) & 53,49 \\
\hline
\end{tabular}

O custo total dos pacientes internados foi de $\mathrm{R} \$ 158.861 .058,90$. Ao considerar que o ano de 2016 teve 366 dias, o custo médio por dia para a unidade hospitalar funcionar foi de $\mathrm{R} \$ 434.046,61$, considerando apenas os custos fixos dos centros de custos foi necessário $\mathrm{R} \$ 377.280,33$ por dia para manter a unidade hospitalar funcionando, aplicados em um total de 1.052 funcionários e uma taxa média de ocupação de $53,49 \%$. Ao considerar o número de pacientes/dia, o custo médio foi de $\mathrm{R} \$ 3.093,44$ por paciente/dia, com mediana por paciente de $\mathrm{R} \$ 5.950,82$.

Observando-se as faixas etárias dos pacientes verificou-se que os extremos de idade se contrapõem sendo que $41,78 \%$ da população concentra-se na faixa etária mais jovem ( 0 a 18 anos) com um custo por membro por mês de $R \$ 643,96$ enquanto no outro extremo apenas $11,87 \%$ na população mais idosa (59 ou mais) com um custo por membro por mês de $\mathrm{R} \$ 4.699,34$, ou seja aproximadamente $581 \%$ a mais com relação ao custo. Desta maneira uma menor parte da população é responsável pelo alto custo (Apêndice 1).

Ao observar o custo por internação, obtivemos uma média de $\mathrm{R} \$$ $6.165,21$ por internação (DP: $R \$ 49.015,75$ ) (Apêndice 2 ). Houve uma internação com custo acima de $\mathrm{R} \$ 2$ milhões referente a um paciente que ficou 170 dias internado no transplante (Apêndice 3). Além dessa internação, ainda houve outros valores discrepantes que, no gráfico, poderiam prejudicar a visualização da distribuição dos custos e, por isso, foram também construídos gráficos das distribuições de $90,0 \%$ das informações com custos mais baixos (Apêndice 4). Identificou-se que 69,9\% (38,51\% + $31,39 \%$ ) da população tiveram um custo de internação até $R \$ 10.000$ o que representa $19 \%$ do total do custo, enquanto apenas $5,22 \%$ da população foi responsável pelas internações acima de 60 mil reais o que representa $47,31 \%$ do custo total (Apêndice 5 ). 
Em relação aos custos por departamento observa-se que o transplante obteve o maior custo médio por internação de $R \$ 57.715,14$, enquanto que o departamento materno-infantil obteve o menor custo médio, de $\mathrm{R} \$ 6.476,12$. Os departamentos de clínica médico-cirúrgica e transplante são os mais custosos em relação ao custo total, representando, respectivamente, 36 e $35 \%$ do custo total (Apêndice 6).

Verificando os custos quanto aos seus direcionadores de custo das 9.602 internações a figura 1 demonstra que dentre eles o maior custo foram as diárias hospitalares, sendo responsáveis por 55\% do custo total das internações de 2016, enquanto que a menor parcela de custos foi direcionada à enfermagem (1\%).

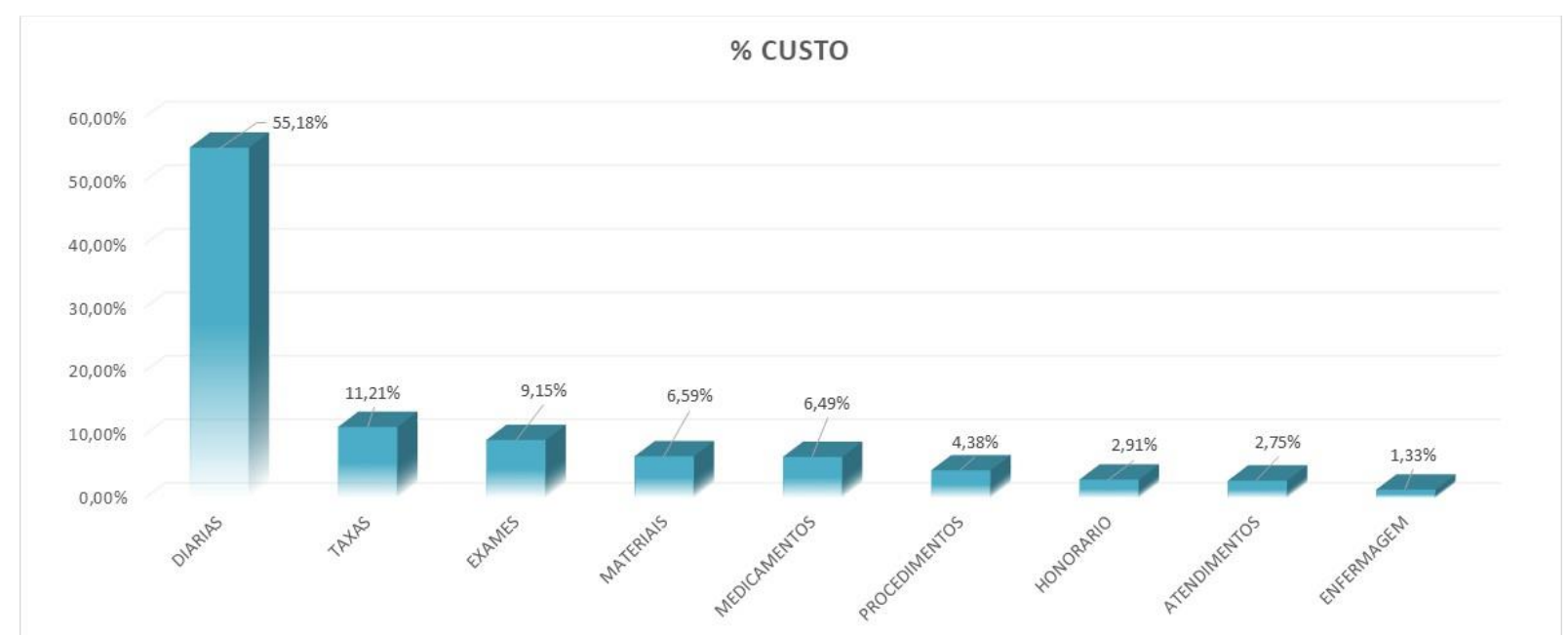

Figura 2. Distribuição do custo das internações de acordo com os direcionadores de custo

Ao considerar os desfechos dos pacientes em cada internação, o maior montante de custo é devido às internações cujos pacientes ficaram vivos (88\%), entretanto, o custo médio por internação é maior dentre internações em que o paciente foi a óbito (Tabela 2).

Tabela 2. Custos por desfecho hospitalar

\begin{tabular}{lcc}
\hline Desfecho & Custo médio & N \\
\hline Óbito & $\mathbf{( R \$ )}$ & 236 \\
Vivo & $77.767,09$ & 9366 \\
\hline
\end{tabular}

Realizando-se a identificação das principais causas de internação e uso de recursos por diagnóstico de alta hospitalar, identificou-se 204 DRG's de alta por 
isso conduziu-se a análise por agrupamento utilizando o MDC, tendo como resultado o MDC de alta com maior custo médio pertencendo a categoria, uso de álcool/drogas e distúrbios mentais orgânicos induzidos por álcool/drogas observado em três internações (Tabela 3).

Tabela 3. Diagnóstico de alta e custos das Internações durante o ano

\begin{tabular}{|c|c|c|}
\hline Major Diagnostic Categories & $\begin{array}{c}\text { Custo médio } \\
\text { (R\$) }\end{array}$ & $\mathbf{n}$ \\
\hline $\begin{array}{l}\text { Uso de álcool/drogas e distúrbios mentais orgânicos induzidos por } \\
\text { álcool/drogas }\end{array}$ & $226.046,22$ & 3 \\
\hline Infecções por vírus da imunodeficiência humana & $96.250,94$ & 9 \\
\hline $\begin{array}{l}\text { Fatores que influenciam status saúde e outros contatos com } \\
\text { serviços de saúde }\end{array}$ & $65.758,57$ & 73 \\
\hline $\begin{array}{l}\text { Doenças infecciosas e parasíticas, sistêmicas ou em local não } \\
\text { especificado }\end{array}$ & $64.449,01$ & 196 \\
\hline $\begin{array}{l}\text { Doenças e distúrbios do sistema musculoesquelético e do tecido } \\
\text { conjuntivo }\end{array}$ & $59.289,89$ & 27 \\
\hline $\begin{array}{l}\text { Doenças e distúrbios do sangue, dos órgãos formadores do sangue, } \\
\text { distúrbios imunológicos }\end{array}$ & $53.063,47$ & 32 \\
\hline Doenças e distúrbios do sistema circulatório & $50.140,88$ & 480 \\
\hline Doenças e distúrbios mentais & $44.578,82$ & 13 \\
\hline Não agrupável & $41.257,25$ & 11 \\
\hline $\begin{array}{l}\text { Doenças e distúrbios mieloproliferativos, neoplasma pouco } \\
\text { diferenciado }\end{array}$ & $40.914,21$ & 15 \\
\hline Doenças e distúrbios do sistema nervoso & $40.364,78$ & 100 \\
\hline Doenças e distúrbios do sistema hepatobiliar e pâncreas & $37.280,65$ & 397 \\
\hline Doenças e distúrbios do sistema respiratório & $34.690,48$ & 538 \\
\hline Doenças e distúrbios dos rins e do trato urinário & $33.979,76$ & 426 \\
\hline Doenças e distúrbios dos ouvidos, nariz, boca e garganta & $32.501,91$ & 57 \\
\hline Lesões, envenenamentos e efeitos tóxicos de drogas & $30.965,85$ & 33 \\
\hline Doenças e distúrbios endócrinos, nutricionais e metabólicos & $28.576,41$ & 44 \\
\hline Doenças e distúrbios do sistema reprodutor feminino & $23.340,83$ & 6 \\
\hline Doenças e distúrbios do sistema digestivo & $21.964,80$ & 425 \\
\hline Doenças e distúrbios da pele, tecido subcutâneo e da mama & $21.226,95$ & 88 \\
\hline Doenças e distúrbios do sistema reprodutor masculino & $14.668,67$ & 143 \\
\hline Doenças e distúrbios dos olhos & $11.045,62$ & 2 \\
\hline Gravidez, parto e puerpério & $7.445,28$ & 3412 \\
\hline $\begin{array}{l}\text { Recém-nascidos e outros neonatos com condição de origem no } \\
\text { período perinatal }\end{array}$ & $5.174,83$ & 3072 \\
\hline
\end{tabular}


Em relação ao custo total o DRG mais custoso consistiu em "gravidez, parto e puerpério", que compõe $16 \%$ do custo total, e "doenças e distúrbios do sistema circulatório", que compõe 15\% do custo total (Apêndice 7).

Em relação à análise de custo médio por DRG em cada departamento (Apêndices 8 a 11), considerou-se o departamento de transplante com o DRG de maior custo médio os "procedimentos importantes de pâncreas, fígado e desvio (shunt)", sendo que o departamento teve um total de 964 internações (214, $22,20 \%$. Para o departamento de clínica médico-cirúrgica o DRG de maior custo foi "transplante de coração e/ou pulmão", demonstrando que das 1.859 internações no departamento, apenas 184 delas foram responsáveis pelo alto custo, que representam $9,90 \%$, de todas as internações. No departamento de oncologia as internações com DRG de "obstrução intestinal" significaram o maior utilizador dos recursos, sendo 212 internações destas 167 internações são responsáveis por 78,77\% dos custos. No departamento materno-infantil, o custo mais elevado equivaleu ao DRG de "bronquiolite e pneumonia por vírus respiratório sincicial", sendo que de 6567 internações neste departamento 219 internações, ou seja, 3,33\% dos diagnósticos contribuíram para a elevação dos custos médios.

Após a mensuração dos custos, conduziu-se a verificação das características das internações quanto aos fatores que influenciaram o aumento do custo hospitalar, na tabela 4 demonstram-se as características do grupo de pacientes, cuja tabela completa está disponível no apêndice 12.

Houve a verificação das associações dos fatores que influenciaram o aumento do custo hospitalar, conforme demonstrado na tabela 5, e tabela completa no apêndice 13. 
Tabela 4. Características dos pacientes segundo o custo total das internações

usto

\section{Características dos pacientes e internações}

Não alto $(<6165,2)$

$\mathrm{n}=\mathbf{4 8 0 0}$

Idade, mediana ( $1^{\circ}$ quartil; $3^{\circ}$ quartil)

Sexo, $n(\%)$

Feminino

Masculino

Desconhecido

Não informado

Raça, n(\%)

Amarela

Branca

Indígena

Negra

Parda

Não informado

Departamento, $\mathrm{n}(\%)$

Materno-infantil

Clínica médico-cirúrgica

Transplante

Oncologia

Status na alta, $\mathrm{n}(\%)$

Óbito

Vivo

Não informado

Tempo de permanência hospitalar mediana (1ํquartil; $3^{\circ}$ quartil)

MDC alta (\%)

Gravidez, parto e puerpério, $\mathrm{n}(\%)$

Doenças e distúrbios do sistema respiratório, $\mathrm{n}(\%)$

Doenças e distúrbios do sistema circulatório, $\mathrm{n}(\%)$
$1,0(1,0 ; 25,0)$

$3140(65,42)$

$1659(34,56)$

$1(0,02)$

$0(0,00)$

$14(0,29)$

$965(20,10)$

$1(0,02)$

$347(7,23)$

$998(20,79)$

$2475(51,56)$

$4419(92,06)$

$246(5,13)$

$113(2,35)$

$22(0,46)$

$20(0,42)$

$4762(99,21)$

$18(0,38)$

$2,6(2,3 ; 3,1)$

$1644(34,25)$

$106(2,21)$

$56(1,17)$
Alto $(\geq 6165,2)$

$\mathrm{n}=4802$

$36,0(24,0 ; 59,0)$

$3156(65,72)$

$1645(34,26)$

$0(0,00)$

$1(0,02)$

$42(0,87)$

$2389(49,75)$

$3(0,06)$

$607(12,64)$

$1708(35,57)$

$53(1,10)$

$2148(44,73)$

$1613(33,59)$

$851(17,72)$

$190(3,96)$

$216(4,50)$

$4551(94,77)$

$35(0,73)$

$3,9(2,7 ; 8,3)$

$1768(36,82)$

$432(9,00)$

$424(8,83)$ 
...continuação

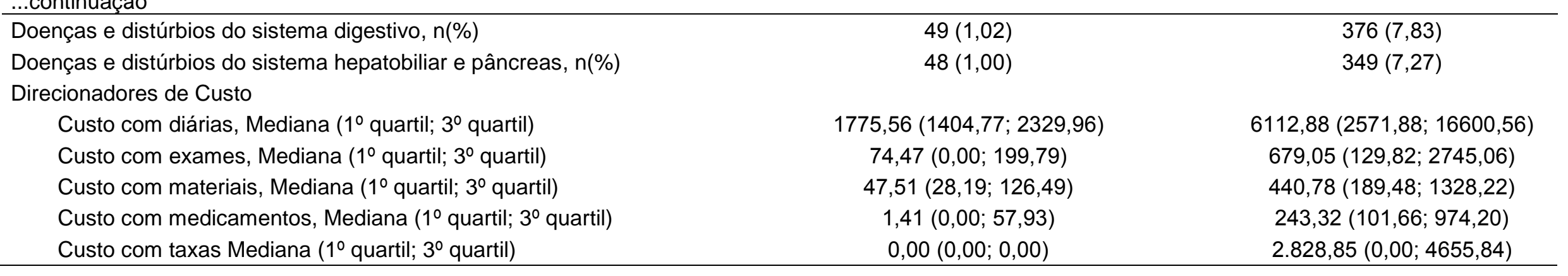

Tabela 5. Associação entre alto custo da internação, tempo de permanência e direcionadores de custo por internação

\begin{tabular}{|c|c|c|c|c|}
\hline $\begin{array}{l}\text { Associação das internações, tempo de permanência e } \\
\text { direcionadores com o custo }\end{array}$ & \multicolumn{2}{|c|}{$\begin{array}{l}\text { Custo } \\
\text { (R\$) }\end{array}$} & $\begin{array}{c}\text { RC } \\
\text { (IC 95\%) }\end{array}$ & Valor-p \\
\hline Idade (anos), mediana (1ํquartil $-3^{\circ}$ quartil) & $1,0(1,0 ; 25,0)$ & $36,0(24,0 ; 59,0)$ & $1,066(1,063 ; 1,069)$ & $<0,001$ \\
\hline Feminino (n=6293) & $3140(49,87)$ & $3156(50,13)$ & $1,119(1,024 ; 1,222)$ & 0,013 \\
\hline Masculino $(n=3304)$ & $1659(50,21)$ & $1645(49,79)$ & 1,000 & \\
\hline $\mathrm{n}$ & 4799 & 4801 & & \\
\hline Branca $(n=3354)$ & $965(28,77)$ & $2389(71,23)$ & $1,449(1,297 ; 1,619)$ & $<0,001$ \\
\hline Negra $(n=954)$ & $347(36,37)$ & $607(63,63)$ & $1,034(0,884 ; 1,210)$ & 0,672 \\
\hline Parda $(n=2406)$ & $998(36,88)$ & $1708(63,12)$ & 1,000 & \\
\hline $\mathrm{n}$ & 2324 & 4746 & & \\
\hline \multicolumn{5}{|l|}{ MDC na alta, n(\%) } \\
\hline $\begin{array}{l}\text { Recém-nascidos e outros neonatos com indicação de origem no } \\
\text { período perinatal ( } n=3072)\end{array}$ & $2742(89,26)$ & $330(10,74)$ & 1,000 & \\
\hline
\end{tabular}




\begin{tabular}{|c|c|c|c|c|}
\hline Doenças e distúrbios do sistema digestivo ( $\mathrm{n}=425$ ) & $49(11,53)$ & $376(88,47)$ & $65,477(47,101 ; 91,022)$ & $<0,001$ \\
\hline Doenças e distúrbios do sistema circulatório ( $n=480$ ) & $56(11,67)$ & $424(88,33)$ & $64,833(47,456 ; 88,573)$ & $<0,001$ \\
\hline Doenças e distúrbios dos rins e do trato urinário $(n=426)$ & $49(11,50)$ & $377(88,50)$ & $62,098(45,108 ; 85489)$ & $<0,001$ \\
\hline Doenças e distúrbios do sistema hepatobiliar e pâncreas ( $n=397$ ) & $48(12,09)$ & $349(87,91)$ & $60,710(44,158 ; 83,466)$ & $<0,001$ \\
\hline \multicolumn{5}{|l|}{ Status na alta, $\mathrm{n}(\%)$} \\
\hline Óbito $(\mathrm{n}=236)$ & $20(8,47)$ & $216(91,53)$ & $7,899(5,499 ; 11,347)$ & $<0,001$ \\
\hline Vivo $(n=9313)$ & $4762(51,13)$ & $4551(48,87)$ & 1,000 & \\
\hline Materno-infantil $(\mathrm{n}=6567)$ & $4419(67,29)$ & $2148(32,71)$ & 1,000 & \\
\hline Oncologia $(n=212)$ & $22(10,38)$ & $190(89,62)$ & $18,852(12,040 ; 29,516)$ & $<0,001$ \\
\hline Transplante $(n=964)$ & $113(11,72)$ & $851(88,28)$ & $15,828(12,744 ; 19,659)$ & $<0,001$ \\
\hline Clínica médica-cirúrgica ( $\mathrm{n}=1859$ ) & $246(13,23)$ & $1613(86,77)$ & $13,699(11,848 ; 15,839)$ & $<0,001$ \\
\hline $\mathrm{n}$ & 4800 & 4802 & & \\
\hline Tempo de permanência (dias) ${ }^{*}$ mediana ( $1^{\circ} \stackrel{\text { quartil }}{-3^{\circ}}$ quartil) & $2,6(2,3 ; 3,1)$ & $3,9(2,7 ; 8,3)$ & --- & $<0,001$ \\
\hline
\end{tabular}

RC: Razão de Chances; IC 95\%: Intervalo de Confiança de 95\% para a razão de chances estimada. * Valores-p obtidos por meio de testes de Mann-Whitney. 
A chance de internação de alto custo aumenta segundo a idade avançada dos pacientes ( $p<0,001)$, aumentando o custo em 6,6\% a cada acréscimo de um ano na idade. Além disso, internações de pacientes do sexo feminino apresentam chance estimada em 1,1 vezes a chance dos pacientes do sexo masculino em aumentar o custo ( $p=0,013$ não significativo a 1\%). Pacientes de raça branca apresentam chance aumentada de internação de alto custo comparado aos de raça parda, com chance estimada em 1,4 $(p<0,001)$ a chance dos pacientes de raça parda e para as raças amarela e negra as chances de alto custo são estimadas em 1,7 e 1,03 vezes a chance dos pacientes de raça parda $(p=0,078$ para raça amarela e $p=0,672$ para raça negra; valores-p não significativos a 1\%).

Quanto ao MDC, pacientes de todas as categorias apresentam chances aumentadas de alto custo ( $p<0,001$ para todas as categorias) comparados aos pacientes da categoria recém-nascidos e outros neonatos com indicação de origem no período perinatal. Essa categoria de referência foi escolhida por apresentar a menor proporção de passagens com alto custo.

Passagens de pacientes que morreram têm chance de alto custo estimada em aproximadamente oito vezes a chance dos que saíram vivos na alta $(p<0,001)$.

Observa-se que as passagens do departamento materno-infantil apresentaram menor proporção de alto custo e as demais apresentam chances aumentadas, onde os departamentos de oncologia, transplante e clínica médicocirúrgica apresentam respectivamente chances estimadas em 18,8 vezes $(p<0,001)$, 15,8 vezes $(p<0,001)$ e 13,7 vezes $(p<0,001)$ a chance de alto custo do departamento de materno-infantil. Investigamos as diferenças entre os grupos de Alto Custo e Não Alto Custo em relação ao tempo de permanência e todos os direcionadores de custos, evidenciados no apêndice 14, os testes para a hipótese de igualdade entre os grupos mostraram evidências de diferenças quanto ao tempo de permanência $(p<0,001)$ e quanto aos custos com atendimentos $(p<0,001)$, diárias $(p<0,001)$, enfermagem $(p<0,001)$, exames $(p<0,001)$, honorários $(p<0,001)$, materiais $(p<0,001)$, medicamentos $(p<0,001)$, procedimentos $(p<0,001)$ e taxas $(p<0,001)$, e todas essas medidas são maiores no grupo de Alto Custo. 


\section{DISCUSSÃO}

Em 8.702 pacientes internados, com a mediana da idade de 23 anos, sendo $67,2 \%$ de pacientes do sexo feminino, 32,7\% brancas, $97,3 \%$ destes pacientes obtiveram alta hospitalar com um total de 9.702 internações no ano. Ao mesmo tempo, achou-se que o tempo de permanência do nosso hospital foi abaixo de 6,50 segundo o registrado a nível nacional, evidenciando que a prestação dos serviços foi eficaz e de qualidade. ${ }^{(17)}$

A taxa média de ocupação $(53,49 \%)$ significou uma relação acima da taxa geral para os hospitais brasileiros e do estado de São Paulo (34 e 49,48\% respectivamente). ${ }^{(51)}$

A instituição sustentou um resultado operacional eficaz conforme o orçamento inicial de $R \$ 163.261 .000,00$, fornecidos pela área financeira da instituição, levando em consideração que o custo apurado foi apenas o custo das internações, tendo finalizado 0 ano com um custo real apurado neste trabalho de $R \$$ 158.861.058,90, não foi foco deste estudo os custos ambulatoriais.

Dentre os direcionadores de custo, as diárias hospitalares foram responsáveis por $55 \%$ de todo o custo da instituição (unidades de internação), representando o custo fixo alocado em uma mão de obra profissional mais especializada.

Em relação aos custos por desfecho notou-se que o maior custo médio equivaleu aos pacientes que foram a óbito ( $R \$ 77.767,09)$. Além disso, os maiores custos médios por MDC de alta constituíram: uso de álcool/drogas e distúrbios mentais orgânicos induzidos por álcool/drogas ( $R$ \$226.046,22), infecções por vírus da imunodeficiência humana ( $R \$ 96.250,94)$, fatores que influenciam status saúde e outros contatos com serviços saúde ( $R \$ 65.758,57)$, doenças infecciosas e parasíticas, sistêmicas ou em local não especificado ( $\mathrm{R} \$ 64.449,01)$, doenças e distúrbios do sistema musculoesquelético e do tecido conjuntivo ( $R \$ 59.289,89)$, doenças e distúrbios do sangue dos órgãos formadores do sangue - distúrbio imunológicos ( $R$ \$ $53.063,47)$, doenças e distúrbios do sistema circulatório ( $R \$ 50.140,88)$. Identificou-se que três pacientes foram responsáveis pelo maior custo médio durante a internação com o desfecho de alta por MDC "o uso de álcool/drogas e distúrbios mentais orgânicos induzidos por álcool/drogas", um estudo conduzido por Sacks et al. 
confirmou que o uso abusivo de álcool tem sido apresentado como um grande problema de saúde e indicador de uso excessivo de recursos financeiros. ${ }^{(52)}$

Contudo, as análises referentes às características populacionais segundo o grupo de pacientes de alto e não alto custo por custo total das internações reportaram que o Grupo de Alto Custo obteve uma mediana de 36 anos na idade, uma maior concentração de internações do sexo feminino e pessoas de raça branca, com um número maior de internações nos departamentos materno-infantil e clínica médicocirúrgica representaram 44,73 e 33,59\%, respectivamente. Ainda as internações mais significativas como influenciadoras no aumento do custo, foram os pacientes com óbito hospitalar 4,50\% e vivo 99,21\%. Quando analisado o tempo de permanência hospitalar a mediana encontrada foi de 3,9 dias, como MDC alta "gravidez parto e puerpério", 9\% para "doenças e distúrbios do sistema respiratório", 8,83\% para "doenças e distúrbios do sistema circulatório", 7,83\% para "doenças e distúrbios do sistema digestivo", $7,27 \%$, para "doenças e distúrbios do sistema hepatobiliar e pâncreas". Assessorando com dados do IBGE sobre a mudança do perfil demográfico e populacional, entendendo a prevalência de doenças crônicas em concordância com o estudo de Dormont et al. sobre o aumento dos gastos com o aumento da idade, confirmando em nossos resultados obteve-se um acréscimo de até $6,6 \%$ no custo operacional hospitalar para cada ano acrescido na idade. ${ }^{(53)}$

A categoria de direcionadores de custo entre as internações referentes ao aumento de custo total percebeu-se que o direcionador taxas (centro cirúrgico e centro obstétrico) obtiveram uma mediana de $R \$ 2.828,85$, seguido das diárias com mediana de $\mathrm{R} \$ 1.775,56$ e para o direcionador de exames obteve-se uma mediana de $R \$ 679,05$.

Após mensuração dos custos hospitalares, identificou-se que havia valores discrepantes de custo, averiguando estes valores, percebeu-se que o custo médio de $R \$ 3.093,44$ por paciente/dia, e mediana por internação de $R \$ 6.165,20$ $(€ 1.574,49)$, o sexo feminino, a raça branca, o tempo de permanência hospitalar, o número de diárias hospitalares, departamentos do hospital [oncologia 18,8 vezes ( $p$ $0,001)$, transplante 15,8 vezes $(p<0,001)$ e clínica médico-cirúrgica 13,7 vezes $(p<0,001)$ ] apresentam uma chance maior no aumento do custo total, corroborando com os resultados encontrados no estudo de Omachonu et al. e divergindo do estudo de Cyganska onde 5,4 do aumento corresponde a $15 \%$ do custo total e $25 \%$ do total de dias de internação, a mediana de $€ 3.145,25$, o conhecimento de fatores discrepantes, 
contribuem para um melhor conhecimentos dos custos hospitalares e ajudam o gerenciamento dessas instituições. ${ }^{(54,55)}$

Não foram localizados artigos que avaliaram a influência do óbito hospital no aumento do custo em um hospital público no Brasil. Porém, um estudo conduzido por Ferraz et al. ${ }^{(56)}$ reporta o aumento do custo de pacientes de uma operadora de plano de saúde nos últimos 3 anos de vida, demonstrando um aumento de $70 \%$ no custo no último ano de vida. ${ }^{(57)}$ Entretanto, no nosso estudo avaliamos as razões de chance de o óbito aumentar os custos hospitalares, encontrando uma maior chance (8 vezes).

Quanto ao MDC de alta, todas as categorias apresentaram chances aumentadas de alto custo comparadas aos pacientes da categoria "recém-nascidos e outro neonato" que não apresentaram significância estatística. Os principais diagnósticos de alta obtidos que apresentaram maiores chances de alto custo foram: "doenças e distúrbios do sistema reprodutor masculino" a chance foi de 242 vezes $(p<0,001)$, "doenças infecciosas e parasíticas sistêmicas ou em local não especificado" foi de 149 vezes ( $p<0,001)$, "doenças e distúrbios do sistema digestivo" foi de 65 vezes $(p<0,001)$, "doenças e distúrbios do sistema circulatório" foi de 64 vezes $(p<0,001)$, "doenças e distúrbios dos rins e do trato urinário" foi de 62 vezes $(p<0,001)$, "doenças e distúrbios do sistema hepatobiliar e pâncreas" foi de 60 vezes $(p<0,001) .{ }^{(25,37)}$ Antioch et al. relataram que os fatores influenciadores no aumento do custo operacional de uma instituição são fundamentais para gerir com eficiência os recursos, e os sistemas de financiamento. ${ }^{(58)}$

\subsection{Limitações}

Não foi possível identificar o custo direto de mão de obra por paciente ou por internação, devido à base de dados de custo utilizada referir-se a base exportada da contabilidade, com os custos médios já alocados nos direcionadores de custo.

O uso do DRG no HIAE ainda não está validado para apurar custos hospitalares na tomada de decisão, portanto assim também foi utilizado no HMVSC para conhecimento do perfil nosológico permitindo conhecer os principais diagnósticos de alta da instituição, como a instituição determinou junto ao Ministério da Saúde, no 
entanto, o resultado permitiu conhecer o perfil das internações, verificando que estas mantiveram os critérios pré-estabelecidos junto ao PROADI-SUS, mas também expandiram seus atendimentos para outros projetos não sendo foco deste estudo, e permitiu rastear o consumo de recursos comparando entre o custo real operacional e custo do orçamento para gerir a instituição durante o ano.

\subsection{Lições aprendidas e contribuições}

Atualmente estamos vivendo no país debates sobre as reformas nas leis trabalhistas e no regime da previdência social, e questões sobre o desfalque no sistema de financiamento da saúde e o que isso significará na vida do brasileiro é um dos problemas que mais tem preocupado a sociedade e gestores. Com a mudança na pirâmide etária e com os incrementos estima-se que, se nada for feito hoje, em menos de vinte anos os gastos na área chegarão a $25 \%$ do PIB, o que representará investimento adicional de $\mathrm{R} \$ 10$ trilhões. ${ }^{(12)}$ Uma das principais lições aprendidas foi conhecer e entender como estão sendo utilizados os recursos financeiros de um hospital público, sendo que na maioria das vezes o problema está nos desperdícios e na falta de otimização dos processos; permitindo uma maior transparência em reportar dados da alocação dos recursos financeiros em relação aos atendimentos financiados pelo SUS e que sua gestão seja possível de solucionar problemas e alcançar resultados financeiros positivos.

Além disso, aprender como processar dados a partir da aplicação bem sucedida de um sistema de custeio, com informações confiáveis, rápidas e que gerem um completo conhecimento dos custos das atividades torna-se um fator poderoso para melhorar o resultado da instituição usando custos por DRG para identificar os principais diagnósticos e a utilização de recursos dos mesmos, sendo o norteador de ações, validando pesos da ferramenta DRG para contribuir com o planejamento orçamentário da instituição.

A principal contribuição da pesquisa foi disponibilizar um modelo para as instituições hospitalares públicas a partir de informações já disponíveis em cada instituição (desfecho de alta, dados clínicos e demográficos), associados com indicadores financeiros concretos e impulsionar discussões tanto no contexto local e coletivo, buscando novas formas de mudanças nas políticas de financiamento. 
Igualmente, permitir que o gestor, por meio das informações dos custos diretos, decida qual e como é a melhor forma de utilizar os recursos; levando em consideração que uma vez que cada instituição pública recebe recursos orçamentários anuais, segundo os critérios estabelecidos pelo Ministério da Saúde e que após a sua determinação, a mesma não poderá utilizar tal recurso para outra finalidade, o entendimento do processo institucional e do perfil de atendimento se torna uma poderosa ferramenta na gestão econômica, um poderoso indicador de viabilidade de qualquer atividade, serviço, departamento, consequentemente apropriando-se de dados que muitas vezes não são acessíveis no país.

Uma sugestão deste estudo é realizar avaliações de custo com nossa base de dados utilizando-a como mix-case comparador de tempo de permanência pelo DRG, assim como, um estudo realizado na Austrália, ${ }^{(44)}$ onde 0 financiamento para um paciente é baseado em preços padrão para escala central de episódios e quando aplicáveis pagamentos separados por custos adicionais verificados pelos valores discrepantes. Também sugere-se que novos estudos permitam discussões sobre novos modelos de remuneração na saúde, como sugerido Porter et al., modelos baseados no pagamento por bundled, ${ }^{(59)}$ para isso o Brasil necessita de dados de custos reais, para que as mudanças estejam embasadas nos custos hospitalares e não nos preços recebidos pelos serviços.

Estudos futuros poderão ser realizados com a metodologia de bottom-up descrita por Kaplan et al., ${ }^{(16)}$ devido a mesma trazer menor distorção do resultado de custo, em relação a metodologia de top down.

Finalmente, o setor público tem apresentado que o grande motivo para não apurar os custos hospitalares são os sistemas de informação, com o modelo que foi desenvolvido para apurar os custos do HMVSC conseguimos avaliar onde e como os custos estavam sendo consumidos pelos pacientes, por meio, da aplicação de uma metodologia adaptada, mostrando que a determinação e verificação da apuração de custos por pacientes, por internação, por departamentos e centro de custos é o mais efetivo para demonstrar resultados estatisticamente significativos. 


\section{CONCLUSÕES}

1. Os dados encontrados puderam subsidiar o conhecimento da alocados dos recursos destinados ao Hospital Municipal Vila Santa Catarina para o ano de 2016, permitindo ao longo do tempo traçar metas orçamentárias compatíveis ao perfil das internações hospitalares, reforçando a necessidade de implantação de uma metodologia de apuração de custo nas instituições públicas brasileiras para a tomada de decisão, como também discussões sobre a implementação de mudanças no modelos de remuneração e valores destinados pelo Sistema Único de Saúde às instituições hospitalares;

2. Os fatores que influenciaram o aumento do custo hospitalar estiveram relacionados ao aumento na idade, a raça branca, pacientes que foram a óbito e que apresentaram maior tempo de permanência hospitalar, bem como as internações no departamento de oncologia. Dentre os Major Diagnostic Category, a categoria "doenças e distúrbios do sistema reprodutor masculino" destacou-se como maior influenciador de aumento do custo. 
7 ANEXOS

Anexo 1. Modelo de gestão hospitalar

A Sociedade Beneficente Israelita Brasileira Albert Einstein utiliza a metodologia de Custeio por Absorção, metodologia aceita para fins de prestação contábil no Brasil. O modelo descrito abaixo foi formulado pela autora com base em informações fornecidas pela área de custo da instituição.

\section{Modelo de formação do processo de lançamentos}

$\mathrm{Na}$ admissão os pacientes são cadastrados no SGH, através de um número de prontuário e um número referente a internação atual, denominado como "passagem", esse registro permite que o paciente seja identificado para qual projeto PROADI-SUS ele pertencerá no decorrer de sua internação e para posterior apuração dos custos.

Todo procedimento e cuidado realizado pela equipe de enfermagem na assistência ao paciente possui um lançamento correspondente conforme quadro 1 . Os lançamentos de procedimentos de enfermagem foram utilizados, como verificação de volumetria de serviços de cada centro de custo. Este processo seguiu o modelo da Terminologia Unificada da Saúde Suplementar (TUSS).

Quadro 1. Lançamentos realizados para descrever o cuidado de enfermagem, composição da diária hospitalar

\begin{tabular}{|ll|}
\hline \multicolumn{1}{|c|}{ Descrição dos procedimentos de enfermagem } \\
\hline Diálise Peritoneal & Antissepsia do Coto Umbilical \\
Hemodiálise Convencional & Aplicação de Injeção \\
Diálise Peritoneal Intermitente & Coleta de Triagem Neonatal Completa \\
CAPD & Curativo \\
Hemofiltração & Curativo Especial \\
Balão Intra-aórtico & Dilatação Ocular \\
Berço Aquecido & Controle de Diurese \\
Bomba de Infusão de Seringa & Controle de outros drenos \\
Bomba de Infusão & Controle de Dreno de Tórax \\
Colchão Térmico & Controle de Drenagem Gástrica \\
\hline
\end{tabular}




\begin{tabular}{|ll|}
\hline ...continuação & \\
Fototerapia & Eletrocardiograma Enfermagem \\
Isolete & Enteroclisma \\
Marca-Passo & Glicemia Capilar \\
Monitorização Hemodinâmica & Heparinização de Cateter Central \\
Monitorização de Pressão Intra Craniana & Instalação de Soro \\
Monitor de Transporte & Irrigação Vesical Contínua \\
Oximetria digital & Lavagem Gástrica \\
Oximetria cerebral & Lavagem Vesical \\
Pressão Arterial Invasiva & Pressão Venosa Central \\
Pressão Arterial Não Invasiva & Quadro Balcânico \\
Respirador & Sondagem Gástrica \\
Terapia Mecânica para profilaxia TVP & Sondagem Vesical Demora \\
Nebulização & Termoterapia Realizada Pela Enfermagem \\
Oxigênio & Tração Musculo Esquelética Cutânea \\
Inalação & Tricotomia \\
Amnioscopia & Saturometria \\
Cardioversão & Bilirrubina Transcutânea \\
Drenagem de Tórax & Cateter Central de Inserção Periférica \\
Entubação traqueal & Quimioterapia Paciente Internado \\
InstalaçãolTroca de CVCICateterização Arterial & Hélio \\
PunçãolParacentese & Óxido Nitroso \\
Traqueostomia & Óxido Nítrico \\
\hline
\end{tabular}

No momento da alta, óbito ou transferência do paciente o cadastro do no sistema de gestão hospital era finalizado para que ocorresse o fechamento da passagem.

Todos os itens de lançamento devem ser lançados no centro de lucro correspondente a realização do serviço e recebimento da receita, caso não seja alocado nas categorias de direcionadores ao centro de lucro, ou taxas de cuidado de enfermagem, esse lançamento é identificado como uma receita definida não alocada (RDNA) no relatório de custo, não sendo possível a apuração destes custos, gerando a uma subnotificação dos recursos utilizados pelo paciente e ocasionando uma distorção do resultado de apuração do custo. Os RDNA's foram acompanhados mensalmente e corrigidos em casos de erros de alocação. 


\section{Auditoria de processos}

No planejamento de implantação do HMVSC foram apontados possíveis riscos de subnotificação da apuração de custos. Sendo realizado auditorias periódicas para alcançar qualidade dos dados apurados.

Admissão do paciente:

Atenção - O gestor de projeto deve avaliar se o cadastro do Plano correto foi lançado na passagem.

Risco - Contabilização de custos indevidos ao projeto, erro no cadastro do Plano no SGH - gera erro de contabilização de projeto.

Atenção - Avaliar se todos os documentos referentes a internação estão anexados ao Prontuário.

As passagens eram acompanhadas pela área de custo do HMVSC e todos os caso que houvesse erro de cadastro de pacientes em planos não correspondente, linhas do cadastro com data de período de internação fora do período que o paciente esteve internado, itens de lançamento gerando saldo de pagamento particular, ao invés do projeto, eram notificados aos gestores.

Ação:

Após a notificação para o gestor correspondente, essas passagens eram corrigidas;

Toda equipe admissional realizou treinamento quanto a forma de lançamentos dos itens no SGH e SAP;

A equipe assistencial realizou treinamento quando a forma de preenchimento dos prontuários do paciente relativo a correta forma de preenchimento utilizando os protocolos institucionais de assistência, e quanto as formas de cobrança.

Foi implantado pelos gestores treinamentos como Lean Six Sigma, PDSA, treinamentos e-learning e presenciais;

O HMVSC não possui um setor de auditoria, por isso todo processo é realizado pelos gestores de áreas;

O Hospital possui um setor de arquivos médicos que realiza a verificação do preenchimento correto de todos os formulários do prontuário conforme critérios descritos nas documentações institucionais utilizadas pelo Hospital Israelita Albert Einstein; 
Este setor realiza também a verificação de lançamentos de altas, preenchimento de DRG e codifica as comorbidades seguindo a Classificação Internacional de Doenças (CID), de todos os prontuários.

\section{Acompanhamentos para validação dos dados}

Diariamente era realizada a extração de uma planilha com todos os pacientes admitidos no HMVSC e verificando os cadastros de admissão no SGH, caso algumas divergências fossem encontradas era reportado a área para correção;

Semanalmente realizaram-se visitas nas áreas assistenciais como suporte para dúvidas e auditoria dos prontuários in loco;

Realizaram-se amostras de prontuários para auditoria completa quando as anotações de cuidado assistencial, para garantir a qualidade na realização dos protocolos institucionais, quanto as formas de cobrança, todas as divergências eram reportadas aos gestores das áreas;

Auxiliou-se com análises em prontuários, quanto a existência de subnotificações ou excessos de lançamentos.

Figura 1 demonstra a avaliação dos lançamentos de custos nos centros de resultado quantos aos RDNA's, sendo ajustados antes do fechamento contábil, para que as distorções não afetassem a identificação, o erro de alocação de cada recurso.

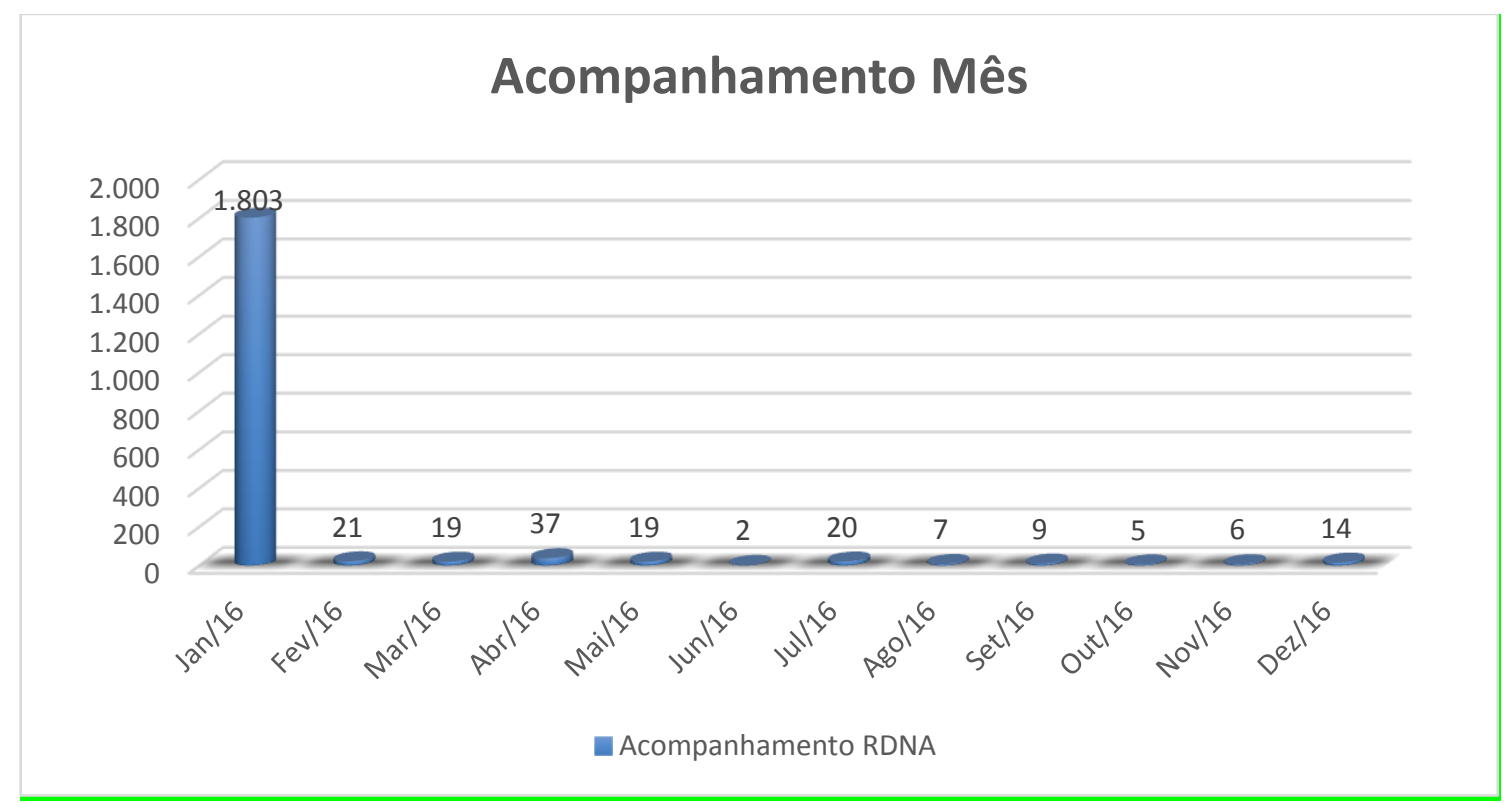

Figura 1. Acompanhamento de lançamentos 


\section{Metodologia de aferição de custos}

Os lançamentos de itens consumidos por internação ocorrem no SGH. Para a apuração de custos, há uma integração entre os sistemas, da seguinte forma:

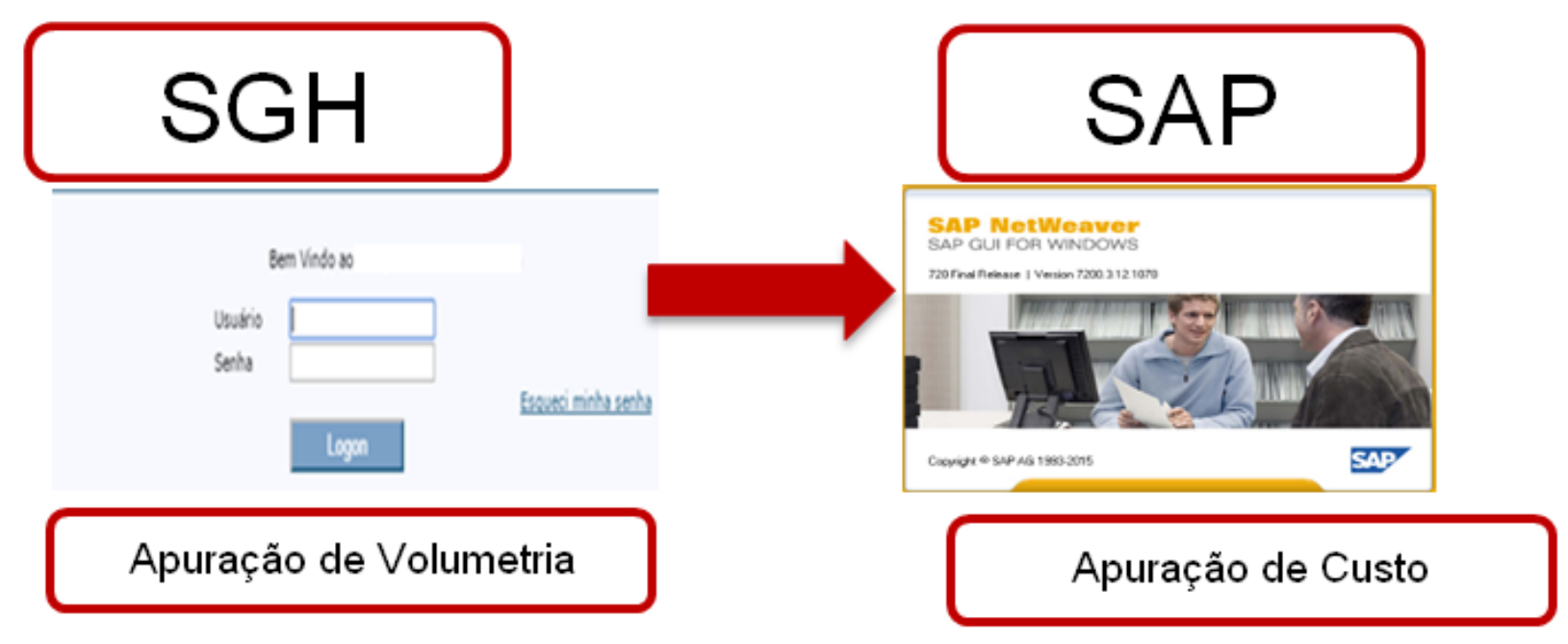

Figura 2. Integração de sistemas

A apuração de resultados é realizada por Centro de Custo (Atividade Final ou Produtivos; Administrativos; Apoio) mensalmente, segundo o Regime Contábil de Competência (Quadros 2, 3 e 4). Os custos dos serviços demandados pelos programas são calculados pela média dos custos (diretos e indiretos) de cada unidade produtiva.

Quadro 2. Atividade final ou produtivos

\begin{tabular}{|cl|}
\hline C. custo & Descrição \\
\hline ECSC & Ecocardiografia \\
MGSC & Métodos gráficos \\
CCSC & Centro cirúrgico \\
COSC & Centro obstétrico \\
RASC & Radiologia \\
TOSC & Tomografia \\
ULSC & Ultrassonografia \\
MASC & Maternidade \\
BESC & Berçário cuidados \\
PISC & Pediatria internação \\
TRSC & Transplante internação \\
CMSC & Clínica médica cirúrgica \\
\hline
\end{tabular}




\begin{tabular}{|c|c|}
\hline LASC & Laboratório patologia clínica \\
\hline AOSC & Ambulatório de oncologia \\
\hline OCSC & Oncologia internação \\
\hline TPSC & Terapia intensiva pediátrica \\
\hline TISC & Terapia intensiva adulto \\
\hline UTSC & UTI neonatal \\
\hline RFSC & Reabilitação e fisioterapia \\
\hline ENSC & Endoscopia \\
\hline DISC & Hemodiálise \\
\hline BSSC & Banco de sangue \\
\hline PASC & Pronto atendimento \\
\hline AMSC & Ambulatório maternidade \\
\hline PSSC & Psiquiatria internação \\
\hline CNSC & Ambulatório de egresso \\
\hline MMSC & Mamografia \\
\hline NESC & Neurofisiologia \\
\hline INSC & Infectologia \\
\hline ANSC & Anestesia \\
\hline HDSC & Hemodinâmica \\
\hline NFSC & Nefrologia \\
\hline RMSC & Ressonância magnética \\
\hline UXSC & UTI transplante \\
\hline ATSC & Ambulatório de transplante \\
\hline
\end{tabular}

Quadro 3. Atividade administrativa

\begin{tabular}{|ll|}
\hline C. custo & Descrição \\
\hline MESC & Medicina do trabalho \\
ROSC & Rouparia \\
SASC & Serviço de arquivo médico \\
DRSC & Diretoria \\
GESC & Gestão corporativa \\
EGSC & Engenharia clínica \\
MTSC & Manutenção \\
UDSC & Utilidades \\
HOSC & Hospitalidade \\
RCSC & Recepção \\
IESC & Ensino e treinamento \\
\hline
\end{tabular}

Quadro 4. Atividade de apoio assistencial

\begin{tabular}{|cl|}
\hline C. custo & Descrição \\
\hline FASC & Farmácia \\
LCSC & Coleta - laboratório \\
NUSC & Nutrição \\
ESSC & Central de material \\
SSSC & Serviço social \\
CISC & Controle infecção hospitalar \\
\hline
\end{tabular}


Ao longo do mês, cada centro de custo recebe alocação de custos diretos mão-de-obra (Quadro 5).

Quadro 5. Alocação de Custos de Mão de Obra direta Por Centro de Custo (Abaixo exemplo) todos os centros de custo utilizaram a mesma metodologia para mão de obra direta

\begin{tabular}{|lclc|}
\hline Posição denominação & $\begin{array}{c}\text { Centro } \\
\text { de custo }\end{array}$ & \multicolumn{1}{c}{ Cargo } & $\begin{array}{c}\text { Jornada de } \\
\text { trabalho }\end{array}$ \\
\hline Coordenador Médico Materno Infantil & AMSC & Coordenador Médico Materno Infantil & 150 \\
Enfermeiro PI & AMSC & Enfermeiro PI & 180 \\
Médico Materno Infantil HM & AMSC & Médico Materno Infantil HM & 120 \\
\hline
\end{tabular}

Para materiais permanentes foi realizada a depreciação de imobilizado, que é um item tangível do balanço patrimonial, que é mantido para uso na produção ou fornecimento de serviços ou mercadorias, e que se espera utilizar por mais de um período, materiais de consumo, prestação de serviço contratado, e outros.

Cada um dos itens de imobilizado segue um critério específico das fabricantes, mas para fins fiscais de demonstração contábil, conforme quadro 6.

Quadro 6. Definição de taxa de depreciação

\begin{tabular}{|lc|}
\hline Base de imobilizado & Taxa de depreciação atual \\
\hline Edificações & 50 anos \\
Instalações e telefonia & 10 anos \\
Veículos & 10 anos \\
Móveis e utensílios & 10 anos \\
Máquinas e acessórios & 10 anos \\
Equipamentos de processamento de dados & 5 anos \\
Equipamentos médicos & 8 anos \\
Instrumentais e aparelhos & 4 anos \\
Intangível - ERP SAP & 9 anos \\
Intangível - ERP SGH & 7 anos \\
Intangível - software aplicação geral, TI e Microsoft & 5 anos \\
Intangível - software dispositivos móveis e websites & 3 anos \\
\hline
\end{tabular}

Depreciação é a alocação sistemática da redução do valor (redução da capacidade de gerar benefício econômico) de um ativo, ao longo da sua vida útil.

Cálculo de alocação de depreciação mensal:

$$
\text { Valor do bem } \div \text { Vida útil } \div 12 \text { Meses }=\text { Parcela de depreciação }
$$


No fechamento mensal, os custos alocados nas áreas não produtivas (Apoio e Administrativas), são transferidos por intermédio de rateio para os Centros de Custos Produtivos (atividade fim).

A metodologia de Rateio utilizada é o método Sequencial, que faz repasses escalonados dos centros de custos não produtivos para os produtivos ou Finais, conforme representado na figura 3.

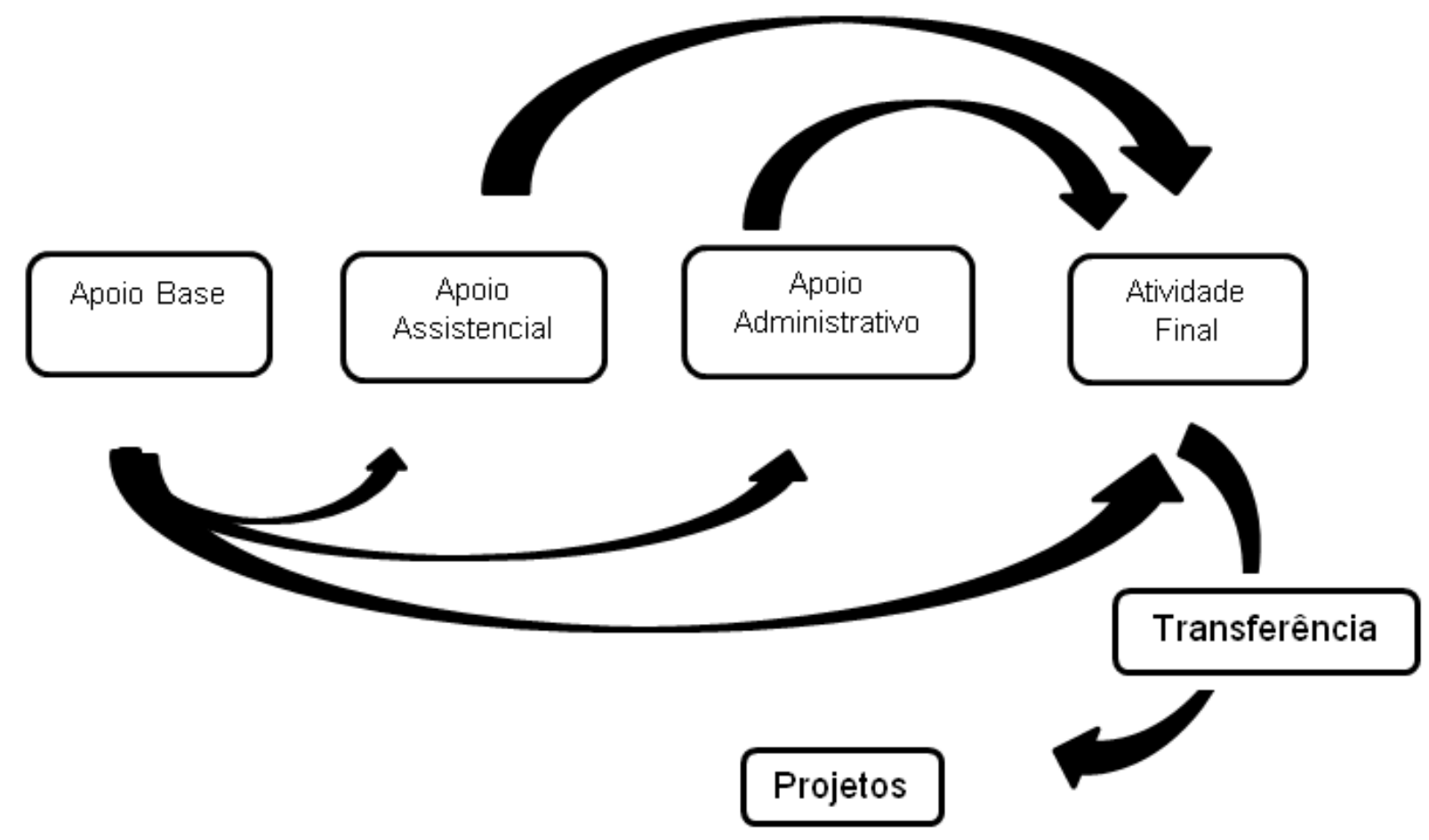

Figura 3. Modelo de método sequencial

Cada centro de custo tem critérios de rateio específico que buscam a melhor relação de causa e efeito, entre o custo a ser distribuído e a área que receberá o custo.

Durante o processo de análise dos resultados mensais foram definidas alterações de critérios de rateios, onde se buscou o item que descrevesse de forma mais adequada a absorção dos custos. $\mathrm{Na}$ abertura do hospital realizou-se $\mathrm{O}$ simulado para os critérios de rateios que seriam utilizados pelos centros de custos para os custos indiretos serem alocados a cada direcionador, após as análises de gestão mensal verificou-se a necessidade de alterações destes critérios e foram realizadas modificações. 
Os centros de custos possuem gestores que atendem em suas funções a demanda de serviços entre eles, estes custos necessitam ser rateado conforme a parcela de utilização da prestação de serviços (Quadro 7).

Quadro 7. Critérios de Rateio de Mão de Obra Indireta nos Centros de Custos (alguns cargos não possuem alocação total de $100 \%$, pois realizam atividades no HIAE também, mas não foram rateadas no HMVSC

\begin{tabular}{|c|c|c|c|c|c|}
\hline \multicolumn{6}{|c|}{ Rateio de apoio assistencial - Gestores de áreas } \\
\hline Gestor & $\begin{array}{c}\text { CC } \\
\text { Responsável }\end{array}$ & Detalhe CC & $\begin{array}{c}\text { Custo } \\
\text { atual } \\
(\%)\end{array}$ & $\begin{array}{c}\text { Forma de } \\
\text { rateio } \\
(\%)\end{array}$ & $\begin{array}{c}\text { Distribuição } \\
\text { de } \\
\text { Headcount }\end{array}$ \\
\hline \multirow{4}{*}{ Gestor 1} & CMSC & Clínica médica e cirúrgica & \multirow{4}{*}{100} & 20 & 82 \\
\hline & Ocsc & Oncologia internação & & 20 & 28 \\
\hline & PSSC & Psiquiatria internação & & 20 & 15 \\
\hline & TRSC & Transplante internação & & 20 & 54 \\
\hline \multirow{5}{*}{ Gestor 2} & ATSC & Ambulatório de transplante & \multirow{5}{*}{100} & & 6 \\
\hline & GESC & Gestão corporativa & & & 8 \\
\hline & HOSC & Hospitalidade & & 50 & 6 \\
\hline & LASC & Laboratório de patologia clínica & & & 6 \\
\hline & RCSC & Recepção & & 50 & 36 \\
\hline \multirow{5}{*}{ Gestor 3} & RESC & Pré-atendimento & \multirow{5}{*}{100} & & 4 \\
\hline & $\operatorname{cosc}$ & Centro obstétrico & & 20 & 41 \\
\hline & ENSC & Endoscopia & & 20 & 4 \\
\hline & ESSC & Central de material & & 20 & 17 \\
\hline & PASC & Pronto atendimento & & 20 & 13 \\
\hline \multirow{10}{*}{ Gestor 4} & ATSC & Ambulatório de transplante & \multirow{10}{*}{100} & 9 & 12 \\
\hline & CNSC & Consultórios & & 9 & 3 \\
\hline & DISC & Hemodiálise & & 9 & 5 \\
\hline & ECSC & Ecocardiografia & & 9 & 3 \\
\hline & OCSC & Oncologia internação & & 9 & 2 \\
\hline & RASC & Radiologia & & 9 & 6 \\
\hline & RMSC & Ressonância magnética & & 9 & 2 \\
\hline & TOSC & Tomografia & & 9 & 4 \\
\hline & TRSC & Transplante internação & & 9 & 1 \\
\hline & ULSC & Ultrassonografia & & 9 & 14 \\
\hline \multirow{4}{*}{ Gestor 5} & MASC & Maternidade & \multirow{4}{*}{100} & 20 & 54 \\
\hline & PISC & Pediatria internação & & 20 & 23 \\
\hline & TPSC & Terapia intensiva & & 20 & 36 \\
\hline & UTSC & UTI neonatal & & 20 & 24 \\
\hline \multirow{2}{*}{ Gestor 6} & ATSC & Ambulatório de transplante & \multirow{2}{*}{100} & & 1 \\
\hline & NUSC & Nutrição & & 100 & 65 \\
\hline
\end{tabular}

Assim também muitas posições de recursos humanos atendem à demanda de atendimento a pacientes de mais de um projeto desenvolvido no hospital, sendo necessário alocar estes custos por intermédio de rateio a cada projeto conforme prestação de serviços (Quadro 8). 
Quadro 8. Critério utilizado para cada um dos cargos que realizam os serviços para mais de um centro de custo e a parcela rateada destes custos.

\begin{tabular}{|c|c|c|}
\hline \multicolumn{3}{|c|}{ Rateio de apoio assistencial } \\
\hline Cargo & C. Custo & Total \\
\hline \multirow{3}{*}{ Instrumentador } & ECOR & 6 \\
\hline & FGSC & 94 \\
\hline & & 100 \\
\hline \multirow{5}{*}{ Coordenador } & AMSC & 25 \\
\hline & $\operatorname{cosc}$ & 25 \\
\hline & MTSC & 25 \\
\hline & PASC & 25 \\
\hline & & 100 \\
\hline \multirow{3}{*}{ Enfermeiro } & CCSC & 50 \\
\hline & PASC & 50 \\
\hline & & 100 \\
\hline \multirow{4}{*}{ Coordenador } & CMSC & 35 \\
\hline & ocsc & 30 \\
\hline & TRSC & 35 \\
\hline & & 100 \\
\hline \multirow{3}{*}{ Técnico enfermagem coleta } & GESC & 40 \\
\hline & LCSC & 60 \\
\hline & & 100 \\
\hline \multirow{5}{*}{ Coordenador médico } & BESC & 20 \\
\hline & MTSC & 20 \\
\hline & PISC & 20 \\
\hline & TPSC & 20 \\
\hline & UTSC & $\begin{array}{c}20 \\
100\end{array}$ \\
\hline \multirow{8}{*}{ Enfermeiro } & ECSC & 15 \\
\hline & MFSC & 15 \\
\hline & MGSC & 5 \\
\hline & RASC & 15 \\
\hline & RMSC & 15 \\
\hline & TOSC & 15 \\
\hline & ULSC & 20 \\
\hline & & 100 \\
\hline \multirow{3}{*}{ Analista treinamento } & IESC & 100 \\
\hline & & 100 \\
\hline & TOSC & 18 \\
\hline \multirow[t]{3}{*}{ Médico Imagem } & GMIM & 82 \\
\hline & RASC & 18 \\
\hline & & 100 \\
\hline Coordenador Médico Suporte Operacional & GTSC & 75 \\
\hline \multirow[t]{2}{*}{ Total } & & 75 \\
\hline & ECOR & 6 \\
\hline \multirow[t]{2}{*}{ Instrumentador } & FGSC & 94 \\
\hline & & 100 \\
\hline
\end{tabular}




\begin{tabular}{|c|c|c|}
\hline \multirow{3}{*}{ Médico Plantonista } & TISC & 74 \\
\hline & TSIN & 26 \\
\hline & & 100 \\
\hline \multirow{3}{*}{ Enfermeiro } & CCSC & 50 \\
\hline & PASC & 50 \\
\hline & & 100 \\
\hline \multirow{3}{*}{ Instrumentador } & ECOR & 8 \\
\hline & RISC & 92 \\
\hline & & 100 \\
\hline \multirow{2}{*}{ Médico Qualidade e Prática Assistencial } & DRSC & 100 \\
\hline & & 100 \\
\hline \multirow{3}{*}{ Médico Plantonista CTI } & TIAD & 50 \\
\hline & TISC & 50 \\
\hline & & 100 \\
\hline \multirow{3}{*}{ Consultor Projetos e Desenvolvimento Programas } & GESC & 46 \\
\hline & MECP & 54 \\
\hline & & 100 \\
\hline \multirow{3}{*}{ Coordenador Hotelaria } & HOSC & 50 \\
\hline & RCSC & 50 \\
\hline & & 100 \\
\hline \multirow{3}{*}{ Médico Plantonista CTI } & TISC & 33 \\
\hline & TSI8 & 67 \\
\hline & & 100 \\
\hline \multirow{3}{*}{ Auxiliar Enfermagem } & MGSC & 12 \\
\hline & ULSC & 88 \\
\hline & & 100 \\
\hline \multirow{3}{*}{ Médico Imagem } & GMIM & 82 \\
\hline & RMSC & 18 \\
\hline & & 100 \\
\hline \multirow{11}{*}{ Técnico de Enfermagem } & ATSC & 10 \\
\hline & CNSC & 9 \\
\hline & DISC & 9 \\
\hline & ECSC & 9 \\
\hline & LCSC & 9 \\
\hline & ocsc & 9 \\
\hline & RASC & 9 \\
\hline & RMSC & 9 \\
\hline & TOSC & 9 \\
\hline & ULSC & 9 \\
\hline & & 100 \\
\hline \multirow{3}{*}{ Enfermeiro } & ATSC & 17 \\
\hline & CNSC & 83 \\
\hline & & 100 \\
\hline \multirow{4}{*}{ Enfermeiro } & ECSC & 15 \\
\hline & MFSC & 15 \\
\hline & MGSC & 5 \\
\hline & RASC & 15 \\
\hline
\end{tabular}




\begin{tabular}{|c|c|c|}
\hline & RMSC & 15 \\
\hline & TOSC & 15 \\
\hline & ULSC & 20 \\
\hline & & 100 \\
\hline \multirow{8}{*}{ Técnico Administrativo } & ECSC & 15 \\
\hline & MFSC & 15 \\
\hline & MGSC & 10 \\
\hline & RASC & 15 \\
\hline & RMSC & 15 \\
\hline & TOSC & 15 \\
\hline & ULSC & 15 \\
\hline & & 100 \\
\hline \multirow{3}{*}{ Instrumentador } & ECOR & 6 \\
\hline & FGSC & 94 \\
\hline & & 100 \\
\hline \multirow{3}{*}{ Instrumentador } & ECOR & 6 \\
\hline & FGSC & 94 \\
\hline & & 100 \\
\hline \multirow{3}{*}{ Médico Transplante } & RISC & 71 \\
\hline & TSIN & 29 \\
\hline & & 100 \\
\hline \multirow{6}{*}{ Médico Transplante } & CHAG & 3 \\
\hline & GTSC & 75 \\
\hline & NCAP & 15 \\
\hline & PRLA & 1 \\
\hline & TRMO & 5 \\
\hline & & 100 \\
\hline \multirow{3}{*}{ Médico Imagem } & GMIM & 82 \\
\hline & RASC & 18 \\
\hline & & 100 \\
\hline \multirow{3}{*}{ Técnico Enfermagem } & CCSC & 50 \\
\hline & ESSC & 50 \\
\hline & & 100 \\
\hline \multirow{3}{*}{ Médico Plantonista CTI } & TIAD & 65 \\
\hline & TISC & 35 \\
\hline & & 100 \\
\hline \multirow{3}{*}{ Médico Plantonista PA } & CMSC & 30 \\
\hline & PA01 & 70 \\
\hline & & 100 \\
\hline \multirow{3}{*}{ Médico Plantonista CTI } & TIAD & 65 \\
\hline & TISC & 35 \\
\hline & & 100 \\
\hline \multirow{3}{*}{ Instrumentador } & ECOR & 6 \\
\hline & FGSC & 94 \\
\hline & & 100 \\
\hline \multirow{2}{*}{ Médico Imagem } & CIUS & 28 \\
\hline & TOSC & 10 \\
\hline
\end{tabular}




\begin{tabular}{|c|c|c|}
\hline & UAUS & 42 \\
\hline & ULSC & 20 \\
\hline & & 100 \\
\hline \multirow{7}{*}{ Técnico Administrativo } & ECSC & 16,66 \\
\hline & MFSC & 16,66 \\
\hline & RASC & 16,67 \\
\hline & RMSC & 16,67 \\
\hline & TOSC & 16,67 \\
\hline & ULSC & 16,67 \\
\hline & & 100 \\
\hline \multirow{6}{*}{ Técnico Administrativo } & CDOF & 2 \\
\hline & CHAG & 3 \\
\hline & GTSC & 75 \\
\hline & NCAP & 15 \\
\hline & TRMO & 5 \\
\hline & & 100 \\
\hline \multirow{3}{*}{ Instrumentador } & ECOR & 8 \\
\hline & RISC & 92 \\
\hline & & 100 \\
\hline \multirow{3}{*}{ Médico Ecocardiografia } & ECOC & 33 \\
\hline & ECSC & 67 \\
\hline & & 100 \\
\hline \multirow{3}{*}{ Instrumentador } & ECOR & 6 \\
\hline & FGSC & 94 \\
\hline & & 100 \\
\hline \multirow{6}{*}{ Coordenador Enfermagem } & CCSC & 20 \\
\hline & $\operatorname{cosc}$ & 20 \\
\hline & ENSC & 20 \\
\hline & ESSC & 20 \\
\hline & PASC & 20 \\
\hline & & 100 \\
\hline \multirow{7}{*}{ Técnico Administrativo } & ECSC & 16,66 \\
\hline & MFSC & 16,66 \\
\hline & RASC & 16,67 \\
\hline & RMSC & 16,67 \\
\hline & TOSC & 16,67 \\
\hline & ULSC & 16,67 \\
\hline & & 100 \\
\hline \multirow{3}{*}{ Médico Imagem } & ULSC & 40 \\
\hline & ULTS & 60 \\
\hline & & 100 \\
\hline \multirow{3}{*}{ Técnico Enfermagem } & CCSC & 50 \\
\hline & ESSC & 50 \\
\hline & & 100 \\
\hline \multirow{3}{*}{ Médico Saúde Corporativa } & MESC & 55 \\
\hline & METR & 45 \\
\hline & & 100 \\
\hline
\end{tabular}




\begin{tabular}{|c|c|c|}
\hline \multirow{4}{*}{ Enfermeiro } & ECOR & 30 \\
\hline & EPUL & 30 \\
\hline & RISC & 40 \\
\hline & & 100 \\
\hline \multirow{2}{*}{ Médico Imagem } & ULSC & 40 \\
\hline & & 100 \\
\hline \multirow{3}{*}{ Médico Plantonista CTI } & TIAD & 65 \\
\hline & TISC & 35 \\
\hline & & 100 \\
\hline \multirow{7}{*}{ Analista Informações Gerenciais } & CDOF & 1 \\
\hline & CHAG & 3 \\
\hline & GTSC & 75 \\
\hline & NCAP & 15 \\
\hline & PRLA & 1 \\
\hline & TRMO & 5 \\
\hline & & 100 \\
\hline \multirow{3}{*}{ Médico Hospitalista } & CMSC & 71 \\
\hline & PA01 & 29 \\
\hline & & 100 \\
\hline \multirow{12}{*}{ Coordenador Enfermagem } & AOSC & 9 \\
\hline & ATSC & 10 \\
\hline & CNSC & 9 \\
\hline & DISC & 9 \\
\hline & ECSC & 9 \\
\hline & LCSC & 9 \\
\hline & OCSC & 9 \\
\hline & RASC & 9 \\
\hline & RMSC & 9 \\
\hline & TOSC & 9 \\
\hline & ULSC & 9 \\
\hline & & 100 \\
\hline \multirow{3}{*}{ Analista Planejamento Controle Financeiro } & GESC & 8 \\
\hline & PECF & 92 \\
\hline & & 100 \\
\hline \multirow{3}{*}{ Coordenador Médico Oncologia } & AOSC & 40 \\
\hline & PRIC & 60 \\
\hline & & 100 \\
\hline \multirow{7}{*}{ Técnico administrativo } & ECSC & 16,66 \\
\hline & MFSC & 16,66 \\
\hline & RASC & 16,67 \\
\hline & RMSC & 16,67 \\
\hline & TOSC & 16,67 \\
\hline & ULSC & 16,67 \\
\hline & & 100 \\
\hline \multirow{3}{*}{ Coordenador Enfermagem } & BESC & 20 \\
\hline & MASC & 20 \\
\hline & TPSC & 20 \\
\hline
\end{tabular}




\begin{tabular}{|lcc|}
\hline.. continuação & UTSC & 20 \\
& & 100 \\
& ADVM & 45 \\
Coordenador Programas Transplantes & CDOF & 1 \\
& CHAG & 3 \\
& GTSC & 30 \\
Instrumentador & NCAP & 15 \\
& PRLA & 1 \\
& TRMO & 5 \\
& & 100 \\
\hline
\end{tabular}

O rateio destinado à área de apoio base é realizado para todos os centros de custos, refere-se a serviços basicamente de condomínio, como água, luz, diesel e outros que tenham a mesmas características e venham a ser necessários. A equipe de manutenção realizou medição de toda área predial para definir a porcentagem de utilização (Quadro 9).

Quadro 9. Critério rateios de áreas de apoio base para determinar percentual de utilização

\begin{tabular}{|llcc|}
\hline Hospital Municipal Vila Santa Catarina & $\begin{array}{c}\text { Dimensão da sala } \\
\left(\mathbf{m}^{\mathbf{2}}\right)\end{array}$ & $\begin{array}{c}\text { Part* } \\
(\%)\end{array}$ \\
\hline TRSC & Transplante Internação & $4.476,29$ & 29,34 \\
PISC & Pediatria Internação & $1.467,57$ & 9,62 \\
CMSC & Clínica Médica Cirúrgica & $1.104,98$ & 7,24 \\
OCSC & Oncologia Internação & $1.073,32$ & 7,03 \\
CCSC & Centro Cirúrgico & 1030,71 & 6,76 \\
ULSC & Ultrassonografia & 635,68 & 4,17 \\
FASC & Farmácia & 511,49 & 3,35 \\
TISC & Terapia Intensiva Adulto & 467,92 & 3,07 \\
LCSC & Coleta - Laboratório & 394,31 & 2,58 \\
DRSC & Diretoria & 376,95 & 2,47 \\
ATSC & Ambulatório de Transplante & 252,84 & 1,66 \\
CNSC & Ambulatório de Egresso & 252,84 & 1,66 \\
RASC & Radiologia & 232,22 & 1,52 \\
LASC & Laboratório de Patologia Clínica & 219,18 & 1,44 \\
RCSC & Recepção & 215,49 & 1,41 \\
BSSC & Banco de Sangue & 215,46 & 1,41 \\
NUSC & Nutrição & 211,59 & 1,39 \\
TPSC & Terapia Internação & 207,45 & 1,36 \\
MASC & Maternidade & 200,97 & 1,32 \\
AMSC & Ambulatório Maternidade & 177,21 & 1,16 \\
\hline & & & continua...
\end{tabular}




\begin{tabular}{llcc|}
...Continuação & & \\
\hline ENSC & Endoscopia & 157,13 & 1,03 \\
ESSC & Central de Material & 151,41 & 0,99 \\
TOSC & Tomografia & 122,32 & 0,80 \\
ROSC & Rouparia & 112,72 & 0,74 \\
PASC & Pronto Atendimento & 89,87 & 0,59 \\
DISC & Hemodiálise & 87,50 & 0,57 \\
COSC & Centro Obstétrico & 87,08 & 0,57 \\
EGSC & Engenharia Clínica & 79,34 & 0,52 \\
RFSC & Reabilitação e Fisioterapia & 73,69 & 0,48 \\
BESC & Berçário Cuidados Intermediários & 69,97 & 0,46 \\
UTSC & UTI Neonatal & 68,29 & 0,45 \\
SASC & Serviço de Arquivo Médico & 61,58 & 0,40 \\
RMSC & Ressonância Magnética & 49,47 & 0,32 \\
GESC & Gestão Corporativa & 44,01 & 0,29 \\
AOSC & Ambulatório Oncologia & 42,64 & 0,28 \\
MESC & Medicina do Trabalho & 32,91 & 0,22 \\
MTSC & Manutenção & 31,50 & 0,21 \\
GTSC & Gestão de Transplante & 28,06 & 0,18 \\
SSSC & Serviço Social & 26,35 & 0,17 \\
INSC & Infectologia & 22,08 & 0,14 \\
ECSC & Ecocardiografia & 21,28 & 0,14 \\
MFSC Medicina Fetal & 18,18 & 0,12 \\
HISC & Higiene & 15,26 & 0,10 \\
CISC & Controle Infecção Hospitalar & 14,92 & 0,10 \\
HOSC & Hospitalidade & 10,50 & 0,07 \\
EMSC & Equipe Multiprofissional & 8,07 & 0,05 \\
RESC & Pré-Atendimento & 6,85 & 0,04 \\
& & 15257,45 & 100,00 \\
\hline
\end{tabular}

*Parcela de participação no rateio.

As informações com os registros de lançamentos do período são importadas para o SAP. Apura-se o percentual de utilização dos serviços por projeto considerando-se a produção total do período em cada centro de resultado.

SAP informações de outras fontes: os centros de resultados que não realizam lançamentos no SGH, como Ensino, Pesquisa, tem sua apuração realizada da seguinte forma: as áreas fazem o controle de utilização de cada serviço, valendo-se de cada sistema existente ou planilha de Excel. Nestes serão apontados os paciente e serviços utilizados em cada período e projeto. Os recursos compartilhados com as áreas prestadoras de serviços serão distribuídos aos projetos utilizando-se do mesmo mecanismo de apuração. O diferencial será que a área de custo receberá do gestor de cada área, o volume total de serviços prestados no período e quantidade serviços 
demandados pelos projetos individualmente. E fará a inserção manual desta volumetria para apuração do percentual de utilização e cálculo do custo compartilhado.

Após a execução do Rateio, temos a apuração dos custos integrais (diretos e indiretos) de cada centro de custo produtivo. Ou seja, todos os gastos relativos ao esforço de produção são atribuídos aos produtos ou serviços realizados. 
Anexo 2. Modelo de apuração PROADI-SUS

A área de custo determinou 3 tipos de custos: custo direto, custo indireto e custo compartilhado:

Custo Direto são custos lançados diretamente nos centros de custos dos projetos do PROADI-SUS. Os custos e despesas em geral, custo com mão de obra. Caso algum Ativo seja adquirido exclusivamente para os projetos do PROADISUS, são lançados integralmente como "despesa do projeto" (Capital: Imobilizado Tangível). Não serão imobilizados e depreciados/amortizados, como ocorrem com ativos de propriedade do Hospital Albert Einstein.

Custo Indireto são recursos utilizados por diversos centros de custos ao mesmo tempo, a porcentagem de utilização é alocada em cada um dos centros de custos utilizado critérios de rateio, conforme Figura 1, estes custos são custos transferidos das áreas de Apoio/ Corporativas para os centros de custos de Atividade. Cada centro de custo tem um critério de rateio, que possui uma "boa relação de causa e efeito" do custo a ser rateado com o serviço prestado.

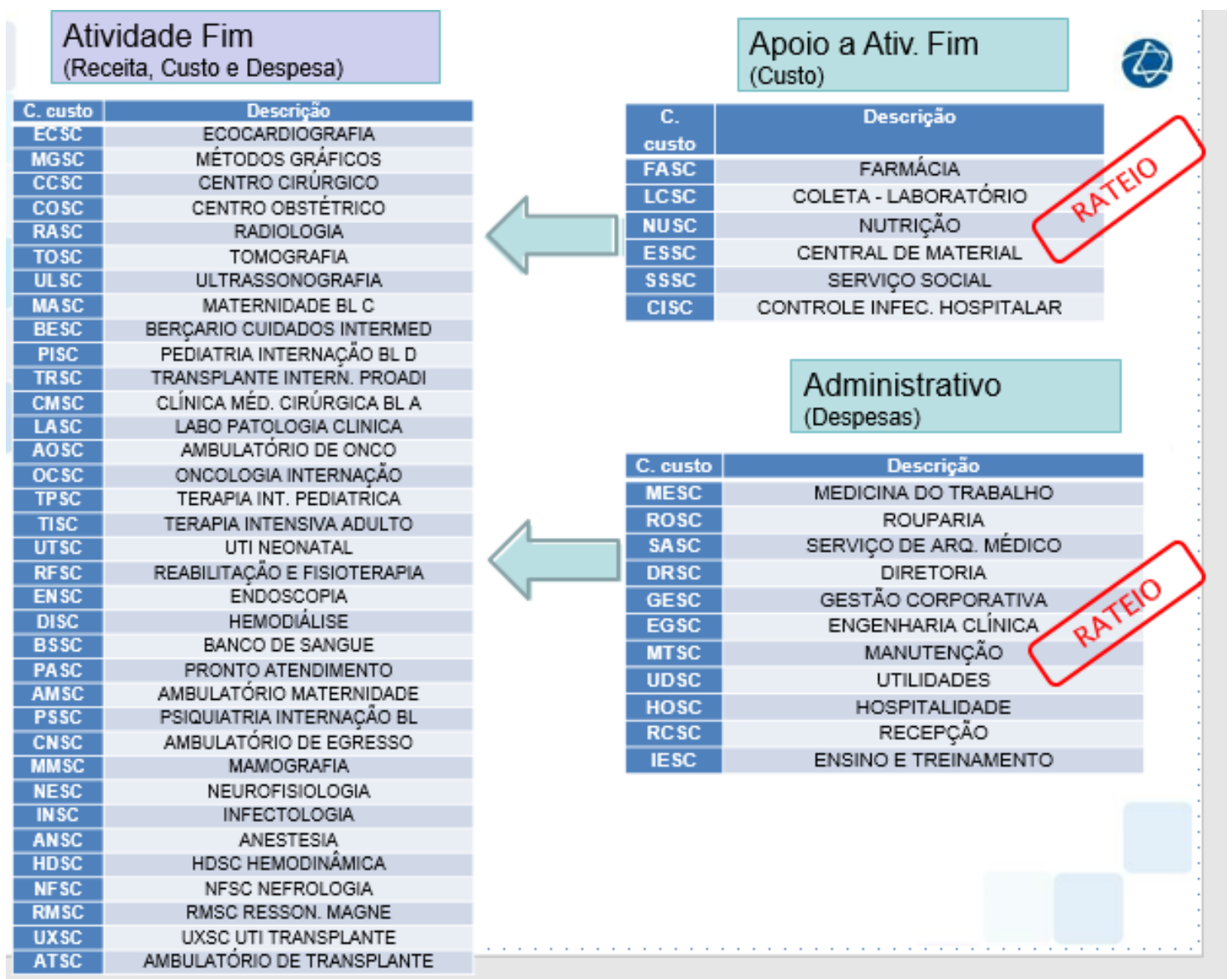

Figura 1. Representação de transferência dos custos de Área de Apoio/Administrativa para Atividade Fim 
Custo Compartilhado são custos transferidos das Áreas de Atividade Fim para os Projetos do PROADI-SUS, pela prestação de serviço aos pacientes dos projetos. Utilizando-se dos direcionadores de custo, (principal item de lançamento) como índice, para transferir custos.

O Os custos por internação e por pacientes do HMVSC são realizados através de custo compartilhado. O método de Apuração de Custos Compartilhados utiliza-se da alocação do custo total das atividades fim nos direcionadores de custo e posteriormente dividido pelo volume de atividades utilizado em cada atividade fim. Por tanto cada direcionador representa o custo médio de uma determinada atividade fim. Assim fornecendo uma carga de dados onde as informações de todas as unidades produtivas foram apuradas através do seu custo médio, mais o custo real de materiais e medicamentos. Modelo de Apuração de Custo Compartilhado.

1 - Direcionador de Custo - A soma de todos os itens lançados no período determina a produção total do Centro de Resultado. E, a quantidade de direcionadores representa o consumo de serviços de cada projeto.

2 - Percentual de Utilização - Cálculo da proporção do volume de direcionadores consumidos pelos projetos em cada período, em relação a produção total da unidade.

Após a determinação dos custos realiza-se a transferências dos custos indiretos das áreas de apoioladministrativas para as atividades fim. Quadro 1 estabelece os critérios de rateio das áreas de apoio e administrativas para as atividades fim.

Quadro 1. Critério rateios para transferência das áreas de apoio/administrativas para atividade fim

\begin{tabular}{|lc|}
\hline Descrição & Critérios de rateio \\
\hline Controle infecção hospitalar & Custo operacional \\
Equipe multiprofissional & \% de utilização - Somente RFSC* \\
Central de material & Custo operacional \\
Farmácia & Materiais Medicamentos e Pacotes \\
Gestão corporativa & Custo operacional \\
Higiene & Custo operacional \\
Hospitalidade & Custo operacional \\
Ensino e treinamento & Custo operacional \\
Nutrição & Custo operacional \\
Recepção & Custo operacional \\
Pré-atendimento & Custo operacional \\
Rouparia & Custo operacional \\
Serviço de arquivo médico & Custo operacional \\
\hline
\end{tabular}




\begin{tabular}{|lc|}
\hline... continuação & \\
\hline Diretoria & Custo operacional \\
Engenharia clínica & Custo operacional \\
Manutenção & Custo operacional \\
Serviço social & Custo operacional \\
Equipe médica transplante & $\%$ de atuação (ATSC* - 60\% / TRSC 40\%) \\
Gestão de transplante & $\%$ de atuação (ATSC - 60\% / TRSC 40\%) \\
Equipe Transplante-Rim & $\%$ de atuação (ATSC - 60\% / TRSC 40\%) \\
Equipe Transplante-Fígado & $\%$ de atuação (ATSC - 60\% / TRSC 40\%) \\
Medicina do trabalho & Custo operacional \\
\hline
\end{tabular}

Para apuração do custo por programa, são utilizados os chamados Direcionadores de Custo. Os Direcionadores de Custo são os principais itens de lançamento de cada unidade produtiva conforme demonstrado no quadro 2.

Quadro 2. Direcionadores de Custo em relação ao centro de custo

\begin{tabular}{|c|c|c|}
\hline Centro de custo & Descrição & Direcionador de Custo \\
\hline ECSC & Ecocardiografia & Exame \\
\hline MGSC & Métodos gráficos & Exame \\
\hline $\operatorname{ccsc}$ & Centro cirúrgico & Taxas \\
\hline cosc & Centro obstétrico & Taxas \\
\hline RASC & Radiologia & Exame \\
\hline TOSC & Tomografia & Exame \\
\hline ULSC & Ultrassonografia & Exame \\
\hline MASC & Maternidade & Diária \\
\hline BESC & Berçário cuidados intermediários & Diária \\
\hline PISC & Pediatria internação & Diária \\
\hline TRSC & Transplante internação & Diária \\
\hline CMSC & Clínica médica cirúrgica & Diária \\
\hline LASC & Laboratório patologia clínica & Exame \\
\hline OCSC & Oncologia internação & Diária \\
\hline TPSC & Terapia intensiva pediátrica & Diária \\
\hline TISC & Terapia intensiva adulto & Diária \\
\hline UTSC & UTI neonatal & Diária \\
\hline RFSC & Reabilitação e fisioterapia & Atendimento \\
\hline ENSC & Endoscopia & Exame \\
\hline DISC & Hemodiálise & Enfermagem \\
\hline BSSC & Banco de sangue & Procedimentos \\
\hline PSSC & Psiquiatria internação & Diária \\
\hline MMSC & Mamografia & Exame \\
\hline NESC & Neurofisiologia & Exame \\
\hline INSC & Infectologia & Exame \\
\hline ANSC & Anestesia & Honorários \\
\hline HDSC & Hemodinâmica & Procedimentos \\
\hline NFSC & Nefrologia & Exame \\
\hline RMSC & Ressonância Magnética & Exame \\
\hline UXSC & UTI transplante & Diária \\
\hline
\end{tabular}


Cada atividade fim possui um direcionador que determinará a transferência do custo, conforme demonstrado nos quadros 3 a 9.

Quadro 3. Categorias dos direcionadores de custo

Categoria

Atendimentos

Diárias

Enfermagem

Exames

Honorários

Materiais

Medicamentos

Procedimentos

Taxas
Código categoria

12

4

6

1

7

10

22

3

2

Quadro 4. Composição dos direcionadores de custo para cada atividade fim

\begin{tabular}{|clc|}
\hline Descrição dos Direcionadores de custos por categoria e centro de lucro \\
\hline Centro custo & Descrição centro de lucro & Categoria \\
\hline ECSC & Ecocardiografia & 1 \\
ENSC & Endoscopia & 1 \\
HDSC & Hemodinâmica & 1 \\
INSC & Infectologia & 1 \\
LASC & Laboratório patologia clínica & 1 \\
MFSC & Medicina fetal & 1 \\
MGSC & Métodos gráficos & 1 \\
MMSC & Mamografia & 1 \\
NESC & Neurofisiologia & 1 \\
NFSC & Nefrologia & 1 \\
RASC & Radiologia & 1 \\
RMSC & Ressonância magnética & 1 \\
TOSC & Tomografia & 1 \\
ULSC & Ultrassonografia & 1 \\
ANSC & Anestesia & 3 \\
RFSC & Reabilitação e fisioterapia & 3 \\
ANSC & Anestesia & 7 \\
RFSC & Reabilitação e fisioterapia & 12 \\
\hline
\end{tabular}

Quadro 5. Descrição da composição da categoria - Atendimento Descrição dos Direcionadores de custos por classificação de serviços

\section{Atendimento}

Termoterapia (tens, ondas, ultrassom, crioterapia)

Atendimento Psicológico Paciente Interno

Atendimento Psicológico Paciente Externo

Consulta Medica Ambulatório Transplantes

Consulta Psicologia Ambulatório Transplantes 


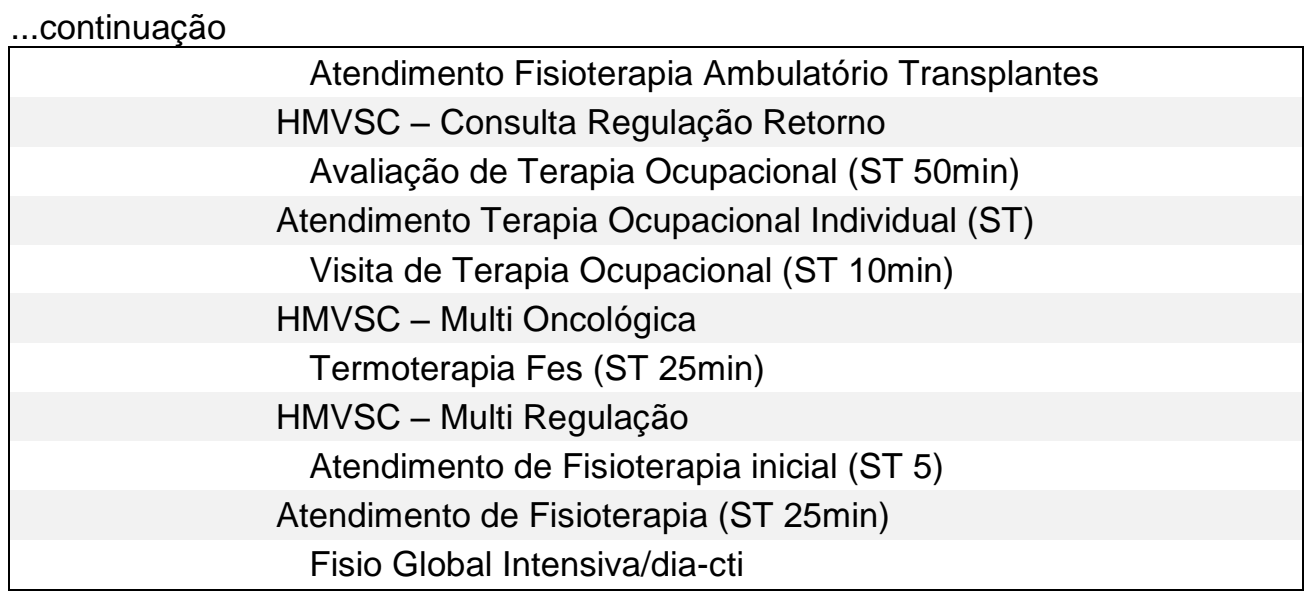

Quadro 6. Descrição da composição da categoria - Diária Hospitalar

\begin{tabular}{|c|}
\hline Descrição dos direcionadores de custos por classificação de serviços \\
\hline Diária hospitalar \\
\hline Diária de Clínica Médica e Cirúrgica \\
Diária de UTI Adulto \\
Diária de UTI Pediátrica \\
Diária de UTI Neonatal \\
Diária de Berçário \\
Diária de Semi Neonatal \\
\hline
\end{tabular}

Quadro 7. Descrição da composição da categoria - Enfermagem

\begin{tabular}{|c|}
\hline Descrição dos Direcionadores de custos por classificação de serviços \\
\hline Enfermagem \\
\hline Hemodiálise Convencional/dia \\
Hemofiltração/dia \\
Observação Clínica Inicial \\
Atendimento de Emergência \\
\hline
\end{tabular}

Quadro 8. Descrição da composição da categoria - Honorário

\begin{tabular}{|c|}
\hline Descrição dos Direcionadores de custos por classificação de serviços \\
\hline Honorário \\
\hline Honorário Anestesista Exames \\
\hline
\end{tabular}

Quadro 9. Descrição da composição da categoria - Exames

\begin{tabular}{|ll|}
\hline \multicolumn{2}{|c|}{ Descrição dos Direcionadores de custos por classificação de serviços } \\
\hline \multicolumn{2}{|c|}{ Exames } \\
\hline Ecocardiografia Doppler & Cultura em Sec Purulenta \\
Endoscopia Digestiva Alta & Cultura p/ Mycoplasma e Ureaplasma \\
Gastrostomia & Cultura em Secreção Vaginal \\
Colonoscopia & Cultura p/ Fungos em Secreção Vaginal \\
Troca/Retirada Sonda Gastrostomia ou Button & Bacterioscópico em Secreção Vaginal \\
Endoscopia Digestiva Alta Infantil & Hepatite B - HBsAg \\
Bacterioscópico em Secreção Traqueal & Glicose em Líquidos \\
Cultura em Líquido Pleural & HIV 1 e 2 (Elisa) \\
\hline
\end{tabular}




\begin{tabular}{|c|c|}
\hline Cultura Anaeróbia em Líquido Pleural & Creatinina na Urina $24 \mathrm{~h}$ \\
\hline Bacterioscópico em Líquido Pleural & DHL em Líquidos \\
\hline Cultura em Urina & Pesquisa p/ Gardenerella \\
\hline Bacterioscópico em Urina & Hemocultura (1a. amostra) \\
\hline Ácido lático (arterial) & Hemocultura (2a. amostra) \\
\hline Ácido lático (Arterial - Perfil) & Hemocultura (3a. amostra) \\
\hline Cálcio lônico (pós-filtro) & Microalbuminúrica de Período \\
\hline Ácido lático (venoso) & Pesquisa Trichomonas em Secreções \\
\hline TTPA & Proteína em Líquidos \\
\hline Clearence de Creatinina & VDRL Liquor \\
\hline Citológico em Outros Materiais & Bacterioscópico em Sec Ocular \\
\hline Fibrinogênio & Cultura em Líquido Sinovial \\
\hline Gasometria Arterial & Cloretos na Urina \\
\hline Gasometria Arterial Perfil & Eritrograma \\
\hline Glicose Perfil & Citológico em Líquido Sinovial \\
\hline Esquizófitos, Pesquisa de & Amilase na Urina $24 \mathrm{~h}$ \\
\hline Líquido Pleural Citológico & pH em Líquidos \\
\hline Citológico em Líquido Ascítico & Potássio na Urina \\
\hline Beta HCG no Sangue & Sódio na Urina \\
\hline Hemograma com Plaquetas & Ureia na Urina \\
\hline Hemoglobina & HMSC Índice de Saturação de Ferro \\
\hline Hemoglobina Perfil & Pesquisa p/ Fungos em Líquido Pleural \\
\hline Hematócrito & Cultura Anaeróbia em Líquido Sinovial \\
\hline Hematócrito Perfil & Bacterioscópico em Líquido Sinovial \\
\hline Cálcio iônico & Bacterioscópico em Lesão Pele \\
\hline Cálcio lônico Perfil & Amilase na Urina \\
\hline Cultura p/ Strepto Grupo B & Amilase \\
\hline Pesquisa de VRE & Troponina quantitativa \\
\hline Cultura em Urina (Jato final) & Eosinófilos, Pesquisa de \\
\hline Bacterioscópico em Urina (Jato final) & Ferro Sérico \\
\hline Cultura Quantitativa em Secreção Traqueal & Glicose na Urina \\
\hline Plaquetas & Dosagem de Imunoglobulina G \\
\hline Potássio Perfil & Lipase \\
\hline Proteína na Urina 24h & Cultura p/ Listeria \\
\hline Reticulócitos & Pesquisa p/ Bk Suco Gástrico \\
\hline Sódio na Urina 24h & Dosagem de Imunoglobulina M \\
\hline Prova de Sobrecarga a Glicose & Proteína C Reativa \\
\hline Sódio Perfil & Triglicérides \\
\hline Tempo de Protrombina & Cultura Anaeróbia em Liquor \\
\hline Urina Tipo I & Hemocultura 4aㅗ Amostra \\
\hline VDRL & HMVSC - Sorologia para HIV Confirmatório \\
\hline VHS & Pesquisa p/ BAAR em Líquido Ascítico \\
\hline Liquor Ácido Lático & Ácido Úrico na Urina 24h \\
\hline Liquor Quimiocitologico & Fósforo na Urina 24h \\
\hline Gasometria Venosa & Potássio na Urina 24h \\
\hline Pesquisa KPC & Larvas de Strongiloides, Pesquisa de \\
\hline Tromboelastograma Pacientes Graves & Magnésio urina 24h \\
\hline Bilirrubina Transcutânea (LABO) & USG Obstétrico com Doppler \\
\hline Teste rápido para HIV & USG Obstétrico \\
\hline HMSC CK-MB & USG Morfológico \\
\hline HMSC Troponina I & USG Morfológico com Doppler \\
\hline HMSC T4 Livre & USG Avaliação Endovaginal do Colo Uterino \\
\hline HMSC TSH & USG Transvaginal Obstétrico \\
\hline HMSC Vitamina B12 & Dipiridamol c/Medicina Nuclear \\
\hline HMSC Bilirrubina Neonatal & USG III Mamas \\
\hline HMSC Proteínas Totais E Frações & Rx Perna \\
\hline HMSC Cloretos Sérico & Rx Punho \\
\hline HMSC Glicose & Rx Joelho \\
\hline
\end{tabular}




\begin{tabular}{|c|c|}
\hline HMSC Cálcio & Rx Pé \\
\hline HMSC Ureia Pós-Diálise & Rx Tórax Frente \\
\hline HMSC Bilirrubina Total E Frações & Rx Abdome Simples \\
\hline HMSC Ácido Úrico & Rx Enema Opaco dos Cólons \\
\hline HMSC Albumina & Rx Escopia (Monitoragem)/Hora \\
\hline HMSC Amilase & Rx Fêmur \\
\hline HMSC Creatinina & Rx Antebraço \\
\hline HMSC Fosfatase Alcalina & Rx Braço (úmero) \\
\hline HMSC Gama GT & Rx Bacia \\
\hline HMSC Lipase & Rx Abdome (3 Posições) \\
\hline HMSC Potássio & Rx Clavícula \\
\hline HMSC Sódio & Rx Tórax Frente e Perfil \\
\hline HMSC TGO & Rm Òrbitas \\
\hline HMSC TGP & Rm Angiografia Artérias llíacas \\
\hline HMSC Ureia & Rm Angiografia Aorta Abdominal \\
\hline HMSC Proteína C Reativa & Rm Sacro-ilíaca \\
\hline HMSC Vancomicina, Dosagem de & Rm Coluna Cervical \\
\hline HMSC Ferritina & Rm Coluna Dorsal/Torácica \\
\hline HMSC CPK & Rm Coluna Lombo Sacra \\
\hline HMSC DHL & Rm Coração-Morfologia \\
\hline HMSC Ferro Sérico & Rm Angiografia Venosa \\
\hline HMSC Fósforo & Rm Hipófise \\
\hline HMSC Magnésio & Rm Bacia \\
\hline HMSC Proteínas Totais & TC Crânio \\
\hline Cultura em Escarro & TC Seios da Face \\
\hline Cultura $\mathrm{p} /$ Fungos em Escarro & TC Angiotomografia Aorta e Membro Inferior \\
\hline Bacterioscópico em Escarro & TC Angiotomografia MMII ou MMSS \\
\hline Pesquisa p/ Fungos em Sec Traqueal & TC Coronárias Score de Cálcio \\
\hline Cultura em Lavado Brônquico & TC Angiotomografia Intracranianos \\
\hline Cultura p/ Fungos em Lavado Brônquico & TC Angiotomografia Abdominais \\
\hline Cultura em Líquido Peritoneal & TC Angiotomografia Torácica \\
\hline Cultura Anaeróbia em Líquido Peritoneal & TC Faringe \\
\hline Bacterioscópico em Líquido Peritoneal & TC Pé \\
\hline Cultura em Líquido Ascítico & TC Tórax \\
\hline Cultura Anaeróbia em Líquido Ascítico & TC Abdome (Inferior/Pélvis) \\
\hline Cultura p/ Fungos em Líquido Ascítico & TC Abdome Total \\
\hline Bacterioscópico em Líquido Ascítico & TC Coluna Cervical \\
\hline Pesquisa $\mathrm{p}$ / Fungos em Urina & TC Coluna Dorsal \\
\hline Pesquisa p/ BAAR em Urina & TC Coluna Lombar \\
\hline Cultura p/ BAAR em Urina & TC Coluna Sacral \\
\hline Cultura em Lesão Pele & TC Perna (Tíbia/Fíbula) \\
\hline Cultura Anaeróbia em Lesão Pele & TC Vasos Angiotomografia Coronária \\
\hline Cultura em Outros Materiais & TC Punção Drenagem Complexo ou Processos \\
\hline Dosagem de D-Dímero & TC Ouvido \\
\hline Creatinina & TC Angiotomografia Abdome e MMII \\
\hline Creatinina na Urina & TC Angiotomografia Cervicais \\
\hline Dimorfismo Eritrocitário, Pesquisa & TC Abdome (Superior) \\
\hline Cultura em Ponta Cateter Vascular & TC Ombro \\
\hline Cultura em Urina (1o jato) & TC Punção Biopsia Simples \\
\hline Bacterioscópico em Úrina (10 jato) & TC Punção Drenagem Simples ou Processos \\
\hline Pesquisa de Leucócitos nas Fezes & TC Coxa (Fêmur) \\
\hline Proteína na Urina & TC Bacia \\
\hline Rotavírus & TC Órbitas \\
\hline Tempo de Trombina & TC Quadril \\
\hline Ureia & US Punção Biopsia. s/Anest Próstata, Derrame \\
\hline Cultura em Liquor & USG Doppler Vascular Carótidas e Vertebral \\
\hline Pesquisa $\mathrm{p} /$ Fungos em Liquor & USG Doppler Vascular. 2 seg. Aorta e Ilíacas \\
\hline Pesquisa p/ BAAR em Liquor & USG I Abdome Superior \\
\hline
\end{tabular}


..continuação

\begin{tabular}{|c|c|}
\hline Bacterioscópico em Liquor & USG I Renal e Trato Urinário Feminino \\
\hline Ácido lático (venoso) & USG Doppler Vasc.3 seg. Aorta, Ilíacas e Si \\
\hline Plaquetas Citrato & USG Abdome Total \\
\hline Perfil Emergência UTI & USG Doppler Vasc. 1 seg. Arterial de MMII o \\
\hline HMSC Clearence de Creatinina & Us III Tireóide \\
\hline HMSC Colesterol Total & USG III Testículos \\
\hline HMVSC- VDRL & USG III Cérebro \\
\hline Pesquisa p/ Fungos em Escarro & USG p/guiar Punção/biopsia \\
\hline Pesquisa p/ BAAR em Líquido Pleural & USG IV Partes Moles \\
\hline Cultura $\mathrm{p} /$ Fungos em Líquido Peritoneal & USG III Próstata \\
\hline Pesquisa p/ Fungos em Líquido Ascítico & USG Trato Urinário + Próstata \\
\hline Cultura $\mathrm{p} /$ Fungos em Urina & USG Doppler Vasc.1 seg. Arterial de MI \\
\hline Pesquisa p/ Fungos em Lesão Pele & USG Doppler Vasc. $1 \mathrm{seg}$. Artérias Renais \\
\hline Cultura p/ Fungos em Lesão Pele & USG Doppler Vasc.1 seg. Outros Órgãos \\
\hline Cultura Anaeróbia em Outros Materiais & USG II Pélvico Transvaginal \\
\hline Pesquisa $\mathrm{p}$ / Fungos em Outros Materiais & USG IV Articulação \\
\hline Cultura p/ Fungos em Outros Materiais & USG Doppler Vasc. 1 seg.Venoso de MMII ou \\
\hline Pesquisa p/ BAAR em Outros Materiais & USG Doppler Vasc.1 seg. Venoso de MI \\
\hline Bacterioscópico em Outros Materiais & USG Doppler Vasc. 1 seg. Sistema Porta \\
\hline Ureia (Líq. Diálise) & USG Doppler Vascular 2 segmentos \\
\hline Ureia (pré-filtro) & USG I Tórax \\
\hline Ureia (pós-diálise) & USG Doppler Vasc.1 Seg.Venoso de MMSS \\
\hline Cálcio na Urina $24 \mathrm{~h}$ & USG I Renal E Trato Urinário Masculino \\
\hline Cultura p/ Fungos em Ponta Cateter Vascular & US Doppler Vasc 1 Seg. Arterial de MMSS \\
\hline Cultura p/ Fungos em Liquor & US Punção Biopsia/Anest Próstata, Derrame \\
\hline Isolamento de Microrganismos Especiais & USG Doppler Vasc.3 seg. Veia Cava Inferior. \\
\hline Creatinina & USG I Abdome Inferior Masculino \\
\hline Acidente de Trabalho Teste Rápido HIV 70 & USG I Abdome Inferior Feminino \\
\hline Perfil Bioquímico Líq. Biológicos & USG Doppler Vascular 1 segmento \\
\hline Sífilis (Teste Rápido) & USG Doppler Vasc.1 seg. Artérias Mesentérica \\
\hline Pesquisa p/ Fungos em Lavado Brônquico & USG Doppler Vasc.2 seg. Veia Cava Inferior \\
\hline Pesquisa p/ BAAR em Lavado Brônquico & USG Punção Biopsia.c/Annest drenagem \\
\hline Bacterioscópico em Lavado Brônquico & \\
\hline
\end{tabular}

Após a alocação de todos os custos é extraído um relatório final dos custos por paciente, para apuração do custo por programa PROADI-SUS do HMVSC, através dos Direcionadores de Custo, conforme demonstrado na figura 2. 


\section{Relatório de Custo Compartilhado por Paciente - Detalhado}

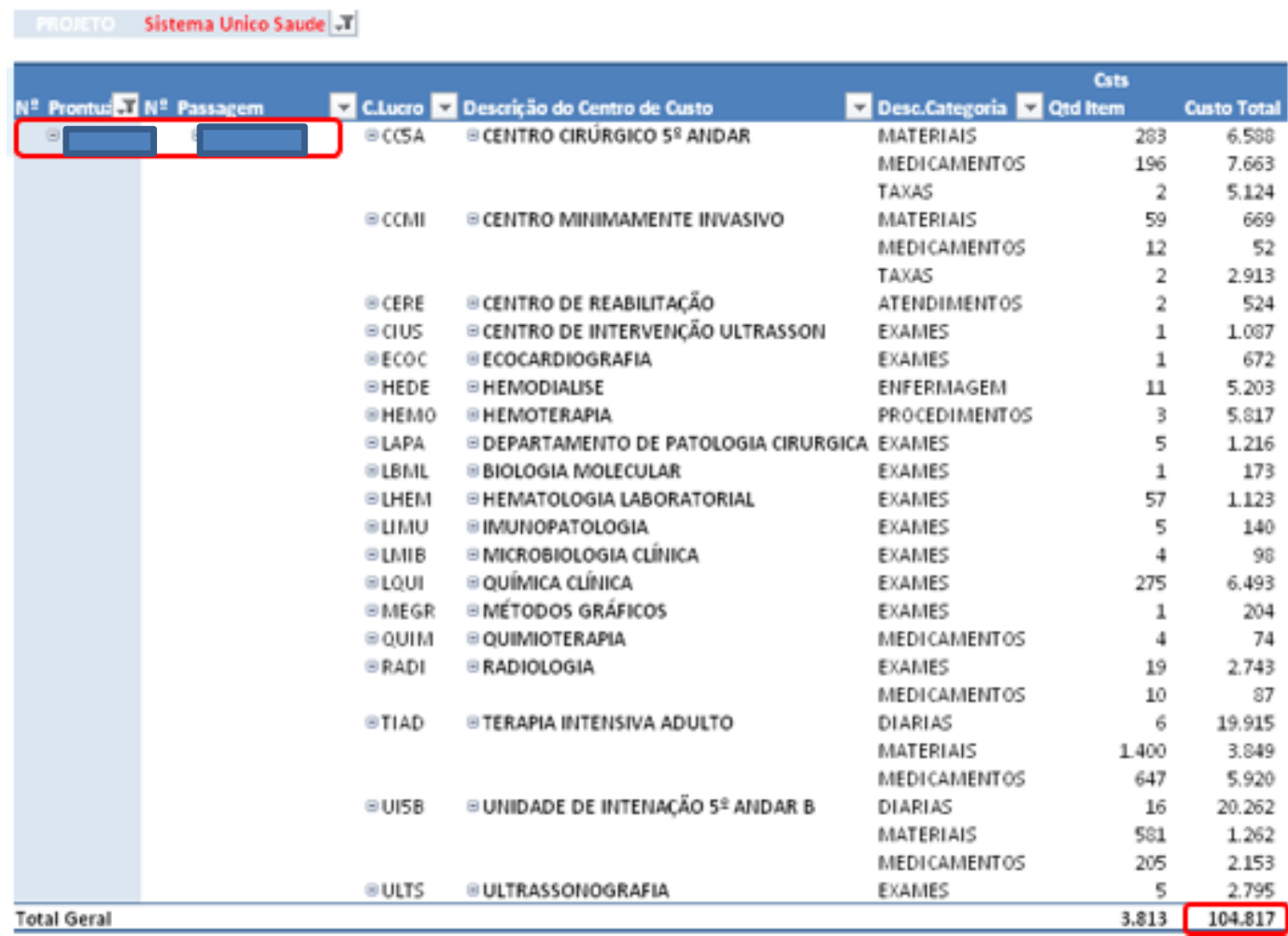

Figura 2. Relatório Final do paciente

Os direcionadores de custo foram subdivido em categorias para alocar cada um dos itens de utilização de serviços e cuidados aos direcionadores de custos foram utilizados na realização da transferência para o projeto de destino que o paciente pertencia. O termo transferência foi empregado pelo hospital Albert Einstein para descrever a alocação dos custos rateados dos centros de custos aos direcionadores para que possa ser identificado ao projeto.

Os custos pela utilização dos serviços são chamados de Custos Compartilhados, são cálculos utilizados para apurar todos os custos diretos e indiretos do período, contabilizados em cada centro de custo e divididos pela produção de direcionadores deste mesmo período. Os Custos Compartilhados representam o custo médio do serviço utilizado pelos pacientes de cada programa no mês. Os custos de materiais e medicamentos são os custos reais dos itens utilizados pelo paciente no período.

$$
\text { Percentual de utilização }=\frac{\text { Produção de cada Projeto }}{\text { Produção Total da Área }}
$$


Para cada projeto realizou-se a criação do Plano no SGH e parametrização no SAP, para que os custos fossem apurados corretamente, pois todos possuem um DE/PARA com centro de custo.

SGH (Plano)

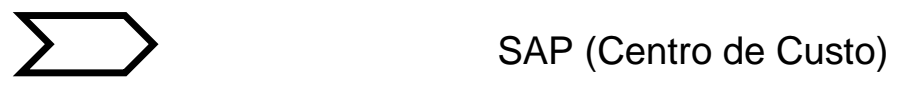

Os relatórios de custo permitem avaliar os custos por paciente e por projeto, identificando os materiais e medicamentos utilizados pelos mesmos, bem como o custo dos serviços (custo médio) demandados pelos mesmos em seus processos de diagnóstico e tratamento. 


\section{REFERÊNCIAS}

1. Silva EN, Silva MT, Pereira MG. Identificação, mensuração e valoração de custos em saúde. Epidemiol Serv Saúde. 2016;25(2):437-9.

2. Alonso M. Custos no serviço público. Rev Serv Púb. 1999;50(1):37-63.

3. World Health Organization (WHO). Brazil [Internet]. Geneva: WHO; c2018 [cited 2017 Nov 2]. Available from: http://www.who.int/countries/bra/en/

4. Paim J, Travassos C, Almeida C, Bahia L, Macinko J. The Brazilian health system: history, advances, and challenges. Lancet. 2011;377(9779):1778-97.

5. Dussault G. A gestão dos serviços públicos de saúde: características e exigências. Rev Adm Pub.1992;26(2):8-19.

6. Brasil. Ministério da Saúde. Secretaria Executiva. Departamento de Monitoramento e Avaliação do SUS. Coordenação-Geral de Monitoramento e Avaliação. Programa de avaliação para a qualificação do Sistema Único de Saúde [Internet]. Brasília (DF): Ministério da Saúde; 2011 [citado 2018 Mar 27]. Disponível em: https://goo.gl/y8BJG5

7. Institute for Healthcare Improvement (IHI). Latin America: overview [Internet]. Boston: IHI; c2018 [cited 2017 Nov 4]. Available from: https://goo.gl/QtGquL

8. Katz M, Franken M, Makdisse M. Value-based health care in Latin America: an urgent discussion. J Am Coll Cardiol. 2017;70(7):904-6.

9. Porter ME. What is value in health care? N Engl J Med. 2010;363(26):2477-81.

10. Brasil. Ministério da Saúde. Proadi-SUS [Internet]. [citado 2017 Out 17]. Brasília (DF): Ministério da Saúde; c2013-2018. Disponível em: https://bit.ly/2qfM3BQ

11. Instituto Brasileiro de Geografia e Estatística. Séries históricas e estatísticas [Internet]. Rio de Janeiro: Instituto Brasileiro de Geografia e Estatística; [202-?] [citado 2018 Mar 27].

Disponível em: http://seriesestatisticas.ibge.gov.br/

12. Instituto Brasileiro de Geografia e Estatística. Projeção da população do Brasil e das Unidades da Federação [Internet]. Rio de Janeiro: Instituto Brasileiro de Geografia e Estatística; [202-?] [citado 2017 Nov 2]. Disponível em: https://bit.ly/2GISlih

13. Simões CC. Relações entre as alterações históricas na dinâmica demográfica brasileira e os impactos decorrentes do processo de envelhecimento da população. Rio de Janeiro: Instituto Brasileiro de Geografia e Estatística; 2016. n. 4. [Estudos e análises. Informação demográfica e socioeconômica].

14. Instituto Brasileiro de Geografia e Estatística. Relações entre as alterações históricas na dinâmica demográfica brasileira e os impactos decorrentes do processo de envelhecimento da população [Internet]. Rio de Janeiro: Instituto Brasileiro de Geografia e Estatística; 2016 [citado 2017 Nov 2]. Disponível em: https://bit.ly/2HnOkSQ

15. Porter ME, Kaplan RS. How should we pay for healthcare? Harv Bus Sch. c2014,2015:1-25.

16. Kaplan RS, Porter ME. How to solve the cost crisis in health care. Harv Bus Rev.

2011;89(9):46-52, 54, 56-61 passim. 
17. Brasil. Ministério da Saúde. Coordenação Geral de Sistemas de Informação. Sistema de gerenciamento da tabela de procedimentos, medicamentos e OPM do SUS [Internet]. Brasília (DF): Ministério da Saúde; [202-?] [citado 2017 Nov 30]. Disponível em: https://goo.gl/8HwFQ

18. La Fogia GM, Coutollenc BF. Desempenho hospitalar no Brasil: a busca da excelência. Banco Mundial. 2009;120:1-4.

19. Lee B. The cost of a great epidemic to a great city, or penny-wisdom and pound-folly. [Presented at Annual Meeting of Baltimore, 1876].

20. Brasil. Ministério da Saúde; Organização Pan-Americana da Saúde. Financiamento público de saúde. Brasília (DF): Ministério da Saúde; 2013. v.1 [Série ECOS: economia da saúde para a gestão do SUS].

21. Brownlee S, Chalkidou K, Doust J, Elshaug AG, Glasziou P, Heath I, et al. Evidence for overuse of medical services around the world. Lancet. 2017;390(10090):156-68. Review.

22. Arashiro LA. Gestão de custo hospitalar: estudo de casos no município de São Paulo [dissertação]. São Paulo: Fundação Getúlio Vargas; 2004.

23. World Health Organization (WHO). World health statistics 2016: monitoring health for the SDGs. Geneva: WHO; c2018 [2018 Mar 27]. Available from: https://goo.gl/Hdl3fU

24. Brasil. Ministério da Saúde; Organização Pan-Americana da Saúde. Introdução à gestão de custos em saúde. Brasília (DF): Editora MS; 2013. v.2. [Série gestão e economia da saúde].

25. Mauss CV, Diehl CA, Bleil C. A gestão de custos como instrumento da eficiência público no Brasil e em outros países. Rev Eletrônica Adm Tur. 2015;6(3):595-609.

26. Nguyen TP, Nguyen TB, Nguyen TT, Vinh Hac V, Le HH, Schuiling-Veninga C, et al. Direct costs of hypertensive patients admitted to hospital in Vietnam-a bottom-up micro-costing analysis. BMC Health Serv Res. 2014;14:514.

27. Nor Azlin MN, Syed Aljunid SJ, Noor Azahz A, Amrizal MN, Saperi S. Direct medical cost of stroke: findings from a tertiary hospital in malaysia. Med J Malaysia. 2012;67(5):473-7.

28. Bozdemir ŞE, Çelebi S, Çakir D, Özcan I, Sigirli D, Sali E, et al. Direct medical cost assessment in the $<2$ years-old hospitalized RSV+LRTI patients. J Pediatr Inf. 2016;10:128-36.

29. Stock GN, Mcdermott C, Chandra C, Kumar S, Ghildayal NS. Operational and contextual drivers of hospital costs. J Heal Organ Manag. 2011;25(12):142-58.

30. Azevedo YG, Santos JV, Gomes AM, Carvalho DR, Oliveira RM. investigação dos métodos de custeio utilizados pelos hospitais públicos do município de Natal/RN. Rev Adm Inov Hosp. 2017;14(1):19-39.

31. Barros CC, Silva JD, Souza FJ, Melo MM, Taveira LB. Há sistemas de custos nos hospitais universitários federais? Rev Estud Contab. 2013;4(6):78-98.

32. Shepard DS, Hodgkin D, Anthony Y. Analysis of hospital costs: a manual for managers. Geneva: WHO; 1998. Available from: http://people.brandeis.edu/ shepard/w-manual.PDF

33. Frank WG. A managerial accounting analysis of hospital costs. Health Serv Res. 1976;11(1):34-44. 
34. Belke R, Berto DJ. Gestão de custos e resultados na saúde. 5a ed. São Paulo: Saraiva; 2012.

35. Abbas K, Gonçalves MN, Leoncine M. Os métodos de custeio: vantagens, desvantagens e a sua aplicabilidade nos diversos tipos de organizações apresentadas pela literatura. Contexto. 2012;12(22):145-59.

36. Rocha W. Da contabilidade de custos à gestão estratégica de custos. Rev Cont Finanças. 2007;18(43):3-8.

37. Wilson EC, Mugford M, Barton G, Shepstone L. Efficient research design: using value-ofinformation analysis to estimate the optimal mix of top-down and bottom-up costing approaches in an economic evaluation alongside a clinical trial. Med Decis Making. 2016;36(3):335-48.

38. Fishman PA, Hornbrook MC. Assigning resources to health care use for health services research: options and consequences. Med Care. 2009;47(7 Suppl 1):S70-5. Review.

39. Medeiros KR, Machado HO, Albuquerque PC, Gurgel Junior GD. O sistema de informação em saúde como instrumento da política de recursos humanos: um mecanismo importante na detecção das necessidades da força de trabalho para o SUS. Cien Saude Coletiva. 2005;10(2):433-40.

40. Bonacim CA, Araujo AM. Avaliação de desempenho econômico-financeiro dos serviços de saúde: os reflexos das políticas operacionais no setor hospitalar. Ciên Saúde Coletiva. 2011;16(Suppl 1):1055-68.

41. Brasil. Constituição 1988. Constituição da República Federativa do Brasil. Brasília (DF): Senado; 1988. [Artigos 196 a 200].

42. The Joint Commission [Internet]. Washington; c2018 [cited 2017 Nov 4]. Available from: https://www.jointcommission.org/

43. Hospital Albert Einstein. Diferenciais [Internet]. São Paulo: Hospital Israelita Albert Einstein; c2016 [citado 2017 Out 18]. Disponível em: https://www.einstein.br/sobre-einstein/diferenciais

44. Antioch KM, Walsh MK. The risk-adjusted vision beyond casemix (DRG) funding in Australia. International lessons in high complexity and capitation. Eur $\mathrm{J}$ Health Econ. 2004;5(2):95-109. Erratum in: Eur J Health Econ. 2004;5(2):115.

45. Vogl M. Improving patient-level costing in the English and the German 'DRG' system. Health Policy. 2013;109(3):290-300.

46. Noronha MF, Veras CT, Leite IC, Martins MS, Braga Neto F, Silver L. O desenvolvimento dos "Diagnosis Related Groups"- DRGs. Metodologia de classificação de pacientes hospitalares. Rev Saude Publica. 1991;25(3):198-208.

47. Centers for Medicare \& Medicaid Services. Design and development of the Diagnosis Related Groups (DRG) [Internet]. Baltimore: CMS; 2016 [cited 2018 Mar 27]. Available from: https://goo.gl/iP9Dpg

48. Espino G. Informação que vale ouro. Rev Melhores Prat. 2015;17:34-7.

49. Bohmer R, Edmondson AC, Feldman LR. Intermountain health care. Boston: Harvard Business School; 2002. Available from: https://hbs.me/2uXQ6HX 
50. Guimarães LS, Hirakata VN. Uso de modela de equações de estimativas generalizadas na análise de dados longitudinais. Rev HCPA. 2012;32(4):503-11.

51. Brasil. Ministério da Saúde. TabNet Win32 3.0: Procedimentos hospitalares do SUS - por local de internação - Brasil [Internet]. Brasília (DF): Ministério da Saúde; [202-?] [citado 2017 Dez 16]. Disponível em: http://tabnet.datasus.gov.br/cgi/tabcgi.exe?sih/cnv/qiuf.def

52. Sacks JJ, Gonzales KR, Bouchery EE, Tomedi LE, Brewer RD. 2010 national and state costs of excessive alcohol consumption. Am J Prev Med. 2015;49(5):e73-9.

53. Dormont B, Martins JO, Pelgrin F, Suhrcke M. Health expenditures, longevity and growth. Social Science Research Network (SSRN). 2008;1-98. Available from:

http://ssrn.com/abstract=1130315

54. Omachonu VK, Suthummanon S, Akcin M, Asfour S. Predicting length of stay for Medicare patients at a teaching hospital. Health Serv Manage Res. 2004;17(1):1-12.

55. Cyganska M. The impact factors on the hospital high length of stay outliers. Procedia Econ Financ. 2016;39(2016):251-5.

56. Ferraz MB, Miranda IC, Padovan J, de Soárez PC, Ciconellil R. Health care costs in the last four years of life for private health plan beneficiaries in Brazil. Rev Panam Salud Publica. 2008;24(2):120-6.

57. Koening A, Picon PD, Feijó J, Silva E, Westphal GA. Estimativa do impacto econômico da implantação de um protocolo hospitalar para detecção e tratamento precoce de sepse grave em hospitais púbicos e privados do sul do Brasil. Rev Bras Ter Intensiva. 2010;22(3):213-9.

58. Antioch KM, Ellis RP, Gillett S, Borovnicar D, Marshall RP. Risk adjustment policy options for casemix funding: international lessons in financing reform. Eur $\mathrm{J}$ Health Econ. 2007;8(3):195-212.

59. Porter ME, Marks C, Landman ZC. OrthoChoice: bundled payments in the county of Stockholm (B). Boston: Harvard Business Review; 2015. 


\begin{abstract}
Purpose: To measure the operational cost of a municipal public hospital in the city of São Paulo and to identify factors influencing cost increase during the year 2016. Methods: A prospective cohort study carried out between January and December 2016, in patients hospitalized at Hospital Municipal Vila Santa Catarina, a tertiary municipal public hospital in São Paulo, Brazil. Results: A total of 8,702 patients were identified with an average patient-day cost of $R(B R) 3,093.33$, with a median of $R(B R)$ $5,950.82$, with a total operating cost of $R(B R) 158,861,058.90$. The transplant had the highest median cost, while the mother had the lowest median. The rate of patients costing up to $\mathrm{R}$ (BR) $10,000.00$ was $69.9 \%$. Among the factors that influenced the increase in cost, age is associated with a $6.6 \%$ increase in cost for each one-year increase in age. Being female present's chance 1.1 times, the chance of increased cost associated with being male. It was also observed that all Major Diagnostic Category discharge diagnoses presented a high-cost increased chance compared to patients with Major Diagnostic Category "newborns and other neonates". Patients who died were 8 times more likely to increase their cost compared to patients who were discharged from the hospital. Patients in the maternal-infant department have a lower proportion of highcost, while Oncology, Transplantation and Clinical-Medical have estimated odds of 18.8 times $(p<0.001), 15.8$ times $(p<0.001)$ and 13,7 times $(p<0.001)$ the high-cost chance of the maternity department. Conclusions: Concluded that the data could subsidize the knowledge of resource allocations, reinforcing the need to implement a methodology to calculate costs in Brazilian public institutions. Among the factors that influenced the hospital cost increase was the increase in age, white race, hospital death, length of hospital stay, as well as hospitalizations in the Oncology department. Among the Major Diagnostic Category, the category Diseases and disorders of the male reproductive system stood out as the major influence of cost increase.
\end{abstract}




\section{Apêndices}

Apêndice 1. Distribuição dos custos

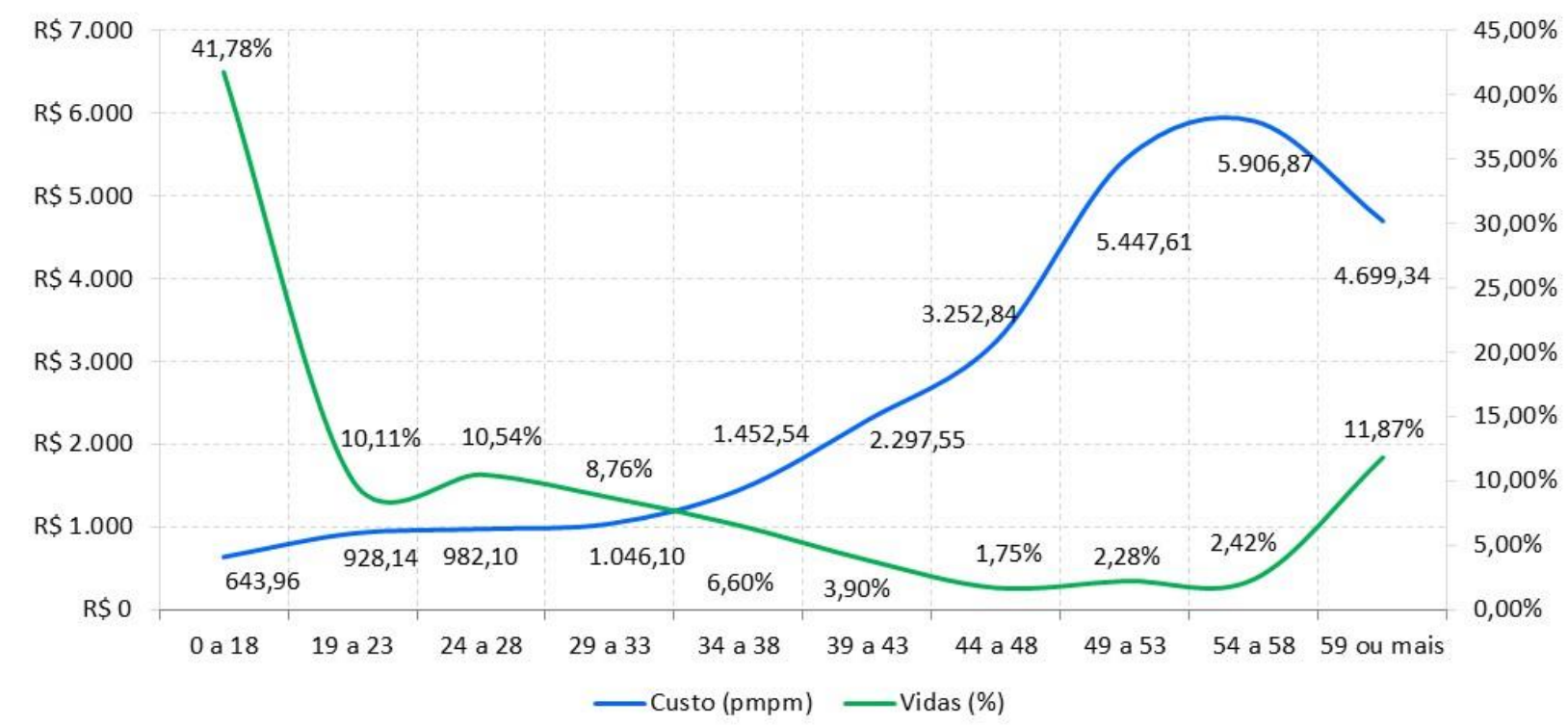

$\mathrm{N}=9602$ internações.

Figura 1. Distribuição do custo total das internações de acordo com faixa etária 
Apêndice 2. Distribuição dos custos das Internações

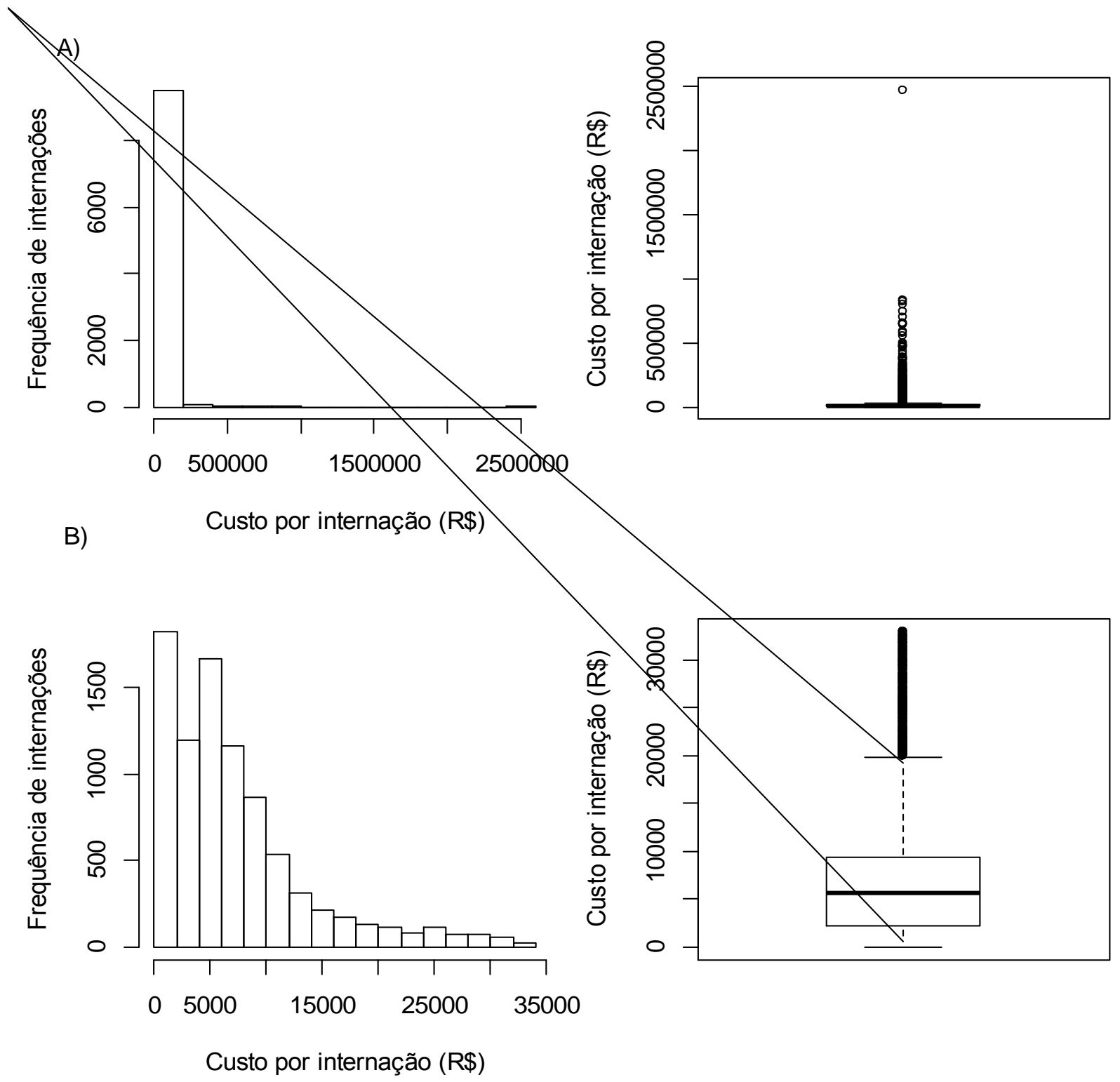

$\mathrm{N}=9602$ internações. A) Todas as internações. B) Internações com custo de até $\mathrm{R} \$ 33.000,00$ ( $N=8640$ que representam $90,0 \%$ das internações).

Figura 1. Custo por internação ocorrida em 2016, em reais 


\section{Apêndice 3. Distribuição dos custos por paciente}

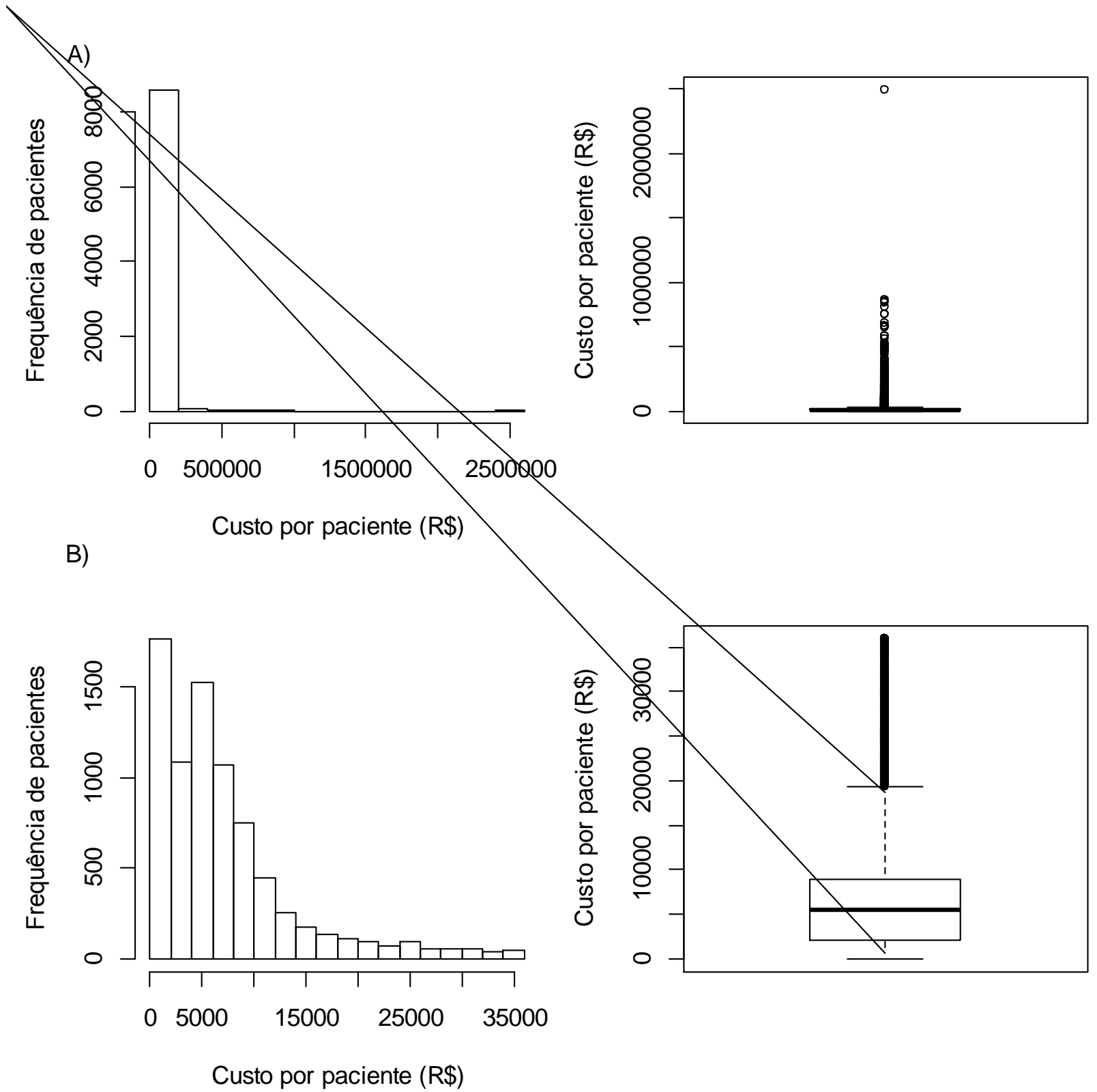

A) Todos os pacientes. B) Pacientes com custo até $\mathrm{R} \$ 36.000,00$ ( $\mathrm{N}=7842$ que representam $90,1 \%$ dos pacientes).

Figura 1. Custo de internações por paciente atendido 
Apêndice 4. Distribuição dos custos sem fatores discrepantes

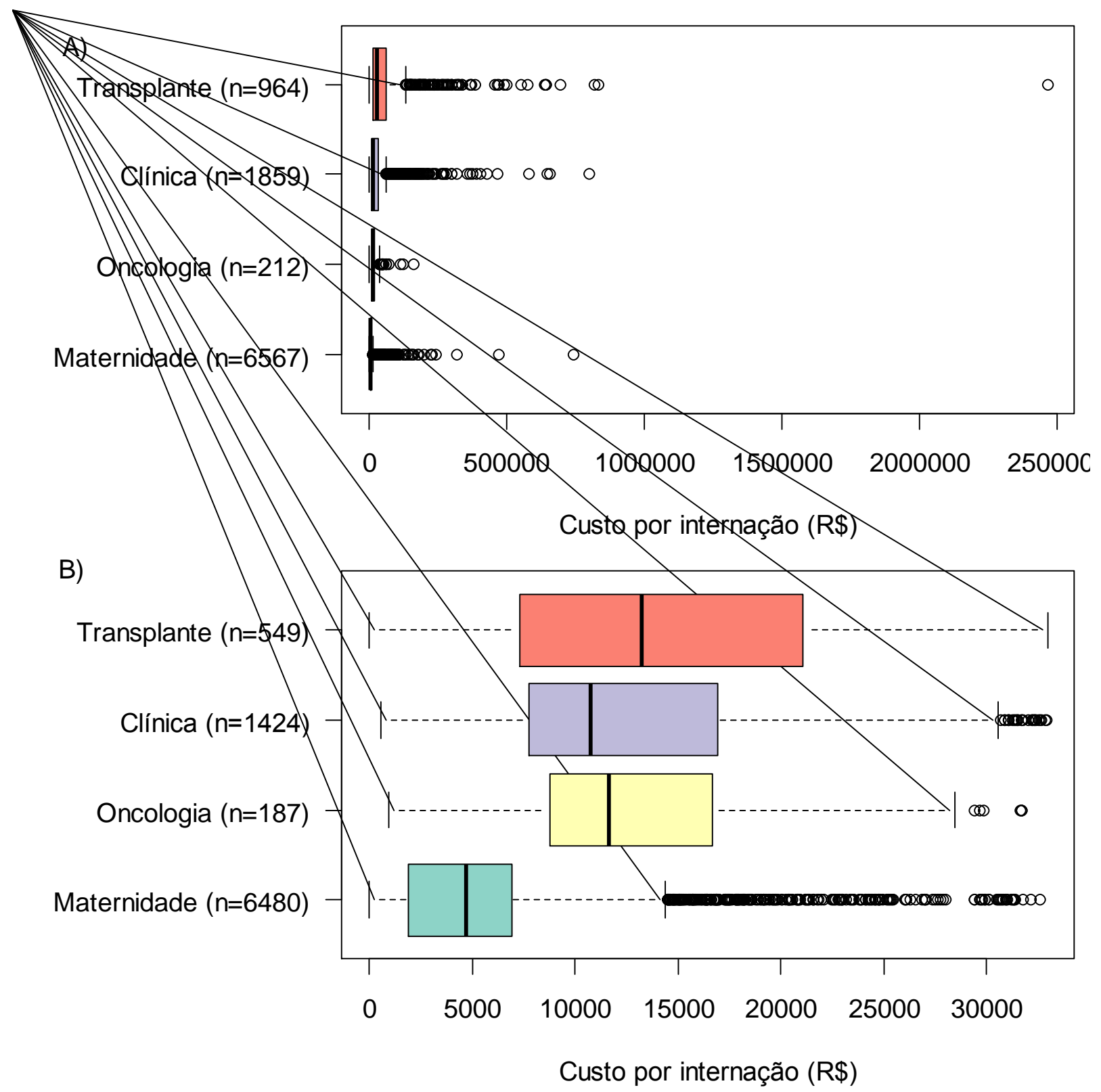

A) Todas as internações. B) Internações com custo de até $R \$ 33.000,00$ ( $N=8640$ que representam $90,0 \%$ das internações).

Figura 1. Custo por internação ocorrida em 2016, em reais de acordo com o departamento 
Apêndice 5. Distribuição dos custos das internações com valor até $R \$ 10.000,00$

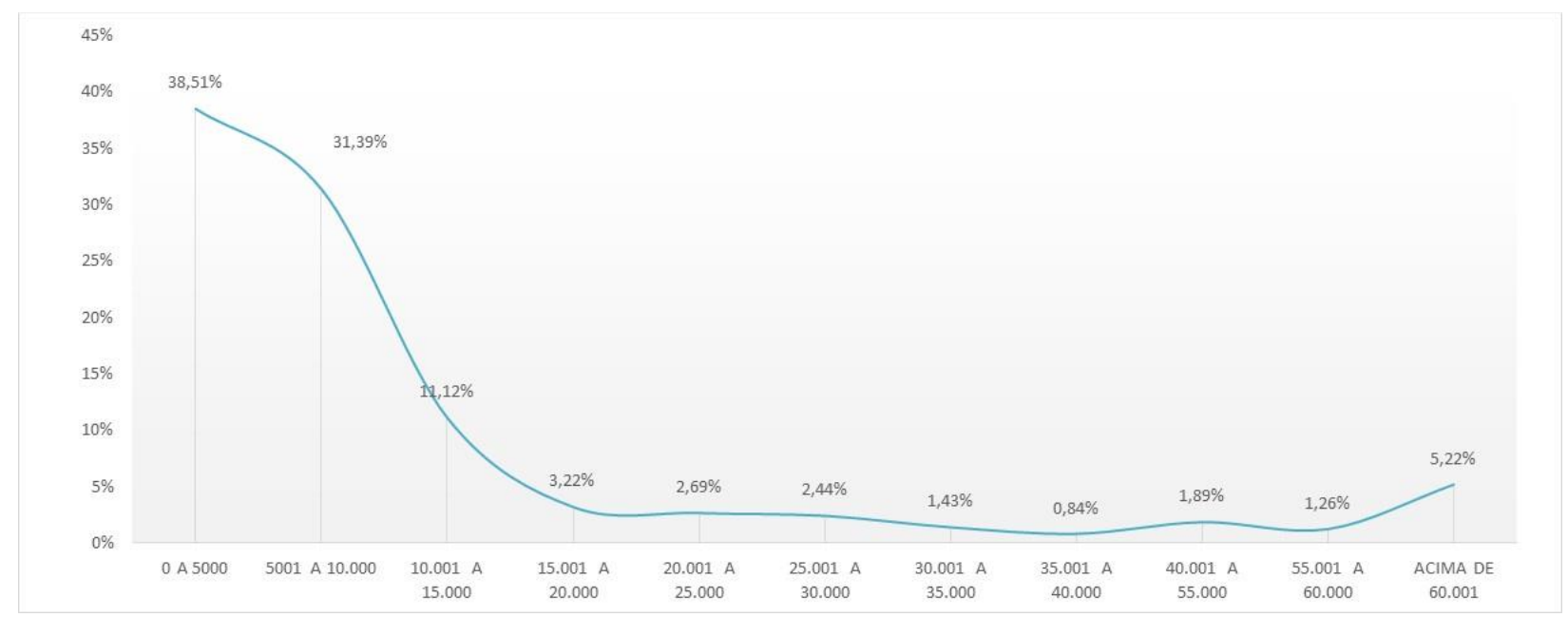

$\mathrm{N}=9602$ internações.

Figura 1. Distribuição do custo total das internações 
Apêndice 6. Distribuição dos custos por departamento

Tabela 1. Custos anuais totais e médios por internações e por departamento

\begin{tabular}{lccc}
\hline Departamento & $\begin{array}{c}\text { Custo total } \\
(\mathbf{R} \$)\end{array}$ & $\begin{array}{c}\text { Custo médio } \\
\text { (R\$) }\end{array}$ & $\mathbf{n}$ \\
\hline Transplante & $55.637 .394,35$ & $57.715,14$ & 964 \\
Clínica médico-cirúrgica & $56.888 .208,16$ & $30.601,51$ & 1859 \\
Oncologia & $3.806 .773,29$ & $17.956,48$ & 212 \\
Materno-infantil & $42.528 .683,11$ & $6.476,12$ & 6567 \\
\hline Total & $\mathbf{1 5 8 . 8 6 1 . 0 5 8 , 9 0}$ & $\mathbf{1 6 . 5 4 4 , 5 8}$ & $\mathbf{9 6 0 2}$ \\
\hline
\end{tabular}

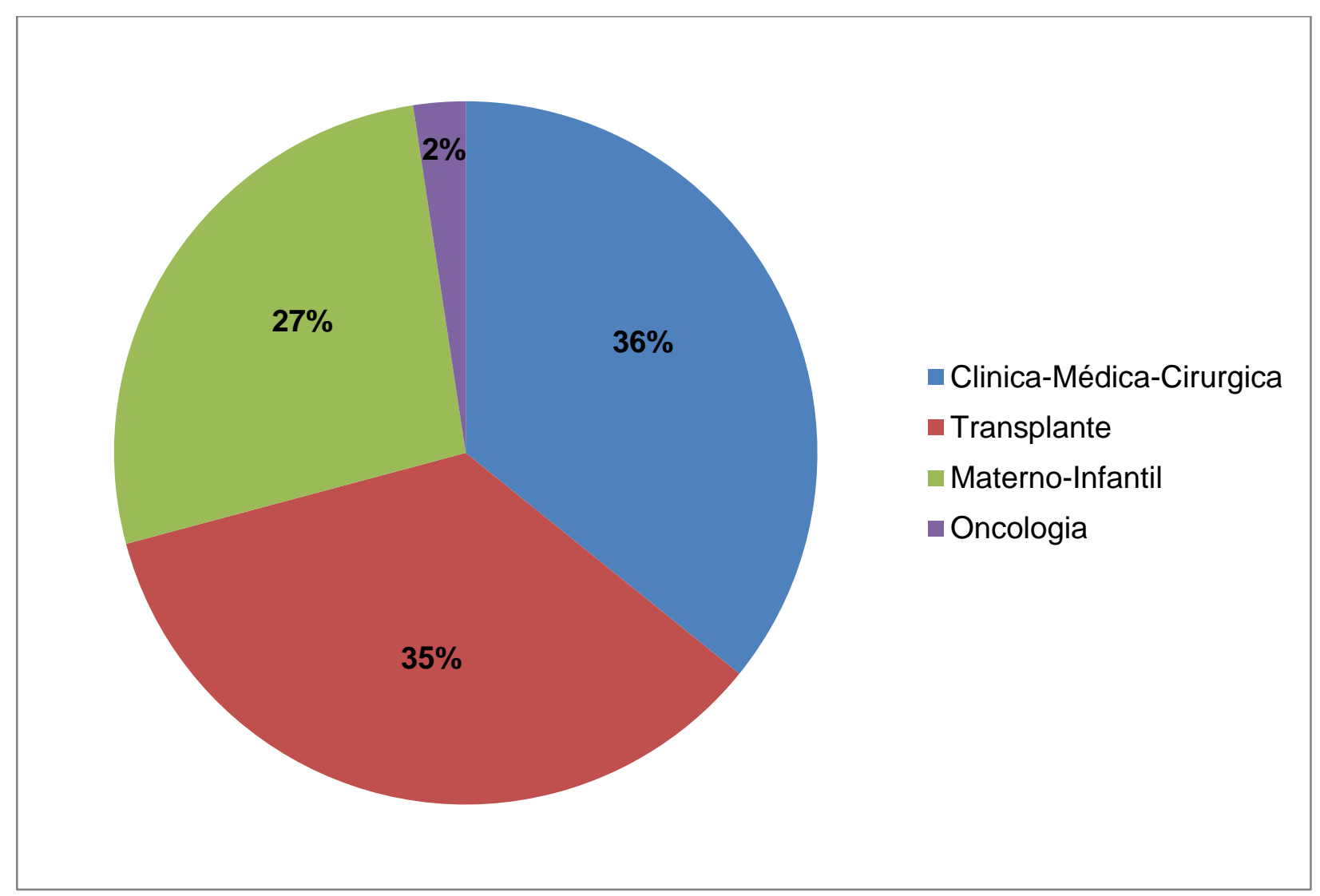

$\mathrm{N}=9602$ internações.

Figura 1. Distribuição do custo total das internações de acordo com o departamento 
Apêndice 7. Distribuição dos custos totais por categoria de alta

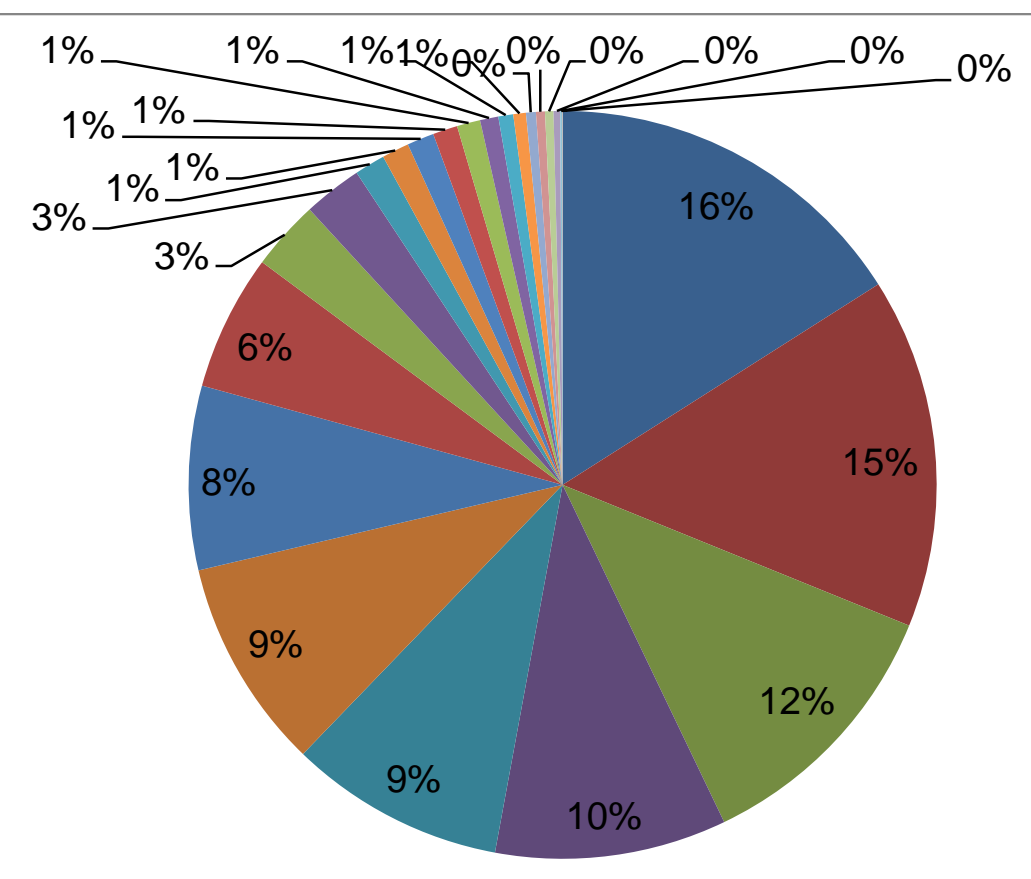

- GRAVIDEZ, PARTO E PUERPÉRIO

- DOENÇAS E DISTÚRBIOS DO SISTEMA CIRCULATÓRIO

- DOENÇAS E DISTÚRBIOS DO SISTEMA RESPIRATÓRIO

- RECÉM-NASCIDOS E OUTROS NEONATOS COM CONDIÇÃO DE ORIGEM NO PERÍODO PERINATAL

- DOENÇAS E DISTÚRBIOS DO SISTEMA HEPATOBILIAR E PÂNCREAS

- DOENÇAS E DISTÚRBIOS DOS RINS E DO TRATO URINÁRIO

- DOENÇAS INFECCIOSAS E PARASÍTICAS, SISTÊMICAS OU EM LOCAL NÃO ESPECIFICADO

- DOENÇAS E DISTÚRBIOS DO SISTEMA DIGESTIVO

- FATORES QUE INFLUENCIAM STATUS SAÚDE E OUTROS CONTATOS COM SERV. SAÚDE

- DOENÇAS E DISTÚRBIOS DO SISTEMA NERVOSO

Figura 1. Distribuição do custo total das internações de acordo com o MDC de alta 
Apêndice 8. Distribuição dos custos médios departamento de transplante

Tabela 1. Custos por DRG dos pacientes do departamento de transplante

\begin{tabular}{lcc}
\hline DRG (maiores custos médios) & $\begin{array}{c}\text { Custo médio } \\
\text { (R\$) }\end{array}$ & N \\
\hline Procedimentos importantes de pâncreas, fígado e desvio (shunt) & $638.224,41$ & 1 \\
Transplante de coração e/ou pulmão & $588.810,61$ & 10 \\
Distúrbios e lesões da coluna vertebral & $458.308,09$ & 1 \\
Implante de desfibrilador cardíaco e de assistência cardíaca & $321.254,66$ & 1 \\
Osteomielite, artrite séptica e outras infecções musculoesqueléticas & $311.935,71$ & 1 \\
Infecções não bacterianas do sistema nervoso exceto. Meningites virais & $253.780,11$ & 1 \\
Outros procedimentos cardiotorácicos & $236.554,73$ & 1 \\
Coma hepático e outros importantes distúrbios agudos do fígado & $156.423,85$ & 7 \\
Procedimentos de amígdalas e adenóide & $153.822,41$ & 1 \\
Insuficiência vascular gastrointestinal & $146.092,32$ & 1 \\
Hemorragia & $118.186,50$ & 2 \\
Importantes procedimentos estomacais, esofágicos e duodenais & $117.506,10$ & 2 \\
Malignidade digestiva & $114.106,20$ & 1 \\
Mau funcionamento, reação, complicação de dispositivo ou procedimento & $110.334,55$ & 9 \\
cardíaco/vascular & $103.901,63$ & 55 \\
Transplante de fígado e/ou intestinal & $103.299,40$ & 5 \\
Importantes infecções e inflamações respiratórias & $101.152,46$ & 1 \\
Malignidades de ouvido, nariz, boca, garganta, craniais/faciais & $99.907,33$ & 1 \\
Cateterismo cardíaco com distúrbio Circulatório. Exceto doença cardíaca & & \\
isquêmica & & 4 \\
Doenças infecciosas e parasíticas incluindo HIV com procedimento de & $94.410,20$ & 4 \\
Centro Cirúrgico & $91.875,11$ & 2 \\
Neoplasmas linfáticos e outras malignidades de comportamento incerto & $90.084,24$ & 10 \\
Outras doenças infecciosas parasíticas & $87.619,80$ & 36 \\
Outros pós-tratamentos e convalescença & $85.916,61$ & 1 \\
Importantes distúrbios esofágicos & $82.381,37$ & 55 \\
Transplante de rins & $80.303,11$ & 5 \\
Outras complicações de tratamento &
\end{tabular}


Tabela 1. Custos por DRG dos pacientes do departamento de clínica médico-cirúrgica

\begin{tabular}{lcc}
\hline DRG (maiores custos médios) & $\begin{array}{c}\text { Custo médio } \\
\text { (R\$) }\end{array}$ & N \\
\hline Transplante de coração e/ou pulmão & $798.589,54$ & 1 \\
Dependência de drogas e álcool com reabilitação ou terapia de & $655.810,47$ & 1 \\
reabilitação/desintoxicação & $214.340,43$ & 3 \\
Outros pós-tratamentos e convalescença & $144.175,89$ & 4 \\
HIV com múltiplas condições importantes relacionadas ao HIV & $118.242,75$ & 1 \\
Recém-nascido com peso entre 750-999g sem procedimento importante & $116.691,49$ & 1 \\
Pós-tratamento neonatal & $113.021,64$ & 4 \\
Doença viral & $110.417,99$ & 4 \\
Doenças infecciosas e parasíticas incluindo HIV com procedimento de & $105.884,59$ & 3 \\
Sala Operatória & $95.413,13$ & 2 \\
Úlceras cutâneas & $78.811,19$ & 3 \\
Amputação de membros inferiores exceto dedos dos pés & $76.131,37$ & 1 \\
HIV com condição importante relacionada ao HIV & $73.516,75$ & 71 \\
Distúrbios de tecido conjuntivo & $73.465,69$ & 8 \\
Septicemia e infecções disseminadas & $70.907,45$ & 9 \\
Infecções bacterianas e tuberculosas do sistema nervoso & $67.037,61$ & 1 \\
Insuficiência renal & $66.733,51$ & 3 \\
Estupor não-traumático e coma & $66.240,57$ & 2 \\
Procedimento extenso não relacionado ao diagnóstico principal & $64.094,47$ & 14 \\
Outros distúrbios nas costas e pescoço, fraturas e lesões & $62.857,86$ & 2 \\
Edema pulmonar e insuficiência respiratória & $62.816,33$ & 32 \\
Outros procedimentos em tecidos cutâneos, subcutâneos e relacionados & $61.396,64$ & 1 \\
Outros procedimentos vasculares & $60.273,48$ & 1 \\
Importantes procedimentos vasculares torácicos e abdominais & $59.222,15$ & 8 \\
Procedimentos dos rins e do trato urinário para malignidade & $56.935,63$ & 4 \\
Distúrbios orgânicos de saúde mental & & \\
Importantes infecções gastrointestinais e peritoneais & &
\end{tabular}


Apêndice 10. Distribuição dos custos médios departamento de Oncologia

Tabela 1. Custos por DRG dos pacientes do departamento de oncologia

\begin{tabular}{lcc}
\hline DRG (maiores custos médios) & $\begin{array}{c}\text { Custo médio } \\
\text { (R\$) }\end{array}$ & N \\
\hline Obstrução intestinal & $51.382,92$ & 3 \\
Outras anemias e distúrbios do sangue e de órgãos formadores do & $46.549,52$ & 1 \\
sangue & $46.411,01$ & 1 \\
Dor abdominal & $45.573,89$ & 1 \\
Importantes procedimentos estomacais, esofágicos e duodenais & $35.898,75$ & 1 \\
Linfoma, mieloma e leucemia não-aguda & $32.800,63$ & 2 \\
Septicemia e infecções disseminadas & $32.467,63$ & 2 \\
Outros procedimentos do sistema digestivo e abdominal & $28.187,82$ & 59 \\
Importantes procedimentos do intestino delgado e grosso & $24.633,72$ & 3 \\
Malignidades de ouvido, nariz, boca, garganta, craniais/faciais & $22 ' 526,45$ & 1 \\
Outra pneumonia & $20.886,31$ & 1 \\
Malignidade dos rins e trato urinário & $20.606,02$ & 3 \\
Outros procedimentos do sistema reprodutivo masculino e procedimentos & $19.879,32$ & 1 \\
relacionados & $17.772,98$ & 9 \\
Outros diagnósticos respiratórios exceto sinais, sintomas e diagnósticos & $17.403,90$ & 1 \\
de importância secundária & $16.349,58$ & 3 \\
Prostatectomia transuretral & $15.322,52$ & 18 \\
Outros procedimentos respiratórios e do peito & $12.998,62$ & 1 \\
Infecções do sistema reprodutivo feminino & $12.763,02$ & 1 \\
Importantes procedimentos pélvicos masculinos & $12.142,98$ & 1 \\
Procedimentos dos rins e do trato urinário para malignidade & $11.850,53$ & 29 \\
Procedimentos uterinos e anexos para malignidade não-ovariana e não- & $11.541,43$ & 10 \\
anexa & $11.199,93$ & 2 \\
Procedimentos anais & $10.615,09$ & 7 \\
Malignidade digestiva & $10.523,47$ & 6 \\
Procedimentos de mastectomia & & \\
Importantes procedimentos de bexiga & & \\
Procedimentos nas mamas exceto mastectomia & & \\
Outros pós-tratamentos e convalescença & & \\
\hline
\end{tabular}


Apêndice 11. Distribuição dos custos médios departamento materno-infantil

Tabela 1. Custos por DRG dos pacientes do departamento materno-infantil

\begin{tabular}{|c|c|c|}
\hline DRG (maiores custos médios) & $\begin{array}{l}\text { Custo médio } \\
\text { (R\$) }\end{array}$ & $\mathbf{N}$ \\
\hline Bronquiolite e pneumonia por vírus respiratório sincicial (rsv) & $133.636,08$ & 1 \\
\hline Recém-nascido com peso entre $500-749 \mathrm{~g}$ com anomalia importante & $109.019,89$ & 1 \\
\hline Recém-nascido com peso entre $750-999 \mathrm{~g}$ sem procedimento importante & $105.899,95$ & 7 \\
\hline Recém-nascido com peso entre $2000-2499 \mathrm{~g}$ com anomalia importante & $103.244,64$ & 1 \\
\hline Peso de recém-nascido menor $500 \mathrm{~g}$ ou menor de 24 semanas & $101.110,74$ & 3 \\
\hline $\begin{array}{l}\text { Recém-nascido com peso entre } 1000-1249 \mathrm{~g} \text { com síndrome, distúrbio } \\
\text { respiratório outra condição respiratória importante }\end{array}$ & $86.750,94$ & 2 \\
\hline $\begin{array}{l}\text { Recém-nascido com peso entre } 1000-1249 \mathrm{~g} \text { com ou sem outra condição } \\
\text { significativa }\end{array}$ & $82.487,40$ & 10 \\
\hline $\begin{array}{l}\text { Recém-nascido com peso entre } 1250 \text {-1499g com ou sem outra condição } \\
\text { significativa }\end{array}$ & $61.724,72$ & 7 \\
\hline Outros diagnósticos do sistema circulatório & $59.911,41$ & 1 \\
\hline $\begin{array}{l}\text { Recém-nascido com peso maior que } 2499 \mathrm{~g} \text { com síndrome, distúrbio } \\
\text { respiratório outra condição respiratória. importante }\end{array}$ & $49.705,10$ & 22 \\
\hline $\begin{array}{l}\text { Recém-nascido com peso entre 1500-1999g com infecção } \\
\text { congênita/perinatal }\end{array}$ & $37.706,48$ & 2 \\
\hline $\begin{array}{l}\text { Recém-nascido com peso entre } 2000-2499 \mathrm{~g} \text { com síndrome, distúrbio } \\
\text { respiratório outra condição respiratória. importante }\end{array}$ & $35.779,02$ & 3 \\
\hline $\begin{array}{l}\text { Recém-nascido com peso entre 2000-2499g com infecção congênita/ } \\
\text { perinatal }\end{array}$ & $35.404,24$ & 3 \\
\hline Edema pulmonar e insuficiência respiratória & $33.351,91$ & 2 \\
\hline Recém-nascido com peso acima de $2499 \mathrm{~g}$ com anomalia importante & $28.497,84$ & 46 \\
\hline Outros procedimentos & $27.920,81$ & 9 \\
\hline Convulsão & $25.863,22$ & 3 \\
\hline Outros procedimentos do sistema reprodutivo feminino e relacionados & $24.782,54$ & 1 \\
\hline $\begin{array}{l}\text { Recém-nascido com peso entre } 1500-1999 \mathrm{~g} \text { com síndrome, distúrbio } \\
\text { respiratório outra condição respiratória importante }\end{array}$ & $23.948,53$ & 2 \\
\hline Recém-nascido com peso entre $1500-1999 \mathrm{~g}$ com anomalia importante & $23.705,41$ & 3 \\
\hline $\begin{array}{l}\text { Recém-nascido com peso entre } 1500-1999 \mathrm{~g} \text { com ou sem outra condição } \\
\text { significativa }\end{array}$ & $23.161,39$ & 30 \\
\hline Procedimento não extenso não relacionado ao diagnóstico principal & $22.806,78$ & 2 \\
\hline Recém-nascido com peso maior que $2499 \mathrm{~g}$ com outra condição significativa & $18.733,48$ & 58 \\
\hline
\end{tabular}


Apêndice 12. Características dos pacientes segundo os fatores que influenciaram o aumento do custo

Tabela 1. Características dos pacientes e das internações, segundo o custo total da internação

\begin{tabular}{|c|c|c|}
\hline \multirow{3}{*}{ Características } & \multicolumn{2}{|c|}{ Custo } \\
\hline & Não alto $(<6165.2)$ & Alto $(\geq 6165.2)$ \\
\hline & $n=4800$ & $\mathrm{n}=4802$ \\
\hline Idade, mediana ( $1^{\circ}$ quartil; $3^{\circ}$ quartil) & $1,0(1,0 ; 25,0)$ & $36,0(24,0 ; 59,0)$ \\
\hline \multicolumn{3}{|l|}{ Sexo, $n(\%)$} \\
\hline Feminino & $3140(65,42)$ & $3156(65,72)$ \\
\hline Masculino & $1659(34,56)$ & $1645(34,26)$ \\
\hline Desconhecido & $1(0,02)$ & $0(0,00)$ \\
\hline Não informado & $0(0,00)$ & $1(0,02)$ \\
\hline \multicolumn{3}{|l|}{ Raça, $n(\%)$} \\
\hline Amarela & $14(0,29)$ & $42(0,87)$ \\
\hline Branca & $965(20,10)$ & $2389(49,75)$ \\
\hline Indígena & $1(0,02)$ & $3(0,06)$ \\
\hline Negra & $347(7,23)$ & $607(12,64)$ \\
\hline Parda & $998(20,79)$ & $1708(35,57)$ \\
\hline Não informado & $2475(51,56)$ & $53(1,10)$ \\
\hline \multicolumn{3}{|l|}{ Plano, $n(\%)$} \\
\hline Maternidade Hospital de Ensino & $4419(92,06)$ & $2148(44,73)$ \\
\hline Oncologia Hospital de Ensino & $22(0,46)$ & $190(3,96)$ \\
\hline Regulação Hospital de Ensino & $246(5,13)$ & $1613(33,59)$ \\
\hline Transplante & $113(2,35)$ & $851(17,72)$ \\
\hline \multicolumn{3}{|l|}{ Status na alta, n(\%) } \\
\hline Óbito & $20(0,42)$ & $216(4,50)$ \\
\hline Vivo & $4762(99,21)$ & $4551(94,77)$ \\
\hline Não informado & $18(0,38)$ & $35(0,73)$ \\
\hline $\begin{array}{l}\text { Tempo de permanência hospitalar, } \\
\text { mediana ( } 1^{\circ} \text { quartil; } 3^{\circ} \text { quartil) }\end{array}$ & $2,6(2,3 ; 3,1)$ & $3,9(2,7 ; 8,3)$ \\
\hline
\end{tabular}


Doenças e distúrbios do sistema nervoso

Doenças e distúrbios dos olhos

Doenças e distúrbios dos ouvidos, nariz, boca e garganta

Doenças e distúrbios do sistema circulatório

$56(1,17)$

$432(9,00)$

Doenças e distúrbios do sistema digestivo

$49(1,02)$

$424(8,83)$

Doenças e distúrbios do sistema hepatobiliar e pâncreas

Doenças e distúrbios do sistema musculoesquelético e do tecido conjuntivo

$48(1,00)$

$376(7,83)$

$5(0,10)$

$349(7,27)$

Doenças e distúrbios da pele, tecido subcutâneo e da mama

$14(0,29)$

$22(0,46)$

$3(0,06)$

$74(1,54)$

Doenças e distúrbios endócrinos, nutricionais e metabólicos

$49(1,02)$

$41(0,85)$

Doenças e distúrbios dos rins e do trato urinário

Doenças e distúrbios do sistema reprodutor masculino

Doenças e distúrbios do sistema reprodutor feminino

Gravidez, parto e puerpério

Recém-nascidos e outros neonatos com indicação de origem no período

perinatal

Doenças e distúrbios do sangue, dos órgãos formadores do sangue, DST, imunológicos

Doenças e distúrbios mieloproliferativos, neoplasma pouco diferenciado

Doenças infecciosas e parasíticas sistêmicas ou em local não especificado

$5(0,10)$

$1(0,02)$

$1644(34,25)$

$377(7,85)$

$138(2,87)$

$5(0,10)$

$1768(36,82)$

$2742(57,13)$

$330(6,87)$

$$
2(0,04)
$$

$30(0,62)$

$1(0,02)$

$14(0,29)$

$10(0,21)$

$186(3,87)$

Doenças e distúrbios mentais

Uso de álcool, drogas e distúrbios mentais orgânicos induzidos por álcool e

$1(0,02)$

$12(0,25)$

\section{drogas}

Lesões, envenenamentos e efeitos tóxicos de drogas

Fatores que influenciam status de saúde e outros contatos com serv. saúde

$0(0,00)$

$3(0,06)$

$8(0,17)$

$20(0,42)$

$25(0,52)$

$0(0,00)$

$53(1,10)$

$9(0,19)$

usto com atendimentos, mediana (1ํquartil; $3^{\circ}$ quartil)

$0,00(0,00 ; 0,00)$

Custo com diárias, mediana ( $1^{\circ}$ quartil; $3^{\circ}$ quartil)

Custo com enfermagem, mediana ( $1^{\circ}$ quartil; $3^{\circ}$ quartil)

$1775,56(1404,77 ; 2329,96)$

$0,00(0,00 ; 0,00)$

$74,47(0,00 ; 199,79)$

$0,00(0,00 ; 432,37)$

$6112,88(2571,88 ; 16600,56)$

$0,00(0,00 ; 0,00)$ $679,05(129,82 ; 2745,06)$ 
...continuação

Custo com honorários, mediana (1ำ quartil; $3^{\circ}$ quartil)

Custo com materiais, mediana ( $1^{\circ}$ quartil; $3^{\circ}$ quartil)

$0,00(0,00 ; 0,00)$

$47,51(28,19 ; 126,49)$

$0,00(0,00 ; 1924,89)$

Custo com medicamentos, mediana (1ㅇ quartil; $3^{\circ}$ quartil)

$1,41(0,00 ; 57,93)$

Custo com procedimentos, mediana ( $1^{\circ}$ quartil; $3^{\circ}$ quartil)

$0,00(0,00 ; 0,00)$

Custo com taxas, mediana (1ㅇ quartil; $3^{\circ}$ quartil)

$0,00(0,00 ; 0,00)$

$440,78(189,48 \cdot 1328,22)$

$243,32(101,66 ; 974,20)$

$0,00(0,00 ; 0,00)$

$2,828,85(0,00 ; 4655,84)$ 
Apêndice 13. Associações dos fatores que influenciaram o aumento do custo

Tabela 1. Associação entre alto custo da internação e características dos pacientes e das internações

\begin{tabular}{|c|c|c|c|c|}
\hline \multirow[b]{2}{*}{ Associações } & \multicolumn{2}{|c|}{ Custo } & \multirow{2}{*}{$\begin{array}{l}\text { RC } \\
(\text { IC } 95 \%)\end{array}$} & \multirow[b]{2}{*}{ Valor-p } \\
\hline & $\begin{array}{c}\text { Não alto } \\
(<6165,20)\end{array}$ & $\begin{array}{c}\text { Alto } \\
(\geq 6165,20)\end{array}$ & & \\
\hline Idade (anos), mediana ( $1^{\circ}$ quartil $-3^{\circ}$ quartil) & $1,0(1,0 ; 25,0)$ & $36,0(24,0 ; 59,0)$ & $1,066(1,063 ; 1,069)$ & $<0,001$ \\
\hline \multicolumn{5}{|l|}{ Sexo } \\
\hline Feminino $(\mathrm{n}=6293)$ & $3140(49,87 \%)$ & $3156(50,13 \%)$ & $1,119(1,024 ; 1,222)$ & 0,013 \\
\hline Masculino ( $\mathrm{n}=3304)$ & $1659(50,21 \%)$ & $1645(49,79 \%)$ & 1,000 & \\
\hline $\mathrm{n}$ & 4799 & 4801 & & \\
\hline \multicolumn{5}{|l|}{ Raça } \\
\hline Amarela $(\mathrm{n}=56)$ & $14(25,00 \%)$ & $42(75,00 \%)$ & $1,748(0,939 ; 3,256)$ & 0,078 \\
\hline Branca $(n=3354)$ & $965(28,77 \%)$ & $2389(71,23 \%)$ & $1,449(1,297 ; 1,619)$ & $<0,001$ \\
\hline Negra $(n=954)$ & $347(36,37 \%)$ & $607(63,63 \%)$ & $1,034(0,884 ; 1,210)$ & 0,672 \\
\hline Parda $(\mathrm{n}=2406)$ & $998(36,88 \%)$ & $1708(63,12 \%)$ & 1,000 & \\
\hline $\mathrm{n}$ & 2324 & 4746 & & \\
\hline \multicolumn{5}{|l|}{ MDC na alta } \\
\hline $\begin{array}{l}\text { Recém-nascidos e outros neonatos com } \\
\text { indicação de origem no período perinatal } \\
(\mathrm{n}=3072)\end{array}$ & $2742(89,26 \%)$ & $330(10,74 \%)$ & 1,000 & \\
\hline Doenças e distúrbios do sistema nervoso $(n=100)$ & $12(12,00 \%)$ & $88(88,00 \%)$ & $60,243(33,198 ; 109,321)$ & $<0,001$ \\
\hline $\begin{array}{l}\text { Doenças e distúrbios dos ouvidos, nariz, boca e } \\
\text { garganta }(n=57)\end{array}$ & $20(35,09 \%)$ & $37(64,91 \%)$ & $15,527(8,942 ; 26,961)$ & $<0,001$ \\
\hline $\begin{array}{l}\text { Doenças e distúrbios do sistema respiratório } \\
(\mathrm{n}=538)\end{array}$ & $106(19,70 \%)$ & $432(80,30 \%)$ & $33,694(26,399 ; 43,005)$ & $<0,001$ \\
\hline $\begin{array}{l}\text { Doenças e distúrbios do sistema circulatório } \\
(\mathrm{n}=480)\end{array}$ & $56(11,67 \%)$ & $424(88,33 \%)$ & $64,833(47,456 ; 88,573)$ & $<0,001$ \\
\hline $\begin{array}{l}\text { Doenças e distúrbios do sistema digestivo } \\
(n=425)\end{array}$ & $49(11,53 \%)$ & $376(88,47 \%)$ & $65,477(47,101 ; 91,022)$ & $<0,001$ \\
\hline $\begin{array}{l}\text { Doenças e distúrbios do sistema hepatobiliar e } \\
\text { pâncreas }(n=397)\end{array}$ & $48(12,09 \%)$ & $349(87,91 \%)$ & $60,710(44,158 ; 83,466)$ & $<0,001$ \\
\hline
\end{tabular}




\begin{tabular}{|c|c|c|c|c|}
\hline $\begin{array}{l}\text { Doenças e distúrbios do sistema } \\
\text { musculoesquelético e do tecido conjuntivo( } n=27)\end{array}$ & $5(18,52 \%)$ & $22(81,48 \%)$ & $35,075(13,840 ; 88,886)$ & $<0,001$ \\
\hline $\begin{array}{l}\text { Doenças e distúrbios da pele, tecido subcutâneo } \\
\text { e da mama }(n=88)\end{array}$ & $14(15,91 \%)$ & $74(84,09 \%)$ & $43,584(24,196 ; 78,507)$ & $<0,001$ \\
\hline $\begin{array}{l}\text { Doenças e distúrbios do sistema reprodutor } \\
\text { masculino }(n=143)\end{array}$ & $5(3,50 \%)$ & $138(96,50 \%)$ & $242,650(98,261 ; 599,210)$ & $<0,001$ \\
\hline Gravidez, parto e puerpério $(\mathrm{n}=3412)$ & $1644(48,18 \%)$ & $1768(51,82 \%)$ & $8,938(7,828 ; 10,205)$ & $<0,001$ \\
\hline $\begin{array}{l}\text { Lesões, envenenamentos e efeitos tóxicos de } \\
\text { drogas }(n=33)\end{array}$ & $8(24,24 \%)$ & $25(75,76 \%)$ & $24,911(11,344 ; 54,702)$ & $<0,001$ \\
\hline $\begin{array}{l}\text { Fatores que influenciam status de saúde e outros } \\
\text { contatos com serviços de saúde }(n=73)\end{array}$ & $20(27,40 \%)$ & $53(72,60 \%)$ & $23,148(12,891 ; 41,569)$ & $<0,001$ \\
\hline Outros $(n=124)$ & $9(7,26 \%)$ & $115(92,74 \%)$ & $104,626(52,548 ; 208,314)$ & $<0,001$ \\
\hline $\mathrm{n}$ & 4797 & 4794 & & \\
\hline \multicolumn{5}{|l|}{ Status na alta } \\
\hline Maternidade Hospital de Ensino ( $\mathrm{n}=6567)$ & $4419(67,29 \%)$ & $2148(32,71 \%)$ & 1,000 & \\
\hline Oncologia Hospital de Ensino ( $n=212)$ & $22(10,38 \%)$ & $190(89,62 \%)$ & $18,852(12,040 ; 29,516)$ & $<0,001$ \\
\hline Regulação Hospital de Ensino ( $n=1859)$ & $246(13,23 \%)$ & $1613(86,77 \%)$ & $13,699(11,848 ; 15,839)$ & $<0,001$ \\
\hline Transplante $(n=964)$ & $113(11,72 \%)$ & $851(88,28 \%)$ & $15,828(12,744 ; 19,659)$ & $<0,001$ \\
\hline $\mathrm{n}$ & 4800 & 4802 & & \\
\hline Tempo de permanência (dias) ${ }^{\star}$ & & & --- & \\
\hline Mediana ( $1^{\circ}$ quartil $-3^{\circ}$ quartil) & $2,6(2,3 ; 3,1)$ & $3,9(2,7 ; 8,3)$ & --- & $<0,001$ \\
\hline Custo com atendimentos $(\mathrm{R} \$)^{*}$ & & & --- & \\
\hline Mediana ( $1^{\circ}$ quartil $-3^{\circ}$ quartil) & $0,0(0,0 ; 0,0)$ & $0,0(0,0 ; 432,4)$ & --- & $<0,001$ \\
\hline Custo com diárias $(\mathrm{R} \$)^{*}$ & & & --- & \\
\hline Mediana ( $1^{\circ}$ quartil $-3^{\circ}$ quartil) & $1775,6(1404,8 ; 2330,0)$ & $6112,9(2571,9 ; 16600,6)$ & --- & $<0,001$ \\
\hline
\end{tabular}




\begin{tabular}{|c|c|c|c|c|}
\hline Custo com enfermagem $(\mathrm{R} \$)^{*}$ & & & --- & \\
\hline Mediana ( $1^{\circ}$ quartil $-3^{\circ}$ quartil) & $0,0(0,0 ; 0,0)$ & $0,0(0,0 ; 0,0)$ & --- & $<0,001$ \\
\hline Custo com exames $(\mathrm{R} \$)^{\star}$ & & & --- & \\
\hline Mediana ( $1^{\circ}$ quartil $-3^{\circ}$ quartil) & $74,5(0,0 ; 199,8)$ & $679,0(129,8 ; 2745,1)$ & --- & $<0,001$ \\
\hline Custo com honorários $(\mathrm{R} \$)^{*}$ & & & --- & \\
\hline Mediana ( $1^{\circ}$ quartil $-3^{\circ}$ quartil) & $0,0(0,0 ; 0,0)$ & $0,0(0,0 ; 1924,9)$ & --- & $<0,001$ \\
\hline Custo com materiais $(R \$)^{*}$ & & & --- & \\
\hline Mediana ( $1^{\circ}$ quartil $-3^{\circ}$ quartil) & $47,5(28,2 ; 126,5)$ & $440,8(189,5 ; 1328,2)$ & --- & $<0,001$ \\
\hline Custo com medicamentos $(\mathrm{R} \$)^{\star}$ & & & --- & \\
\hline Mediana (1ำ quartil - $3^{\circ}$ quartil) & $1,4(0,0 ; 57,9)$ & $243,3(101,7 ; 974,2)$ & --- & $<0,001$ \\
\hline Custo com procedimentos $(\mathrm{R} \$)^{\star}$ & & & --- & \\
\hline Mediana (1ำ quartil - $3^{\circ}$ quartil) & $0,0(0,0 ; 0,0)$ & $0,0(0,0 ; 0,0)$ & --- & $<0,001$ \\
\hline Custo com taxas $(\mathrm{R} \$)^{\star}$ & & & -- & \\
\hline Mediana ( $1^{\circ}$ quartil $-3^{\circ}$ quartil) & $0,0(0,0 ; 0,0)$ & $2828,9(0,0 ; 4655,8)$ & --- & $<0,001$ \\
\hline
\end{tabular}

RC: Razão de Chances; IC 95\%: Intervalo de Confiança de 95\% para a razão de chances estimada. ${ }^{*}$ Valores-p obtidos por meio de testes de MannWhitney. 
Apêndice 14. Relação entre os grupos de alto e não alto custo com tempo de permanência e direcionadores de custos

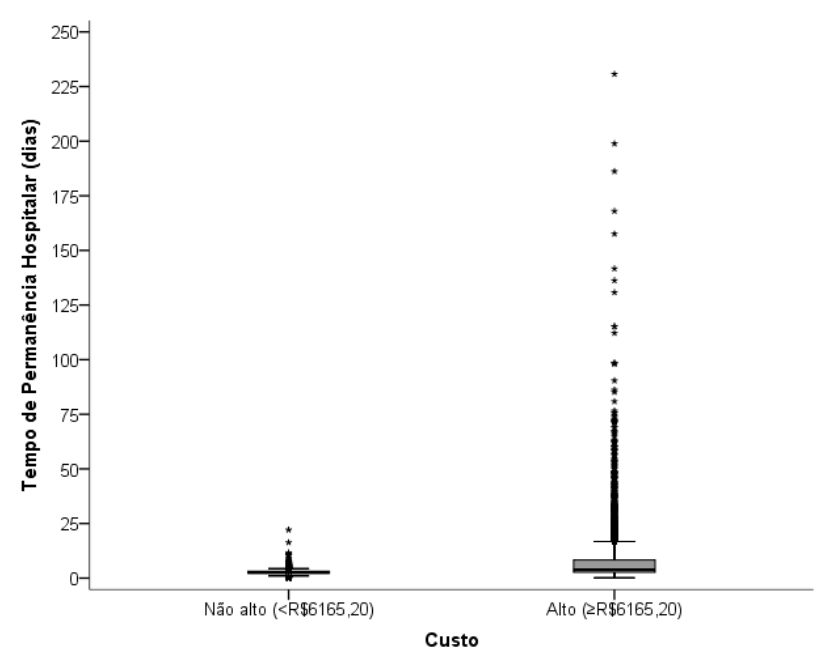

Figura 1. Relação entre tempo de permanência hospitalar e alto custo

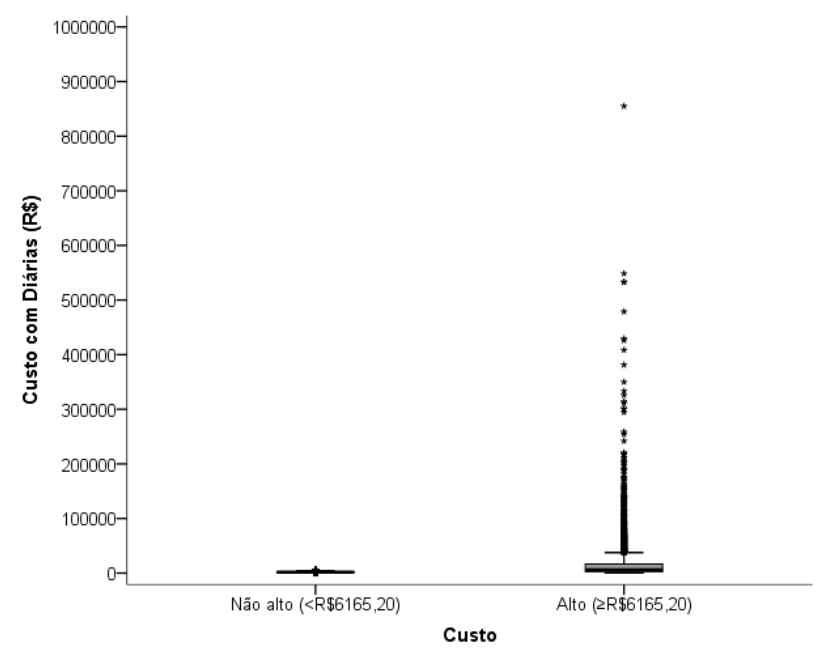

Figura 3. Relação entre custo com diárias e alto custo

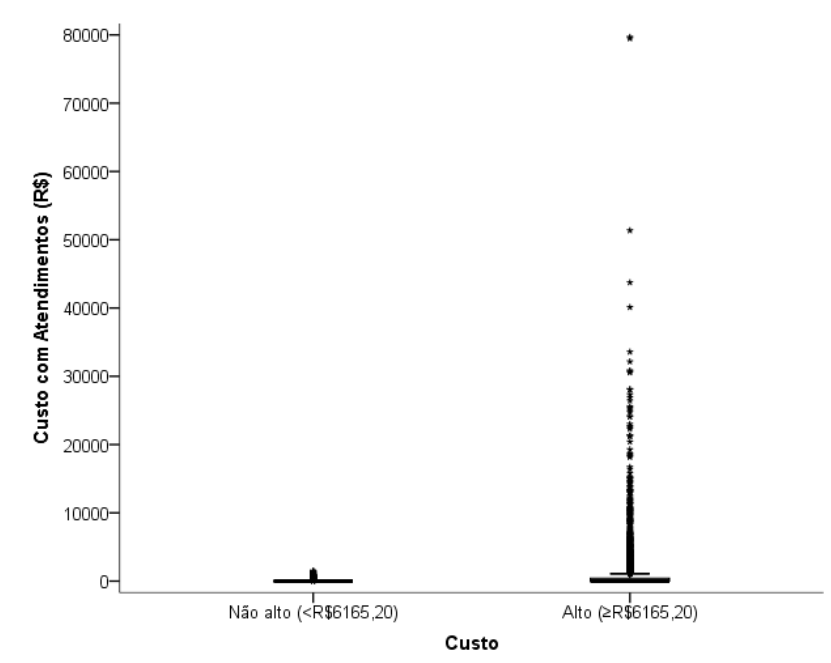

Figura 2. Relação entre custo com atendimentos e alto custo

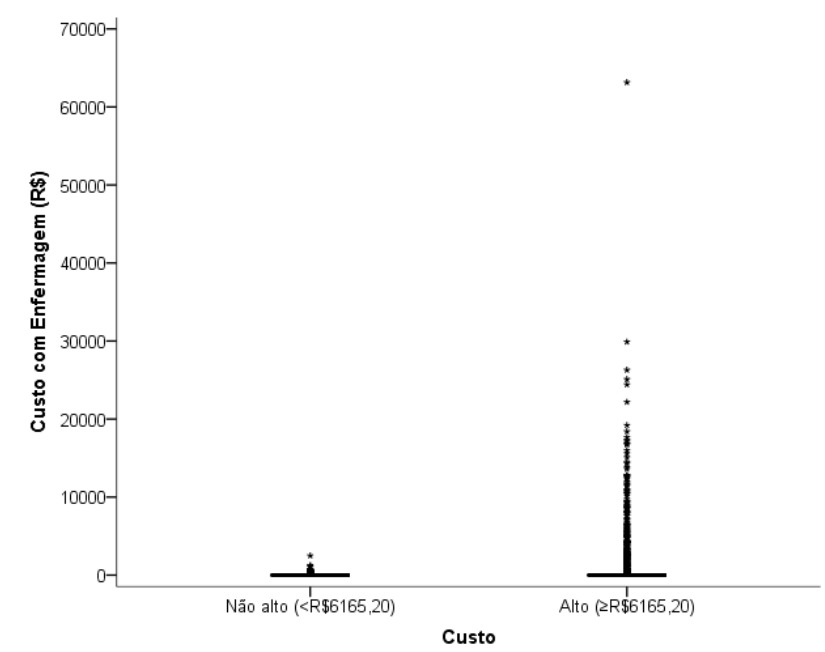

Figura 4. Relação entre custo com enfermagem e alto custo 


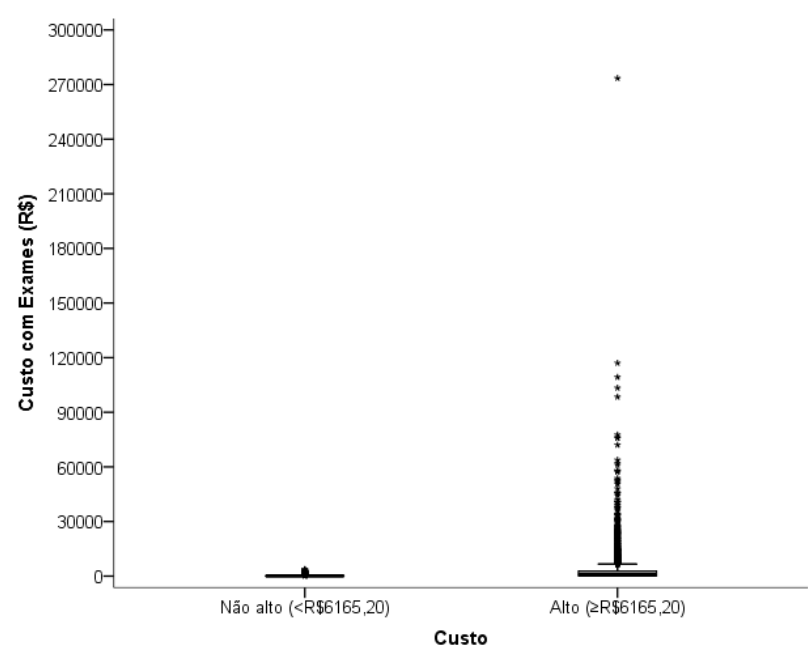

Figura 5. Relação entre custo com exames e alto custo

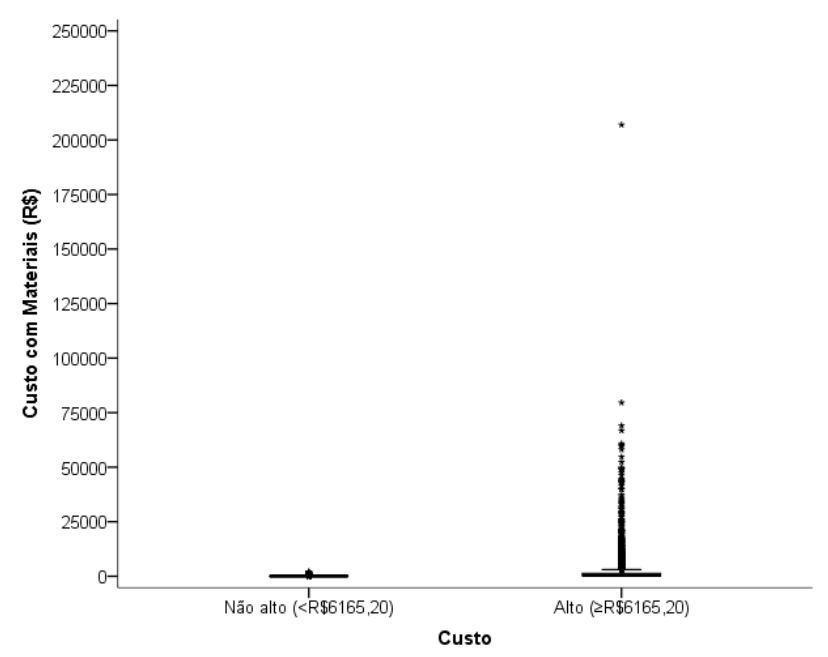

Figura 7. Relação entre custo com materiais e alto custo

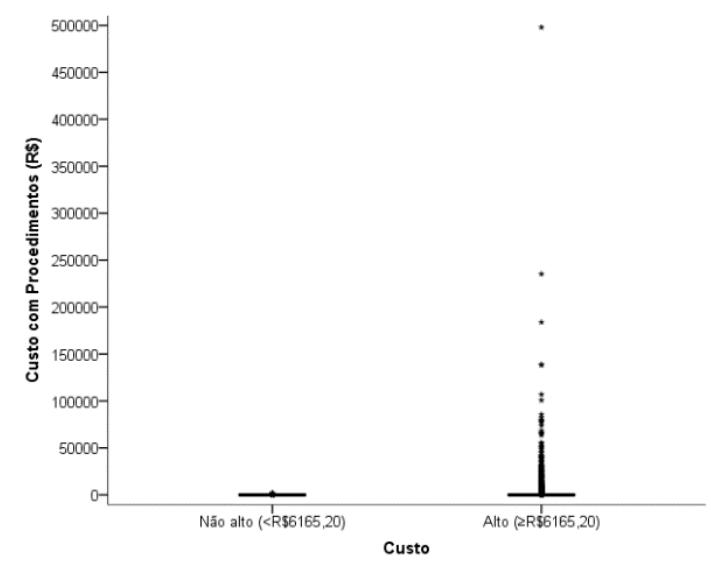

Figura 9. Relação entre custo com procedimentos e alto custo

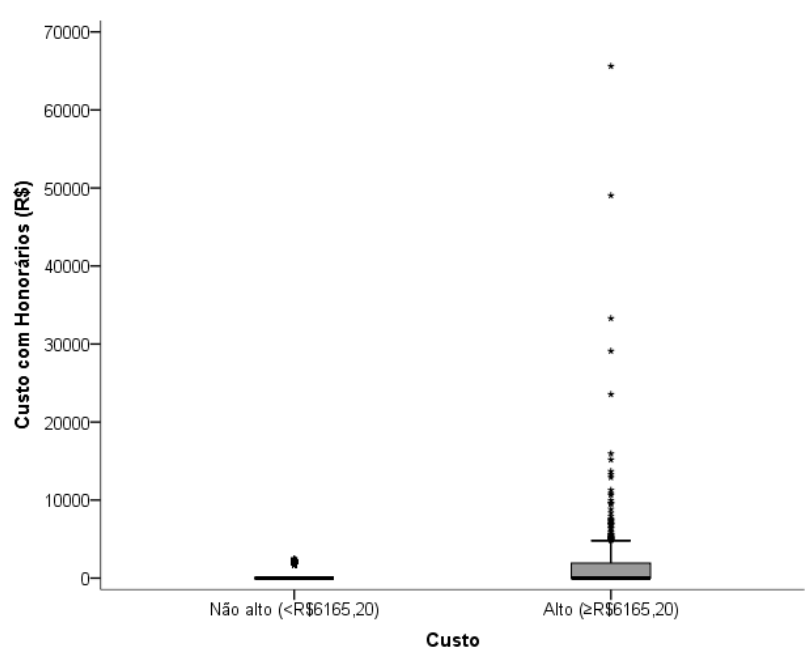

Figura 6. Relação entre custo com honorários e alto custo

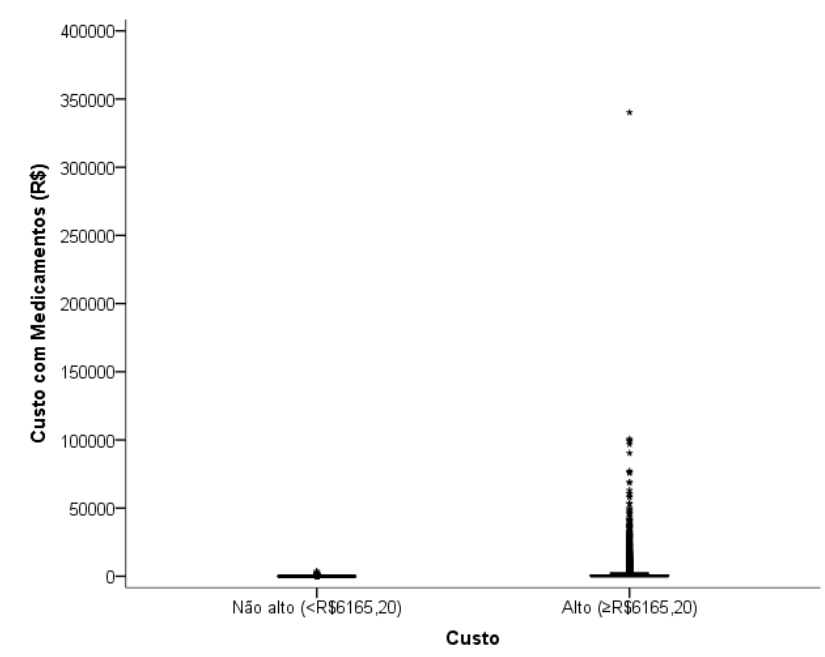

Figura 8. Relação entre custo com medicamentos

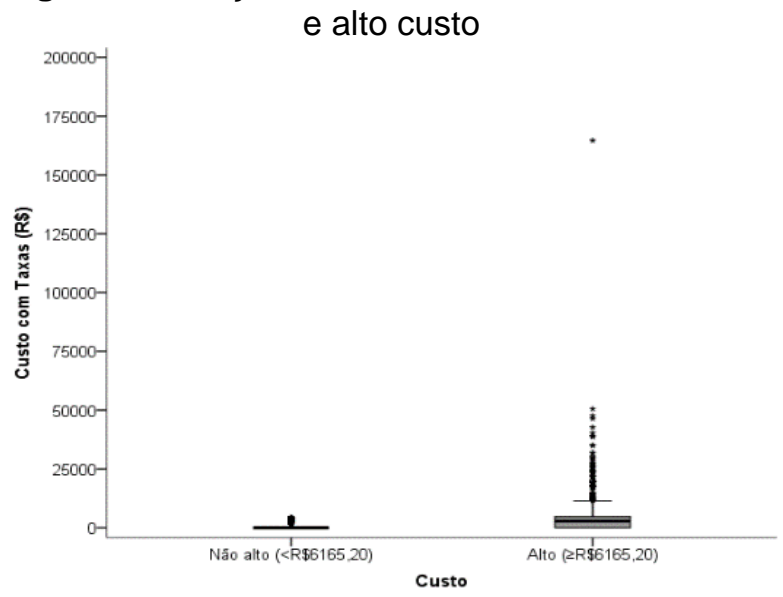

Figura 10. Relação entre custo com taxas e alto custo 